Florida International University

FIU Digital Commons

FIU Electronic Theses and Dissertations

University Graduate School

2-20-1998

\title{
The influence of weak parental and peer attachment on academic achievement among late adolescent college students
}

Michael Erik Fass

Florida International University

DOI: $10.25148 /$ etd.FI15101353

Follow this and additional works at: https://digitalcommons.fiu.edu/etd

Part of the Psychology Commons

\section{Recommended Citation}

Fass, Michael Erik, "The influence of weak parental and peer attachment on academic achievement among late adolescent college students" (1998). FIU Electronic Theses and Dissertations. 3286.

https://digitalcommons.fiu.edu/etd/3286

This work is brought to you for free and open access by the University Graduate School at FIU Digital Commons. It has been accepted for inclusion in FIU Electronic Theses and Dissertations by an authorized administrator of FIU Digital Commons. For more information, please contact dcc@fiu.edu. 


\section{FLORIDA INTERNATIONAL UNIVERSITY}

Miami, Florida

THE INFLUENCE OF WEAK PARENTAL AND PEER ATTACHMENT ON ACADEMIC ACHIEVEMENT AMONG LATE ADOLESCENT COLLEGE STUDENTS

A dissertation submitted in partial satisfaction of the requirements for the degree of DOCTOR OF PHILOSOPHY

IN

PSYCHOLOGY

by

Michael Erik Fass

1998 


\section{To: Dean Arthur W. Herriott}

College of Arts and Sciences

This dissertation, written by Michael Erik Fass, and entitled The Influence of Weak Parental and Peer Attachment on Academic Achievement among Late Adolescent College Students, having been approved in respect to style and intellectual content, is referred to you for judgment.

We have read this dissertation and recommend that it be approved.

Mary J. Levist

William Kurtines

Lilly M. Langer

Jonathan G. Tubman, Major Professor

Date of Defense: February 20, 1998

The dissertation of Michael Erik Fass is approved.

Dean Arthur W. Herriott

College of Arts and Sciences

Dr. Richard L. Campbell

Dean of Graduate Studies

Florida International University, 1998 
OCOPYRIGHT 1998 by Michael Erik Fass

All rights reserved. 


\section{ACKNOWLEDGMENTS}

I wish to thank Dr. Tubman, Dr. Levitt, Dr. Kurtines and Dr. Langer for their assistance, patience, and willingness to serve on this committee. I especially want to thank Dr. Tubman for his research suggestions, his editorial guidance, his patience, and his willingness to work with a "non-traditional" student. A special thanks to Dr. Levitt for her many years of encouragement and support. And to my wife, Terri, mille grazie for the little pushes during the entire process. 


\author{
ABSTRACT OF THE DISSERTATION \\ THE INFLUENCE OF WEAK PARENTAL \\ AND PEER ATTACHMENT ON ACADEMIC \\ ACHIEVEMENT AMONG LATE ADOLESCENT COLLEGE STUDENTS \\ by \\ Michael Erik Fass \\ Florida International University, 1998 \\ Miami, Florida \\ Professor Jonathan G. Tubman, Major Professor
}

The current study examined the influence of weak parental and peer attachment on academic achievement among late adolescent college students. In previous research, weak attachment to parents and/or peers had been found to have an adverse influence on the academic success of college students. This study also examined the potential moderating influence of several cognitive and non-cognitive psychosocial variables that might act as protective factors for weakly attached students and, therefore, enhance their academic competence. Data regarding attachment, cognitive variables, and non-cognitive variables were collected using several self-report measures. The multi-ethnic sample of students in this study $(n=357)$ attended an urban university. Students were classified into one of nine parental-peer attachment groups (e.g., Low-Low, Medium-Medium, High-High). Attachment groups were compared in terms of cognitive and non-cognitive variables. Contrary to the hypothesis, no statistically significant academic achievement differences 
were revealed for the group of college students who perceived themselves to be weakly attached to both parents and peers. Analysis of variance (ANOVA) identified the HighHigh group to be significantly different in terms of academic outcome variables from the other eight groups while the Low-Low group had significantly lower levels of noncognitive variables than several of the other attachment groups. Hierarchical multiple regression analyses revealed that cognitive variables accounted for significant amounts of variance in academic outcomes and that several non-cognitive variables were significant predictors of scholastic competence. Correlational analyses revealed that parental and peer attachment were positively correlated with several cognitive and non-cognitive variables but neither was significantly correlated with self-reported college GPA. In general, the findings do not provide support for a main effect of weak attachment to parents and peers upon academic adversity among college students. Results suggest that both cognitive variables and non-cognitive variables may moderate academic risk due to weak attachment to parents and peers. Descriptive within group analyses of the Low-Low group revealed a heterogeneous group of students with regards to academic outcomes and scores on noncognitive measures. Gender and ethnic differences were found for attachment status but not for cognitive or non-cognitive variables. Implications for interventions and suggestions for future research are presented. 
I. STATEMENT OF THE PROBLEM .................................................. 1

II. LITERATURE REVIEW ................................................................... 8

Attachment and Social Support Systems ......................................... 8

Academic Achievement, Attachment, and Social Support .......... 12

Risk, Competence, and Resilience ................................................ 16

Non-Cognitive Moderating/Compensatory Variables ................... 23

Cognitive and Contextual Moderating/Compensatory Variables

III. METHODOLOGY ............................................................................... 33

Participants ...................................................................................... 33

Measures ........................................................................................................ 33

Procedures ................................................................................. 38

IV. RESULTS ................................................................................................ 39

Attachment Analyses of Entire Sample ............................................ 39

Correlational Analyses of Attachment, Cognitive, and

Non-Cognitive Variables ................................................................. 44

Hierarchical Multiple Regression and MANCOVA Analyses ..... 51

Attachment Group Analyses ............................................................ $\quad 55$

V. DISCUSSION ............................................................................... 68

The Influence of Weak Parental and Peer Attachment ................. 68

The Influence of Cognitive and Non-Cognitive Variables ............ $\quad 74$

The Influence of Ethnicity, Gender, and Parental Education ....... $\quad 77$

Interventions ........................................................................................... 81

Limitations and Implications .......................................................... 83

LIST OF REFERENCES ....................................................................................... 88

APPENDIXES 


\section{LIST OF TABLES}

TABLE

PAGE

1. Means and Standard Deviations of Ethnic Groups on Measures Attachment, Cognitive Variables, and Non-Cognitive Variables

2. Frequencies and Proportions of Ethnic Categories in Attachment Groups

3. Means and Standard Deviations of Male and Female College Students on Measures of Attachment, Cognitive Variables, and Non-Cognitive Variables 45

4. Correlations between Attachment and Cognitive and NonCognitive Variables for the Entire Sample

5. Correlations for Attachment, Cognitive, and Non-Cognitive Variables for Group 1 (Low-Low)

6. Correlations for Attachment, Cognitive, and Non-Cognitive Variables for Group 5 (Medium-Medium)

7. Correlations for Attachment, Cognitive, and Non-Cognitive Variables for Group 9 (High-High)

8. Hierarchical Multiple Regression Model Predicting Students' College GPA by Demographic Variables, Attachment Variables, Cognitive Variables, and Non-Cognitive Variables

9. Hierarchical Multiple Regression Model Predicting Students' Scholastic Competence by Demographic Variables, Attachment Variables, Cognitive Variables, and Non-Cognitive Variables

10. Means and Standard Deviations of Academic Variables by Attachment Groups

11. Means and Standard Deviations of Non-Cognitive Variables by Attachment Group

12. Hierarchical Multiple Regression Model Predicting Low-Low Students' Scholastic Competence by Demographic Variables and Non-Cognitive Variables 


\section{LIST OF FIGURES}

FIGURE

PAGE

1. Low-Low Group: Locus of Control ................................................................ 65

2. Low-Low Group: Global Self-Esteem........................................................... 65

3. Low-Low Group: Scholastic Competence ...................................................... 66

4. Low-Low Group: College GPA....................................................................... 66

5. Low-Low Group: Self-Reported Intellectual Ability .................................. 67 
Widespread interest in academic achievement and academic competence has led to extensive studies of individual and contextual factors that may potentially increase risk for academic failure. The decline in college academic achievement and the desire of colleges and universities to increase academic integration and college adjustment among at-risk students are two of the many reasons why increased knowledge about potential academic risk factors, as well as potential academic protective factors is significant (Larose \& Roy, 1991). Within this body of literature, student academic risk research has concentrated on several factors that appear to be linked to potential academic adversity for students along the entire educational continuum.

While the majority of academic risk research has examined the "status characteristics" associated with academic risk such as family poverty, low parental education, minority status in an inner city school, parental death or divorce (Finn \& Rock, 1997; Peng, 1994), other researchers have studied behavioral outcomes among at-risk students including low grade point averages, school truancy and school dropout, and drug-related behavior (Richardson \& Colfer, 1994). This heightened interest in risk factors for poor academic performance has also produced a number of studies that have investigated the effects of positive or negative attachment relationships and social support systems on students' academic achievement ( Abbey, Abramis, \& Caplan, 1985; Felsten \& Wilcox, 1992; Gerdes \& Mallinckrodt, 1994; Kenny, 1990; Kenny \& Donaldson, 1991, 1992; Mallinckrodt, 1988; Mindel, 1980; Stewart \& Vaux, 1986; Tracey \& Sedlacak, 1987, 1989; Zea, Jarama, \& Bianchi, 1995). While specific family dynamics such as divorce and 
parenting styles have been studied as potential risk factors for academic failure, academic risk due to weak parental attachment and/or weak peer attachment has received surprisingly little attention. This study investigated relations among both weak parental and weak peer attachment and academic achievement in a sample of late adolescent college students.

An extensive body of evidence supports the life span perspective suggesting that attachment, an affectional bond between parent and child, appears to be a permanent although evolving process across the life span (Antonucci, 1990; Levitt, 1991; Rutter, 1995; Takahashi, 1990). Therefore, research on academic risk has examined the influence of parent-child relationships on academic performance from the elementary to the postsecondary school years. While the majority of research on relations between attachment and academic performance has studied elementary, middle school, and high school students, the protective benefits of parental attachment for academic achievement in college has received growing research attention (Bell, Allen, Hauser, \& O'Conner, 1996, Cutrona, Cole, Colangelo, Assouline, \& Russell, 1994; Hoffman \& Weiss, 1987; Lapsley, Rice, \& Shadid, 1989; Lopez, 1991; May \& Logan, 1993; Rice, Cole, \& Lapsley, 1990). While overinvolvement of parents may have negative consequences (Lopez \& Andrews, 1987), a positive parent-adolescent relationship appears to have "significant relationships to concurrent adolescent educational achievements and career development" (Bell et al,, 1996, p.350).

In addition to research on relations between attachment to parents and academic achievement, several studies have investigated relations between peer attachment/low 
peer acceptance and academic achievement (Cotterell, 1992; French, Conrad, \& Turner, 1995; Holohan, Valentiner, \& Moos, 1994; Kupersmidt, Coie, \& Dodge, 1990; Loeber, 1990; Ollendick, Weist, Bordan, \& Greene, 1992; Parker \& Asher, 1987; Rice, 1990). Attachment research suggests that attachment to peers is both developmentally normative during adolescence and qualitatively different from attachment to parents (Ainsworth, 1989; Berndt, 1979). Current research on peer attachment and academic performance has focused on the potential risks related to low peer attachment/low peer acceptance for students at various ages or various educational levels (Loeber, 1990; Parker \& Asher, 1987; Rice, 1990). While there has been growing interest in attachment between late-adolescent college students and their parents, there is considerably less research on the separate relationship between peer attachment and academic achievement for late adolescent college students.

Extensive research has been conducted on the combined effects of peer and parental attachment/social support systems on adolescents' psychological well-being, self-esteem, and ability to cope with stress (Antonucci, 1990; Armsden \& Greenberg, 1987; Bell, Avery, Jenkins, Feld, \& Schoenrock, 1985; Cohen \& Willis, 1985; Heller \& Swindle, 1983; Holahan \& Moos, 1981; Kahn \& Antonucci, 1980; Levitt, 1991; Licitra-Klecker \& Waas, 1993). However, fewer studies have examined the combined effects of peer and parental relationships on college academic achievement. Studies that have examined relations between attachment or social support and college academic achievement suggest that social support positively influences successful college adaptation including such outcomes as academic achievement and college attrition (Abbey et al., 1985; Hays 
\& Oxley, 1986; Mindel, 1980; Reifman \& Dunkel-Schetter, 1990; Riggio, Watring, \& Throckmorton, 1993; Robins, Lese, \& Herrick, 1993; Zea et al., 1995). The current study was designed to provide additional evidence regarding the potential adverse influence of weak peer and weak parental attachment on the academic achievement of late adolescent college students.

While strong attachment to parents and/or peers has become a focus of academic achievement studies, there is a limited amount of research on relations between weak parental attachment or weak peer attachment and academic achievement. Previous studies have examined relations between weak attachment to parents and academic achievement or relations between weak attachment to peers and academic achievement. These studies have tended to focus on separate attachment relations (i.e., either parent or peer) rather than these joint facets of weak attachment (Coie, Terry, Lennox, Lochman, \& Hyman, 1995; Ekstrom, 1989; Finn, 1989; Parker \& Asher, 1987). The current study examined the combined influence of both weak parental and weak peer attachment on academic achievement. If previous studies are correct, and weak attachment to either parents or peers places students at higher risk for academic failure, then the combined influence of weak parental attachment and weak peer attachment should multiplicatively increase risk for poor academic outcomes. This study tested the hypothesis that students who perceive themselves to be weakly attached to both parents and peers would be less academically successful than students who perceived greater attachment to either parents or peers.

Several studies that have investigated the relations between attachment and academic achievement limited their investigations to the relation between parental and/or 
peer attachment and academic achievement. These studies did not include variables potentially moderating the influence of weak attachment such as high self-esteem or perceived intellectual ability (Cutrona et al., 1994; Hershberger \& D'Augelli, 1992; Weir \& Okun, 1989). In contrast, studies that have examined relations among cognitive or noncognitive variables and college achievement have not measured parental or peer attachment as part of their designs (Brown, Lent, \& Larkin, 1989; Larose \& Roy, 1991; Zarb, 1981). The current study examined the potentially moderating or compensatory influence upon academic achievement of several cognitive and noncognitive variables among late adolescent college students who perceived themselves to be weakly attached to both parents and peers. The results of this study should extend current understanding of the nature of the risk posed by weak parental and weak peer attachment for academic failure. In addition, this study should aid in the identification of specific cognitive and non-cognitive variables that moderate or compensate for risk for academic failure among a sample of college students.

A primary research question of this study was: Do parental and peer attachment have significant influences on academic achievement among late adolescent college students? A secondary research question was: Which cognitive or non-cognitive variables act as moderating influences upon academic failure among students who perceive themselves to be weakly attached to both parents and peers? Based on previous research, it was hypothesized that college students would have different degrees of perceived parental and peer attachment. While weak attachment to both parents and peers should place most students at risk for poor academic achievement, cognitive and/or non-cognitive 
protective factors would enable some at-risk students to be academically competent.

These questions were examined in both between group (i.e., the nine attachment groups) and within group (i.e., individual attachment groups) analyses.

In summary, the focus of this study was to gain a better understanding of how cognitive variables and psychosocial non-cognitive variables significantly interact to moderate or compensate for the effects of weak parental and weak peer attachment in late adolescent college students. The specific aims of this study were:

1. To determine whether there are meaningful differences in perceived attachment relationships among adolescent college students. The research literature suggests that the majority of students would have strong attachment to their peers while remaining strongly attached to their parents. Based on recent research, it was hypothesized that only a minority $(10 \%-20 \%)$ of college students would perceive themselves to be low in parental attachment and low in peer attachment (Armsden \& Greenberg, 1987; Fass, 1996; LicitraKlecker \& Waas, 1993; Sebald, 1993).

2. To determine the influence that combined weak parental attachment and weak peer attachment has on the academic achievement and academic competence of late adolescent college students. While research suggests that either weak parental attachment or weak peer attachment should place students at risk for poor academic achievement, recent studies on resilience suggest that several psychosocial protective factors may counteract conditions of adversity and enable at-risk individuals to function competently. It was hypothesized that the compounding effects of weak attachment to both parents and peers would have an adverse effect on academic achievement within the group of weakly 
attached college students.

3. To identify which cognitive and non-cognitive psychosocial variables may act as potential resilience factors predicting higher academic functioning among the low parent and low peer attached college student. It was hypothesized that one or more non-cognitive psychosocial variables such as self-esteem, androgyny, internal locus of control, and optimism might be found to be protective factors positively influencing the academic competence of the low parent and low peer attached group of students. While one or more non-cognitive variables may protect against academic adversity, this current study also examined the potential moderating influence or compensatory influence of several cognitive variables (i.e., intellectual ability, scholastic competence). In addition, this study assessed the relative importance of attachment to academic competence in comparison to several cognitive and non-cognitive variables. 


\section{Chapter 2: Review of the Literature}

The ensuing literature review focuses on recent studies of the salient concepts pertaining to the present study. The literature review parallels the order of the three hypotheses tested in this study. The first section contains a review of the attachment and social support literature, followed by a discussion of relations between academic achievement and attachment, and succeeded by a review of the literature associated with the concepts of risk, competence, and resilience. The review concludes with a discussion of pertinent literature related to the key cognitive variables (i.e., intellectual ability, scholastic competence) and non-cognitive psychosocial variables (i.e., self-esteem, optimism) included in this study.

\section{Attachment and Social Support Systems}

The marrow of the Ainsworth-Bowlby attachment theory is that meaningful social attachments, especially those between child and parent, are crucial to the overall psychological well-being of the individual (Ainsworth, Blehar, Waters, \& Wall, 1978; Bowlby, 1973). Bowlby's ethological theory of attachment views attachment as an enduring affective bond that provides security and promotes the development of various competencies in social, intellectual, and psychological domains as well as promoting adaptive environmental functioning (Kenny \& Donaldson, 1991). Initial attachment dyads are considered to be psychologically significant since the initial attachment experiences form the foundation for social expectations of future attachment relationships (Levitt, Coffman, Guacci-Franco, \& Loveless, 1993). Repeated interactions between mother or another primary caregiver and the child influence the formation of "internal working 
models" about the self, significant others, and the larger social world. Internal working models or cognitive representations of this early relationship act as prototypes for future attachment relationships. (Bowlby, 1969; Bretherton, 1985; Rothbard \& Shaver, 1994). Deficiencies in attachment during the formative years may produce insecure behavior patterns and failure to thrive. Early attachment problems are also hypothesized to have a negative effect on attachment relationships in later life (Bradford \& Lyddon, 1995; Kobak \& Sceery, 1988; Sroufe, 1983).

Although much has been studied and written about the Ainsworth-Bowlby conceptualization of attachment as it relates to infancy and early childhood, there is growing interest in attachment relationships beyond childhood and into adolescence and adulthood (Bartholomew \& Horowitz, 1991; Brennan, Shaver, \& Tobey, 1991; Bretherton, 1985; Collins and Read, 1990; Greenberg, Siegel, \& Leitich, 1983; Hazen \& Shaver, 1987; Kahn \& Antonucci, 1980; Levitt, 1991; Weiss, 1982). Consistent with the life span perspective of attachment, these studies suggest that attachment relationships between child and parent may vacillate at particular transitional developmental stages, but the initial attachments are likely to continue across the individual's lifetime (Antonucci, 1990; Collins \& Read, 1990; Greenberg et al., 1983; Levitt, 1991; Takahashi, 1990). These studies have also indicated that most adolescents develop strong attachments to peers but that these newly formed peer attachments do not replace, but complement parental attachment. The majority of adolescents appear to remain attached to parents while developing new peer relationships. In addition, several studies show attachment to parents and peers to be largely congruent or equivalent in strength (Armsden \& 
Greenberg, 1987; Lictra-Klecker \& Waas, 1992).

Previous research has demonstrated correlational relations between strong attachment to parents and/or peers and a wide range of positive psychosocial outcomes. Research suggests that psychological well-being (Greenberg et al., 1982), coping with stress (Cohen \& Wills, 1985), social bonding capabilities (Kalish \& Knudtson, 1976) and social and personal identity (Lapsley, Rice, \& Fitzgerald, 1990) are positively associated with strong attachment relations. Several recent studies including one meta-analysis have demonstrated a significant relations between adolescent self-esteem and strong attachment to parents and peers (Armsden \& Greenberg, 1987; Bell, Avery, Jenkins, Feld, \& Schoenrock, 1985; Paterson et al., 1995; Rice, 1990).

Studies of life span attachment relationships have become closely related to research on the significance of social support systems and social support networks. Some theorists have proposed that attachment relationships form a part of, or become a specialized subset of the social support system (Antonucci, 1990; Levitt, 1991; Takahashi, 1990). It has been suggested that social support networks "may be an observable manifestation of attachment styles"' (Blain et al., 1993, p. 228). A current trend in social support system research is the distinction being formulated between objective characteristics of support networks and perceived social support. Objective network characteristics support include size, density, proximity and other related structural elements of the support system, along with the actual support perceived by the network. Perceived social support refers to the psychological and supportive impact the structural system has upon the individual (Blain et al., 1993; Heller \& Swindle, 1983; Licitra-Kleckler \& Waas, 1993; Procidano \& Heller, 
1983). Perceived social support, as well as perceived attachment, is based on the individual's perception that his/her support needs are being satisfied by parents, peers, or other support group members. While there is limited research on the identification of differences between what is perceived to be available and what is actually available (Winemiller, Mitchell, Sutliff, \& Cline, 1993), perceived support has been shown to relate to personal well-being more than mere objective indicators of support (Antonucci, 1990).

During the past few decades, there has been a widening interest in the attachment relations of late-adolescent college students. While the developmental task of separationindividuation has received a great deal of attention in adolescent research, studies suggest that late adolescent college students remain strongly attached to, and influenced by, their parents (Hoffman, 1984; Kenny, 1987, 1990; Kenny \& Donaldson, 1991, 1992). Bank, Slaving, and Biddle (1990) found that college students valued their parents' opinions as much as with the opinions of their peers but more so than the opinions of faculty members. Recent research suggests that strong attachments between late adolescent college students and their parents foster competence, psychological adjustment, coping ability, and career development (Bell et al., 1985; Blain et al., 1993; Blustein, Walbridge, Freiedlander, \& Palladino, 1991; Brack, Gay, \& Matheny, 1993; Hays \& Oxley, 1986; Maurer, 1982; Lapsley et al., 1990). Ryan \& Lynch (1989) concluded that attachment to parents, rather than detachment, during adolescence and young adulthood optimizes individuation and identity development. Congruent with the Ainsworth-Bowlby conceptualization of attachment, the current study attempted to identify attachment patterns and academic achievement differences among late adolescent college students. 


\section{Academic Achievement, Attachment, and Social Support}

Extensive research has established that positive parental attachment tends to foster academic achievement across the entire educational continuum in both high and low risk samples. This literature has emphasized that positive parental support promotes higher grade point averages, general academic attainment, and academic persistence among children, early adolescents, and late adolescents (Bell, Allen, Hauser, \& O'Conner, 1996; Clark, 1983; Finn \& Rock, 1983; Gloria \& Robinson, 1994; Hoffman \& Weiss, 1987, Kobak \& Sceery, 1988; Peng, 1994). For example, Cutrona et al., (1994) studied the degree to which parental support predicted college GPA among a predominantly first- and second-year sample of university students who were not in daily contact with their parents. In two independent samples, parental social support was a significant predictor of college GPA. While perceived parental social support accounted for a modest proportion of the total variance in academic achievement, it was a significant predictor of GPA. In contrast, social support from friends or romantic partners were not significant predictors of college GPA. The authors concluded that parents who express belief in their children's abilities facilitate adaptive behaviors in the academic domain.

Just as strong parental attachment has been linked to successful transitions to college and general academic achievement, negative or low attachment to parents has been found to contribute to academic risk for some adolescents. Researchers have identified several facets of parent-child (student) interactions as potential risk factors for poor academic performance. For example, a student's poor relationships with his or her parents (Finn, 1989), poor communication with parents about feelings and thoughts (Ekstrom, Goertz, 
Pollack, \& Rock, 1986), low parental educational expectations for children (Dornbusch et al., 1987), and lack of encouragement from parents to persist in academics (Bean \& Metzner, 1985; Okun et al., 1996) are all identified as placing the student at risk for poor academic outcomes.

For example, Lopez (1991) explored whether college students who classified themselves in one of four family alignments (noncoalition, mother-coalition, fathercoalition, or triangulation) reported different scores on measures of college adjustment including academic adjustment. Significant group differences for the four groups were found for both personal adjustment and academic adjustment. These results suggested that a triangulated family alignment (i.e., in which a child is conflictually dependent on both parents) may place the child at highest risk for poor academic adjustment. While a supportive family is considered to be an important predictor of academic success among college students, it appears that certain types of conceptual family dynamics, including weak parental attachment, may increase students' risk for academic failure.

In addition to the influence of the quality of parental attachment on adolescents' academic achievement, numerous studies have focused on relations between students' peer networks and academic achievement. While some studies have shown that peer influence contributes to a lack of academic effort (Bishop, 1989; Goodlad, 1984), many studies have suggested a positive link between peer acceptance/peer support and academic success among both children and adolescents (Brown, Clasen, \& Eicher, 1986; Cotterell, 1992; French et al., 1995; Kupersmidt, Coie, \& Dodge, 1990; Holahan et al., 1994; Ollendick, Weist, Bordan, \& Greene, 1992). In addition, Bean (1983) and Hearn (1985) 
found that positive interaction with friends was a significant determinant of college satisfaction. Cottrell (1992) suggested that among working-class adolescents, peer support may exert a considerable influence on academic outcomes and academic decisions depending on whether peer approval is critical to self-esteem. This research suggests that an adolescent with weak parental attachment may be more influenced academically by his or her peers than an adolescent with strong parental attachment. Research also suggests that if one's peer group is comprised of peers who have high levels of academic motivation, peer group influence will have a positive effect on the individual's academic effort (Berndt, Laychak, \& Park, 1990). Therefore, within a college environment, peer support should cultivate academic achievement among late adolescent college students.

While a growing body of literature during the past two decades has addressed the negative psychological and maladaptive behavioral outcomes associated with low peer acceptance or low peer attachment (Coie, Lochman, Terry, \& Hyman, 1992; Kupersmidt \& Coie, 1990; Loeber, 1990; Rice, 1990), surprisingly few studies have examined relations between low peer acceptance or attachment and academic achievement. One such study was Parker \& Asher's (1987) meta-analysis that demonstrated low peer acceptance during adolescence acted as a "risk indicator" of poor future developmental adjustment including academic failure. Poor school adjustment was also correlated with peer rejection in several other studies of adolescents (Coie, Terry, Lenox, Lochman, \& Hyman, 1995; Ladd, 1990). While peer acceptance and rejection studies may be investigating concepts that share many similarities to attachment and social support, they may represent different underlying processes. 
While the majority of studies of the effects of parent or peer attachment on academic success has focused on one or the other of these supportive groups, several studies have found that social support positively affects general academic achievement from elementary school to college (Levitt, Guacci-Franco, \& Levitt, 1990; Mallinckrodt, 1988; Reifman \& Dunkel-Schetter, 1990; Sarason, 1981). Social support for college students has also been found to contribute to successful college adaptation which has traditionally been defined in part by academic performance (Abbey et al., 1985; Baker \& Siryk, 1984; Gerdes \& Mallinckrodt, 1994; Riggio et al., 1993). One study examined relations between social support, psychosocial competence, and successful adaptation to college, including meeting needed academic requirements (Zea et al.,1995) This study found that in an ethnically diverse sample of college students, perceived social support was a significant predictor of adaptation to college, while locus of control was not. In addition, Weir and Okun (1989) found structural social support (i.e., family, friends, faculty, clubs) had a main effect on college satisfaction among urban, community college students.

Studies of the influence of social support on students' academic achievement or academic adaptation to college have varied depending upon the ethnicity and culture of the students sampled. Hispanic-American and African-American college students appear to utilize social support more often than Anglo-American college students in several studies (Mindel, 1980; Stewart \& Vaux, 1986). While social support appears to be a positive influence for Hispanic-Americans, Anglo-Americans, and African-Americans, several studies suggest that social support does not have a positive influence on the college adaptation of Asian-American students (Liang \& Bogat, 1994; Zea et al., 1995). 
Asian-American students' reliance on self-discipline rather than on parental or peer support may be a potential explanation for this ethnic/cultural difference.

The research literature on attachment and social support clearly suggests a significant positive correlation between academic achievement and positive attachment or social support, as well as an association between academic failure and weak attachment or weak social support. However, this literature does not describe the possible influence on academic achievement of both weak parental attachment and weak peer attachment. If weak parental or weak peer attachment places the student at risk for academic failure, the combined influence of weak attachment to both of these significant groups should increase the student's risk for academic failure in a multiplicative manner. The current study was designed to examine a particular group of college students, those who perceive themselves to be weakly attached to both parents and peers, to ascertain their risk for academic adversity. If, regardless of their weak attachment to both parents and peers, students in the sample are found to be academically successful, this achievement in the face of adversity may be viewed as a form of academic resilience. Therefore, it is important to identify cognitive and/or non-cognitive psychosocial variables that may play a moderating or compensatory role in this process of academic resilience. Due to the expected ethnic and cultural diversity of the participants in the current study, additional information concerning ethnic/cultural variations in relations between attachment and academic achievement was considered to be an additional focus of inquiry.

Risk, Competency, and Resiliency

For the purposes of this study, risk factors will be events, stressors, genetic 
factors, and environments that predispose individuals and populations to specific negative outcomes. The magnitude of a particular risk is measured as "the probability of a specific negative outcome in a population when the risk is present, compared with the probability when it is absent" (Cowan, Cowan, \& Schulz, 1996, p. 9). As previous research has established, weak attachment to parents and/or peers is a risk factor for adverse outcomes among both children and adolescents. In addition, it has been suggested that risk should not be discussed without specifying the negative outcome potentially resulting from the risk at hand (Cowan et al., 1996). For the present study, weakly attached late adolescents should be at-risk for: a) academic failure that might influence these individuals not to have applied for college admission; b) not to be accepted by a college; or, c) if accepted, to have poor academic functioning.

The related concept of vulnerability refers to the susceptibility or predisposition of a particular individual to suffer a potentially negative outcome. While the concept of risk emphasizes potential negative outcomes for a population such as children of schizophrenic parents, vulnerability emphasizes the threat to an individual (Masten \& Garmezy, 1987). Therefore, the vulnerability of a specific individual is largely dependent on that individual being in a group that is at-risk and encountering particular detrimental influences (i.e., at individual, social, cultural, contextual levels) for further development. Although the term vulnerability usually connotes an internal locus of a problem (e.g., genetic factors), factors such as low self-esteem, personality traits, and depression are often categorized as vulnerability factors. A crucial distinction between vulnerability processes and risk mechanisms is that risks have a main effect influence while the influence of vulnerability 
derives from an interaction effect, (i.e., between individual and context; Cowan et al.,1996).

Research on risk mechanisms and resilience has focused on the indirect chain effects that risk factors such as environmental and affective deficiencies might have on the individual. Psychosocial "turning points" (e.g., divorce, early pregnancy, marriage) can direct an individual's life trajectory onto an at-risk pathway or they can redirect an individual onto a more adaptive pathway. Turning points are viewed as having the potential to alter behavior, affect, and cognition, and thus, have a profound effect on an individual's life course (Graber \& Brooks-Gunn, 1996; Pickles \& Rutter, 1991; Rutter, 1994). Peer rejection/low peer acceptance has been shown to function as this type of significant link in an adolescent's developmental pathway and studies have demonstrated that strong family support enhances resilience among adolescents while concurrently promoting psychological well-being (Dubois, Fehner, Brand, Adam, \& Evans, 1992; McFarlane, Bellissimo, \& Norman, 1995). Adolescent peer rejection compounded by weak parental attachment may place an adolescent at a higher level of vulnerability by setting in motion a series of linked negative events.

While research on turning points continues to be an important area of investigation, transitional periods of development have also attracted research attention over the past decade. Transitional periods such as reproductive transitions (i.e., puberty, pregnancy, menopause) or educational transitions (i.e., elementary to middle school, high school to college) are seen as developmental tasks that require new modes of adaptation to biological, psychological, or social changes (Graber \& Brooks-Gunn, 1996). Transition- 
linked turning points that occur during transitional periods, accompanied by specific developmental challenges, may be more salient to vulnerability than non-transition turning points. In addition, individual differences in response to transition experiences appear to be affected by several factors including the individual's development prior to the transitional challenge (Graber, Brooks-Gunn, \& Petersen, 1996). Therefore, the adversity of weak attachment during the transitional period of late adolescence may have a profound effect on late adolescent developmental tasks. If Liddle (1994, p.172) is correct that "a protective family creates a low risk proximal environment that shields the adolescent from noxious elements in a high-risk distal environment", perhaps low attachment to parents creates a higher risk proximal environment that offers little protection from the high risk distal environment. One of the major objectives of the current study is to determine how the multiple risk status of adolescents with weak parental attachment and weak peer attachment affects academic achievement during a transitional life experience.

Over the past several years, increasing numbers of studies have focused on individuals who are described as competent or who display competence in a particular environment. Competence is a multidimensional construct that may be broadly defined as an individual's capacity to interact effectively with the environment (White, 1959). While an individual may be competent in specific domains such as affective competence, social competence, and academic competence, the term itself is used to describe the observable impact of skillful coping (Blechman, 1990, 1991; Blechman \& Wills, 1992; Wills, Blechman, \& McNamara, 1996). Evidence that a supportive family acts to promote 
competence in children and adolescents may be found in longitudinal studies conducted by Werner and associates $(1986,1989$; Werner \& Smith, 1982). Factors such as parental emotional support and open communication between parent and child are but two of the factors that appear to provide the child or adolescent with the necessary foundation for competence (Wills et al., 1996). Amato \& Ochiltree (1986) suggested that the family provided the "resources of competence" through family structural resources including inherited capacities, parental income and education, and family process resources, such as parental help and attention. Therefore, two major aims of the current study are to determine levels of academic competence among college students who perceive themselves to be without parental support or peer support, and to identify the cognitive and non-cognitive variables that facilitate academic achievement among these at-risk students.

Described by Cicchetti and Garmezy (1993) as a refreshing and optimistic component of the psychopathology-risk equation, the concept of resilience has drawn a great deal of research attention over the past decade. Resilience in an individual has been described as successful adaptation despite risk and adversity (Masten, 1994). Theoretically linked to the concepts of risk and vulnerability, resilience has been studied in relationship to schizophrenia, chronic stress, at-risk environments and traumatic historical occurrences (Downey \& Coyne, 1990; Elder, 1974; Garmezy, 1974; Watt, Anthony, Wynne, \& Rolf, 1984). Research on resilience has studied the dispositional characteristics and personal experiences of competent children and adults who have been exposed to distal and proximal stressors including profound childhood poverty, affectional deprivation, physical 
or sexual abuse, physical and mental disability, or a background of familial mental disorders including schizophrenia and depression (Garmezy, 1983; Luthar, 1993). Surprisingly, weak attachment to both parents and peers, though conceptually resembling a risk factor, has been overlooked in resilience research.

While protective factors, moderating variables, and compensatory variables ameliorate the effects of risks or adversities, these concepts are not interchangeable. Protective factors are seen as individual or environmental characteristics that enhance the likelihood of better outcomes for at-risk individuals (Masten, 1994). In the field of child psychopathology, genetic-constitutional variables such as sex or temperament are considered to be protective factors (Rutter, 1979). In the context of the current study of at-risk late adolescents, variables such as intellectual ability or internal locus of control are factors that might operate as protective factors. A moderating variable interacts with a predictor variable and thus impacts the level of the dependent variable (Holmbeck, 1997). For example, if the interaction of high optimism and weak peer and parental attachment impacted the level of academic achievement, moderated effects would be present. While moderating factor is a label reserved for effects involving interactions between specific attributes and risk, compensatory variables/factors are associated with main effect models (Garmezy, Mastemn, \& Tellegen, 1984). A compensatory factor distinguishes high risk individuals who do well from those who do poorly. A compensatory process is said to exist when a particular risk variable and a specific variable were independently associated with a particular outcome (Pellegrini, 1990).

Garmezy (1985) has categorized three types of protective factors that may facilitate 
better outcomes for at-risk individuals. Adopting a life span perspective, Garmezy believes the three main categories of protective factors are: a) dispositional attributes or personality factors, b) affectional ties and support from within the family, and c) external support from institutions such churches or schools. Protective factors may be risk specific in that they are protective in one risk domain but are not protective in another. In the current study, weakly attached students with protective factors such as high self-esteem, intellectual ability, internal locus of control, optimism, or androgynous traits may be able to negotiate the academic developmental transition through college even though they lack two of the three aforementioned protective factors: family support (parent attachment) and a specific external support systems (peer attachment).

In the current study, resilience is operationalized as academic competence and it was assessed as a college student's acceptable (i.e., passing), grade point average (GPA), and if he or she was progressing toward completion of his or her undergraduate degree. Since statements of overall resilience are vague and of limited utility, this study was limited to examining academic resilience as opposed to emotional or social resilience (Luthar, 1993). Given their weak parental and weak peer attachment status, weakly attached but academically competent students would be demonstrating a pattern of resilience. Although vulnerable due to their reported low levels of attachment, certain cognitive, non-cognitive, or experiential factors have allowed these individuals to cope successfully in their college environments.

This study will examine key individual differences associated with risk negotiation among late adolescent college students to: a) isolate key moderating variables associated 
with resilient outcomes; and, b) gain a better understanding of the mechanisms involved in protective processes. Interactions among key variables were examined to identify some of the dispositional protective factors that allow individuals confronted by adversity to follow an adaptive pathway, thereby reducing personal vulnerability to adverse outcomes. Just as Rutter (1987) has argued that risk does not lie in the risk variable or marker but rather in the processes that emerge from the variable, the same is true for resilience. Although the protective factor or moderating variable must first be isolated, it is the associated underlying process that is at the heart of resilience research.

\section{Non-Cognitive Moderating/Compensatory Variables}

The following potentially moderating psychosocial variables were used in the current study to determine which variable or variables may act as potential protective factors allowing weak parental and weak peer attached students to achieve academic success in spite of their risk status. While other psychosocial variables were examined in this research literature, self-esteem, locus of control, optimism, androgyny, and global self-esteem formed the core group of non-cognitive variables. Four research foci associated with these variables were: whether these psychosocial variables would reveal: a) attachment group differences; b) gender differences; c) ethnic differences; and, d) the proportion of variance in academic achievement each of these variables predicted.

Self-Esteem. A great deal of the literature on risk moderating variables and protective factors has focused on the role of self-esteem a resilience factor (Brooks, 1992, 1994; Rutter, 1985; Werner, 1993). Self-esteem and related concepts including self-efficacy and locus of control appear to be true protective factors although the specific development 
and strengthening of these self-concepts is not fully understood. Rutter summarized the significance of self-esteem for the vulnerable individual by stating " it is protective to have a well-established feeling of one's own worth as a person together with confidence and conviction that one can successfully cope with life's challenges" (Rutter, 1990, p. 206). The influence of self-esteem on resilience would appear to be partially a function of: a) an individual feeling that he or she has control over his or her own life; and, b) making personal choices to shape the decisions that affect one's future. Self-esteem is a dynamic and reciprocal process in that self-esteem guides actions and the consequences of these actions in turn affect one's sense of self-esteem (Brooks, 1992).

The accepted view of self-esteem is that it is an attitude and like all attitudes, the genesis and development of self-esteem is a by-product of interactions between the individual's personality and his or her social experiences (Ockerman, 1979; Rosenberg, 1965). While some of the literature on self-esteem suggests that self-esteem is a byproduct of the joint influences of both parents and peers (Hoffman, 1984; Lempers \& Clarke-Lempers, 1992), the majority of studies have shown that the quality of adolescent attachment to parents is the predominant significant influence on overall self-esteem (Gecas \& Schwalbe, 1993; Patterson, Pryor, \& Field, 1995), although peer attachment still plays a crucial role (Armsden \& Greenberg, 1987; Burke \& Weir, 1978; Paterson et al., 1995). These studies appear to confirm Berndt's (1979) independent "social worlds" perspective, that parent and peer attachment contribute to different facets of self-esteem among adolescents.

Positive attachment to parents and to peers during adolescence is certainly not the only 
factor contributing to self-esteem. Most studies suggest that gender, social interaction beyond the boundaries of the family, achievement or positive experiences in the areas of academics, the arts, or athletics are variables that enhance self-esteem in children and adolescents and thus promote resilience (Brooks, 1992; Nolen-Hoeksema \& Girgus, 1994, Rutter, 1993). Studies of self-esteem have found significant gender differences, with women reporting lower levels than men at different ages including late adolescence (Cairns, McWhirter, Duffy, \& Barry, 1990; Chubb, Fertman, \& Ross, 1997; Eccles, Wigfeld, Flanagan, Miller, Reuman, \& Yee, 1989; Simmons and Rosenberg, 1975). High self-esteem has been correlated with test scores, grades, and general academic success at a range of educational levels, in addition to moderating relations between GPA and college satisfaction (Byme, 1984; Chubb et al., 1997; Finn \& Rock, 1997; Hansford \& Hattie, 1982; Okun, 1991; Weir \& Okun, 1989). Self -esteem as an isolated variable or combined with other psychosocial variables appears to facilitate resilience among adolescents and create what Brooks (1994) has described as "islands of competency" for at-risk individuals.

Locus of Control. In addition to late adolescents' self-esteem, locus of control was measured as a potential moderating mechanism for weak attachment. Numerous studies have assessed whether people perceive themselves as having an internal locus of control, i.e., the degree to which they control their own destinies, or an external locus of control, the degree to which they believe their destinies are determined by forces other than themselves such as luck, fate, or powerful others (Rotter, 1975). It is hypothesized that the majority of weakly attached but competent late adolescents will rate themselves 
significantly more internal than external with respect to locus of control. Several studies have shown that compared to "externals", "internals" act more independently, cope better with a range of stressors, and are more optimistic and hardworking (Benassi, Sweeney, \& Dufour, 1988; Lefcourt, 1982; Rotter, 1990). Although a few studies have reported no significant gender difference (Adame, Johnson, \& Cole, 1989; Chubb et al., 1997), other studies have found that women are more external than men when assessing locus of control and achievement (Cairns et al., 1990; Findley \& Cooper, 1983; Stipek \& Weiszt, 1981).

More relevant to this study, however, there appears to be a strong relationship between internal locus of control and academic achievement or academic self-esteem (Cone \& Owens, 1991; Gose, Wooden, \& Muller, 1980; Kanoy, Wester, \& Latta, 1990; Kleinfeld, 1971; Maqsud \& Rouhani, 1991; Miller \& Irving, 1995; Nunn \& Nunn, 1993; Trice, 1985). Several studies have suggested that next to intellectual ability, internal locus of control predicts the greatest proportion of variance in academic achievement (Klein \& Keller, 1990; Miller \& Irving, 1995) Of considerable research interest is the likelihood that internals may differ from externals in the manner by which they seek social support and in the kinds of support they receive (Luthar, 1993; Sandler \& Lakey, 1982).

Androgyny. Although androgyny is not as commonly cited as self-esteem or locus of control in the literature of variables potentially moderating the hypothesized effects of weak attachment on academic achievement, Werner \& Smith (1982) found androgynous behavior to be a significant factor in the resiliency manifested in their long-term study of at-risk children. The androgyny model assumes that masculinity and femininity are 
independent and complementary dimensions and that both masculinity and femininity contribute uniquely and positively to the prediction of specific outcomes such as selfconcept (Marsh \& Byrne, 1991; Whitely, 1983). Androgynous individuals, having instrumental masculine traits and nuturant feminine traits, may have social and psychological advantages compared to sex-typed late adolescents (Bem, 1974; Pei-Hui \& Ward, 1995). For example, androgynous individuals may have a more flexible repertoire of behaviors and adaptive qualities than non-androgynous individuals that allow easier negotiation and escape from risk pathways. Therefore, individuals who perceive themselves to be androgynous may be less limited in responding to the demands of the contemporary world or stressful environments (Bem, 1975).

Research on androgyny has found a positive relation between androgyny and psychological well-being ( Bem, 1975; Gilbert, 1981; Whitley, 1983), mental health (Bem \& Lenney, 1976; Bem, Martyna, \& Watson, 1976; Orlofsky, 1977), and high self-esteem (Bem, 1981; Lamke, 1982; Whitley, 1983). Although categories of androgyny that reflect both "high female" and "high male" characteristics are positively associated with selfesteem, it appears that most of the predicted variance in outcomes can be attributed to the "male" score alone (Marsh \& Myers, 1991). Therefore, high masculinity seems to be related to high self-esteem in either gender while the relationship between high femininity and self-esteem is more ambiguous.

Optimism. Optimism, defined as a generalized tendency to expect positive outcomes (Kassin, 1995) was also measured for its potential to moderate the influence of weak parental and peer attachment. According to Seligman (1991), the explanatory style of 
optimism fosters an external, specific, and temporary attribution for failure, while crediting success to internal, global, and permanent factors. Dispositional optimism has been found to reduce stress in college students as well as to be an important predictor of both adjustment to college and lower alcohol or other drug use among college students (Aspinwall \& Taylor, 1992; Scheier \& Carver, 1992; Scheier, Carver, \& Bridges, 1994). Optimistic individuals with high self-esteem also appear to have better social relationships and make greater use of social support than less optimistic individuals (Scheier, Weintraub, \& Carver, 1986; Taylor, 1989; Taylor \& Brown, 1988). If optimists do have "the gitt of turning stumbling blocks into stepping stones" as expressed by one theorist (McGinnis, 1987, p. 16), this trait could prove to be a significant protective factor moderating weak parental and peer attachment.

Global Self-Worth. As described by Harter (1990), global self-worth/global selfesteem is a distinct construct that refers to an individual's overall judgment about his or her worth as a person. It is assessed by asking an independent set of questions rather than by combining domain-specific judgments. Global self-worth is heavily determined by how an individual performs in domains of importance to that individual rather than by the positive regard of significant others. A cognitive strategy for maintaining high global selfworth involves discounting domains where one has performed poorly and overestimating the importance of those domains in which one has performed competently (Marsh, 1986). In one study, intellectual ability was found to be a much stronger predictor of global selfworth than was family support or physical appearance (Harter, 1990). The least potent predictor of global self-esteem in the same study was friend/peer support. 


\section{Cognitive and Contextual Moderating?Compensatory Variables}

Several cognitive variables were measured in the current study to determine what influence these variables have on the academic competence of college students, in particular those students who perceive themselves to be weakly attached to both parents and peers. Self-reported intellectual ability and scholastic competence are two salient continuous cognitive variables incorporated in the study.

Intellectual Ability. Research on the prediction of academic achievement has highlighted the salience of several academic/cognitive variables including perceived intellectual ability, intelligence scores, and aptitude test scores. These and other academic variables have been shown to account for approximately $25 \%$ to $50 \%$ of the variance in academic achievement (Khan, 1966; Zarb, 1981). In numerous studies, general ability as measured by scholastic aptitude tests and intelligence tests is significantly correlated with classroom outcomes and GPA (Horn, Bruning, Schraw, Curry, \& Katkanant, 1993; Jensen, 1973; Teachman, 1996).

Previous studies of at-risk children have shown that those with higher intelligence or better scholastic competence or scholastic achievement tend to be more resilient (Luthar, 1993; Rutter, 1987, 1989). Greater cognitive abilities not only act to enhance individuals' self-esteem but they also become protective in nature by providing at-risk individuals greater ranges of adaptive strategies or coping skills (Rutter, 1989). In addition, intellectually advanced students utilize these cognitive capabilities to sustain their self-esteem, to buffer themselves from environmental stressors, or to recruit providers of social support (Milgram \& Palti, 1993). 
A critical question is whether an individual's high intellectual ability and scholastic competence are antecedents to the individual's high self-esteem or if the high self-esteem acts as a precursor to high intellectual ability and scholastic competence. While high intellectual ability accompanied by scholastic success acts to enhance one's self-esteem (Luthar, 1993), it is also probable that a high level of self-esteem boosts one's perception of intellectual and scholastic ability and it may influence persistence. The full impact of high intellectual ability in moderating adverse psychological variables such as low attachment is not known, but within the college environment of these late adolescents, the moderating influence is likely to be considerably greater. Several researchers have also theorized that success or failure in a specific domain will affect an individual's self-esteem in proportion to how important that domain is to the individual (Coopersmith, 1967; James, 1890/1963; Osborne, 1995). If this is the case, a college student's self-esteem would undoubtedly be affected by success or failure in academic performance.

Scholastic Competence. This cognitive variable differs from intellectual ability on several levels. While intellectual ability taps general intellectual competence, scholastic competence is less global in scope and is related more to academic functioning including doing well at one's studies and completing assignments (Neemann \& Harter, 1986). In addition, scholastic competence may compensate for attachment-related vulnerabilities by allowing students to develop a high level of self-esteem in a specific academic domain (Tennant, Bebbington, \& Hurry, 1981). The additive effect of scholastic competence and high self-esteem may have pronounced influence on a student's academic competence. 
Okun \& Fournet (1993) interpreted scholastic competence as being conceptually equivalent to academic self-esteem. Scholastic competence also appears to be similar as a concept to academic efficacy that has been used in several previous studies (Brown, Lent, \& Larkin, 1989; Lent \& Hackett, 1987). The current study measured scholastic competence by assessing four conceptually related items from the Self-Perception Profile for College Students (Neemann \& Harter, 1986). A sample item was: "Some students feel confident they are mastering coursework BUT other students do not feel so confident." It appears that college students do make a distinction between scholastic competence and intellectual ability.

\section{Parental Educational Level}

Numerous studies have demonstrated that cognitive factors (intellectual ability and scholastic competence) and key psychosocial factors (attachment, locus of control, optimism, androgyny, self-esteem) are significant predictors of academic achievement at all levels of education. While a combination of these factors predict the vast majority of the variance in academic achievement, several other factors including parental education, and family socioeconomic status also appear to influence students' academic achievement. Research suggests that the more educated one's parents are, the more likely they are to support and encourage their children's educational goals (Brown \& Robinson Kurpius, 1997; Lin, 1990; Winfeld, 1991). In their study of school engagement among minority students from low-income homes, Finn and Rock (1997) found that parents' educational attainment to be one of many factors that contributed to academic resilience. While level of parents' educational attainment may influence children through modeling 
and a supportive family environment that rewards academic success, students in families in which both parents graduated from college reported fears of failure and/or disgrace if they were unable to graduate from college (Peng, 1994). Parents employed in professions that require higher educational attainment also appear to directly influence their child's internalized values related to academic performance (Bank et al., 1990). While level of family income has been found to be a significant predictor of academic success (Finn \& Rock, 1997), low income families with parents who did not have much educational success may create a less optimistic atmosphere concerning education and their children's futures (Bell et al., 1994; Galambos \& Silbereisen, 1987).

The current study was designed to determine the influence of parental and peer attachment on academic achievement among late adolescent college students. A second objective of the study was to determine which cognitive and/or non-cognitive variables act as moderating influences upon academic adversity among students who perceive themselves to be weakly attached to both parents and peers. The specific aims of this study were (a) to determine whether there is a meaningful difference in perceived attachment relationships among college students; (b) to determine the influence of combined weak parental attachment and weak peer attachment on the academic achievement and academic competence of late adolescent college students; and, (c) to identify cognitive and/or non-cognitive variables that may act as potential protective factors enabling students at risk for academic adversity to be academically competent. 
Chapter 3: Method

\section{Participants}

Respondents in this study were 357 college students attending a four-year university during the winter and spring semesters of 1997 . The participants were 255 female students ( $71.4 \%)$ and 102 male students (28.6\%) ranging in age from 18 to 24 years $(M=20.66, S D=1.9)$. The ethnic backgrounds of the participating students were European-American (15.7\%), African-American (12.0\%), Hispanic-American (66.4\%), Asian-American (3.4\%), or Other (2.5\%). Class standing of the participants included $151(42.3 \%)$ first or second year students and $206(57.7 \%)$ juniors or seniors. A small percentage of students $(7.6 \%)$ belonged to a fraternities or sororities. Most $(94.4 \%)$ were unmarried. Due to the urban setting of the university, $78.2 \%$ of the participants lived at home with one or more parent. The mean grade/academic level completed by the participants' mothers was $13.88(\mathrm{SD}=3.25)$ while their fathers' mean grade/academic level completed was $14.19(\mathrm{SD}=3.90)$.

\section{Measures}

Inventory of Parent and Peer Attachment (Appendix A). Attachment levels were assessed using the Inventory of Parent and Peer Attachment (IPPA) developed by Armsden and Greenberg (1987). This two part assessment is a self-report questionnaire that measures the cognitive and affective qualities of parent and peer attachment among late adolescents and young adults. It includes subscale scores for trust, communication, and alienation. The IPPA is based on the assumption that parental attachment is a source of continuing psychological well-being for adolescents and young adults while significant 
peers begin to serve as important attachment figures in addition to parents (Lopez \& Gover, 1993). Two separate attachment scores, for parents or peers, are calculated by adding the trust and communication scores and then subtracting the alienation score. The IPPA has been used successfully in numerous studies (e.g., Armsden \& Greenberg, 1987; Blain et al., 1993; Jong, 1992; Lapsley et al., 1990; Nada Raja et al., 1992; O’Koon, 1997; Paterson et al., 1995; Quintana \& Lapsley, 1987; Schneider \& Younger, 1996). Scores on the IPPA have been found to be significantly associated with positive self-esteem, affective status, and less externally oriented locus of control (Armsden \& Greenberg, 1987; Lewis et al., 1987).

Responses to the IPPA are based on a 5-point Likert scale. Response categories are Almost Never or Never (1), Seldom (2), Sometimes (3), Often (4), and Almost always or Always (5). Negatively worded statements are later recoded. Higher scores indicate stronger attachment to parents or peers. Internal consistency coefficients for this instrument have been reported to be above .90 . Armsden and Greenberg (1987) reported Cronbach's alpha coefficients of .91, .91, and .86 for the Parent Trust, Communication, and Alienation factors, respectively. Alphas for the Peer scales were .91 for Communication, .87 for Trust, and .72 for Alienation. Three-week test-retest reliability coefficients were .93 for the Parent Attachment Scale and .86 for the Peer Attachment Scale (Armsden \& Greenberg, 1987). Alpha coefficients for the Parent Attachment Scale for the present study were .91 for Trust, .90 for Communication, and .75 for Alienation. The Peer Attachment Scale's alpha coefficients for this study were .92 for Trust, .86 for Communication, and .67 for Alienation. 


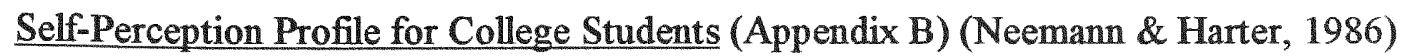
has been used successfully in several studies (Harter, 1990; Neemann \& Harter, 1986; Okun \& Fournet, 1993). This profile consists of twelve domains in addition to global selfworth: scholastic competence, intellectual ability, creativity, job competence, athletic competence, physical appearance, romantic relationships, peer social acceptance, close friendships, parent relationships, sense of humor, and morality. This self-report profile consists of 54 statements, i.e., four items for each of the 12 domain subscales and six items for the global self-esteem subscale. A respondent must first decide which students were more like himself/herself and then decide whether the statement about those students was sort of true or really true for himself/herself. For example, a job competence item forces the respondent to initially choose between Some students are not very proud of the work they do on their job but Other students are proud of the work they do on their job. Responses are scored on a 1 to 4 scale. A higher mean score on the relevant items indicates higher self-esteem in that specific domain. Of particular relevance to this study are the areas of intellectual capacity and scholastic competence. Neemann and Harter (1986) reported that subscale reliabilities assessed by coefficient alpha ranged from .76 to .92 for the entire sample. The alpha coefficients for the present study ranged from .77 (Job Competence) to .92 (Athletic Competence).

Rosenberg Self-Esteem Scale (Appendix C) (Rosenberg, 1965) consists of 10 selfstatement items and is an index of overall self-esteem. The Rosenberg Self-Esteem Scale (RSE) has been used extensively and has been shown to be highly reliable in numerous studies (Chubb et al., 1997; Cranston \& Leonard, 1990; Osborne, 1995; Paterson et al., 
1995). The original RSE was scored with a Guttman scale but the RSE is frequently scored with a Likert scale, as in this study. Participants are asked to strongly agree, agree, disagree, or strongly disagree with ten statements such as "I feel that I have a number of good qualities" or "All in all, I am inclined to feel that I am a failure." A total self-esteem score is calculated by summing the responses. Silber and Tippitt (1965) reported 2-week test-retest reliability coefficients to be .85 and .88 . The Cronbach alpha of the RSE in one recent study was .85 (Paterson et al., 1995). The RSE has shown evidence of convergent validity, via significant correlation, with other measures of self-esteem (Cranston \& Leonard, 1990; Rosenberg, 1965; Silber \& Tippitt, 1965). In the current study, the alpha coefficient of the RSE was .90 .

Bem Sex-Role Inventory (Appendix D) (Bem, 1974) is a paper-and-pencil self-report instrument that distinguishes androgynous individuals from sex-typed individuals. The Bem Sex-Role Inventory (BSRI) consists of 60 personality characteristics. Twenty of these characteristics are prototypical masculine personality characteristics (e.g., independent, assertive), 20 are prototypical feminine characteristics (e.g., affectionate, understanding), and 20 are neutral characteristics (e.g., truthful, happy). Each participant is asked to indicate on a scale from 1 (Never or almost never true) to 7 (Always or almost always true) how each characteristic describes himself/herself. The degree of sex-role assignment is defined as a Student's $t$-ratio for the difference between the total points assigned to the feminine and masculine traits. If a person's masculinity score and femininity scores are approximately equal $(t \leq 1)$, that person is labeled androgynous (Bem et al., 1976). Previous studies have found the 
BSRI to have reliable subscales (Brems \& Johnson, 1990; Pei-Hui \& Ward, 1994). Cronbach's alphas for this study were .82 for the masculinity subscale and .79 for the femininity subscale.

Levenson's Locus of Control Scale (Appendix E) (Levenson, 1974) was developed as an alternative to Rotter's (1966) locus of control scale. The brief version (Sapp \& Harrod, 1993) of Levenson's Locus of Control Scale consists of nine items covering the three dimensions of internal control, chance, and powerful others with demonstrated alpha coefficients of $.59, .65$, and .72 , respectively. The nine items are rated using a seven-point Likert scale ranging from strongly agree to strongly disagree. The predictive and construct validity of the scale have been supported empirically. The brief version of Levenson's (1974) scale has been found to be a reliable and valid alternative to the full scale in cases in which locus of control is not the major focus of the research (Sapp \& Harrod, 1993). For the present study, the overall alpha coefficient for all nine items was .80. The alpha coefficients for the individual subscales were .73 for internal control, .70 for chance, and .81 for powerful others.

Life Orientation Test-Revised (Appendix F) (Scheier et al., 1994) is a self-report questionnaire used to assess optimism. The Life Orientation Test-Revised (LOT-R) is a six-item scale (plus four filler items) that uses a five-point Likert scale ranging from strongly disagree (1) to strongly agree (5). Three items are keyed in a positive direction, three items are keyed in a negative direction, and the six items are summed to provide an overall optimism score. The LOT-R has been found to have high internal consistency and test-retest reliability and it has performed well in tests of convergent and discriminant 
validity (Scheier, et al., 1994). The LOT-R appears to be particularly well-suited for measuring optimism among college-age respondents. The alpha coefficient for the LOT-R in the current study was .80 .

Student Academic Profile (Appendix G) is a measure developed for this study to assess the current academic achievement of the participants and a brief academic history of the participant while he or she was in secondary school. This self-report questionnaire consists of 10 items and provides information on the continuity or discontinuity of academic competence among the participants. The SAP required respondents to answer questions concerning present GPA, high school GPA, how many times he or she changed majors, whether academics was stressed by parents and/peers, and to what the student attributed his or her academic success to (e.g., hard work, intellectual ability, both, luck). Procedure

Respondents were recruited from psychology classes and participating students received one hour of research credit. Participation was voluntary and confidentiality was guaranteed. A three-digit identification number was assigned to each respondent. Data collection took place in large groups in psychology classrooms. A packet of questionnaires and measures, including a Student Information Questionnaire (i. e., age, marital status, class rank) was given to each respondent. Respondents were instructed to read each form carefully and then choose the answer that pertains to them individually. On average, it took 30 minutes to complete these measures. The seven measures used in this study were presented to participants in a counterbalanced format. 


\section{Chapter 4: Results}

\section{Attachment Analyses of Entire Sample}

Scores for late adolescent students' perceptions of their attachment relationships with parents and peers were obtained through the use of the IPPA. Similar to Armsden \& Greenberg's (1987) categorization, the score distributions for the student participants were divided into three groups (low, medium, high) for both parent and peer attachment. Via a crosstabulation, nine separate peer and parental attachment groups were created ranging from a low peer and low parental attachment group to a high peer and high parental attachment group. The number of students in each of these groups ranged in size from 20 students (High Parent-Low Peer) to 60 students (High Parent-High Peer). A chisquare analysis of the distribution of students across the nine parent and peer attachment categories indicated a significant association between the two forms of attachment: $x^{2}(4$, $\underline{\mathrm{N}}=357)=35.27, \mathrm{p}<.0001$ ). These results are consistent with previous studies of adolescent attachment patterns (Armsden \& Greenberg, 1987; Sebald, 1993).

As anticipated, a small proportion (14.8\%) of the students perceived themselves to be weakly (low) attached to parents and weakly attached to peers (Low-Low Group). Perceived peer attachment for the total sample $(\mathrm{N}=357, \mathrm{M}=56.6, \mathrm{SD}=10.4)$ and perceived parental attachment for the total sample $(\mathrm{N}=357, \mathrm{M}=60.7, \mathrm{SD}=16.2)$ was similar to attachment levels found in Armsden and Greenberg's (1987) normative college sample. In the current study, the Low Peer and Low Parent Group had a mean peer attachment score of 41.7 and a mean parental attachment score of 30.6 compared to the High Peer and High Parent Group whose mean peer and parent attachment scores were 
75.3 and 78.0 , respectively.

One-way analyses of variance (ANOVAs) of parent and peer attachment scores yielded no differences based on marital status (single vs. married), class rank, or fraternity/sorority membership. While there was no significant difference in mean levels of peer attachment by ethnicity, there were significant differences in mean levels of parental attachment by ethnicity, $\underline{\mathrm{F}}(4,353)=2.98, \mathrm{p}<.02$. Asian-American students reported the lowest levels of attachment to parents $(M=41.7)$ and post-hoc tests revealed this group to have significantly lower levels of attachment when compared to Hispanic-American students $(M=57.7)$. A chi-square analysis of ethnicity by the attachment typology did reveal a significant difference: $x^{2}(4, \underline{N}=357)=49.9, p<.05$. The data revealed that Hispanic-Americans were overrepresented in the Medium-Low Group and the High-High Group, African-Americans were overrepresented in the Low-Low Group, AngloAmericans were overrepresented in the Low-Low Group and underrepresented in the High-High Group, and Asian-Americans were overepresented in the Low-Low, LowMedium, and Low-High groups.

It was anticipated that there would be a significant difference in the distribution of attachment statuses by ethnicity due to cultural differences related to parent-child relationships and socialization among the ethnic groups included in this study (i.e., Hispanic-Americans, Asian-Americans). While Armsden and Greenberg (1987) found no significant differences between Caucasians and non-Caucasians in peer attachment and parental attachment, the data of the current study suggest that ethnic differences in 
parental and/or peer attachment are consistent with a previous study that included AfricanAmericans, Asian-Americans, Anglo-Americans, and Latinos in its sample (Zea et al., 1995). It would appear that due to the complexity of ethnicity-attachment relations, individuals of diverse ethnic groups may perceive their attachment to parents and peers to be significantly different. These results are summarized in Tables 1 and 2 .

An ANOVA of parental attachment scores by students' age revealed no significant differences but there was a significant difference by age group for mean levels of peer attachment, $\underline{F}=(6,351)=2.43, \underline{p}<03$. The oldest group ( 24 year-old students) was the least attached to peers $(M=53.9)$ and this group was significantly less attached than the two youngest age groups in this study: 18 year-old students $(M=63.9)$ and 19 year-old students ( $M=63.1$ ) Significant differences were also found for peer attachment by residence status, with students living at home reporting a higher level, $\underline{F}=(1,355)=$ $3.99, \mathrm{p}<.05$. There was no significant difference by residence status in mean levels of parental attachment. Chi-square analyses of residence status by the attachment typology, gender by the attachment typology, and age by the attachment typology were not significant.

As expected, a significant gender difference was found for mean levels of peer attachment, $\underline{F}=(1,355)=6.99, \mathrm{p}<.01$, while there was no significant difference in mean levels of parental attachment by gender. Females' higher levels of peer attachment is consistent with previous studies and this difference may be related to women's higher levels of friendship intimacy (Colby \& Damon, 1983; Lapsley et al., 1990; Nada Raja et al., 1992). No significant mean differences between males and females were found for 
Table 1

Means and Standard Deviations of Ethnic Groups on Measures of Attachment, Cognitive Variables, and Non-Cognitive Variables

\begin{tabular}{|c|c|c|c|c|c|}
\hline \multirow[b]{2}{*}{ Variable } & $\begin{array}{l}\text { Hispanic-Amer. } \\
\quad(n=237)\end{array}$ & $\begin{array}{l}\text { Anglo-Amer. } \\
(n=43)\end{array}$ & $\begin{array}{l}\text { African-Amer } \\
(n=56)\end{array}$ & $\begin{array}{l}\text { Asian-Amer } \\
(n=12)\end{array}$ & \multirow[b]{2}{*}{$F$} \\
\hline & $\mathrm{SD}$ & $\mathrm{SD}$ & SD & $\mathrm{SD}$ & \\
\hline 1. Peer Att. & $59.96(14.1)$ & $58.19(17.3)$ & $61.00(13.7)$ & $65.42(15.2)$ & 1.23 \\
\hline 2. Par. Att. & $57.71(19.4)$ & $52.21(18.9)$ & $52.45(21.9)$ & $41.67(21.3)$ & $2.98 *$ \\
\hline 3. Sch. Com. & $2.96(.71)$ & $2.84(.74)$ & $2.94(.67)$ & $2.77(.63)$ & .47 \\
\hline 4. Int. Abil. & $3.24(.72)$ & $3.11(.81)$ & $3.06(.74)$ & $2.96(.83)$ & 1.17 \\
\hline 5. GPA & $4.34(1.1)$ & $4.02(1.0)$ & $4.51(1.2)$ & $4.33(0.9)$ & 1.23 \\
\hline 6. Locus & $50.31(7.4)$ & $48.12(6.7)$ & $49.82(7.0)$ & $45.67(8.9)$ & 1.89 \\
\hline 7. Optim & $22.54(5.0)$ & $22.72(4.6)$ & $21.42(5.4)$ & $19.91(3.9)$ & 1.90 \\
\hline 8. Self-est. & $33.28(5.6)$ & $34.59(4.6)$ & $31.82(5.8)$ & $32.25(3.7)$ & 1.69 \\
\hline 9. GlobalSE & $3.21(.65)$ & $3.21(.60)$ & $3.11(.64)$ & $2.98(.60)$ & .64 \\
\hline 10. Andrg. & $2.51(1.1)$ & $2.49(1.2)$ & $2.61(1.2)$ & $2.00(1.1)$ & 1.19 \\
\hline
\end{tabular}

Note: ${ }^{*} \mathrm{p}<.05 ;$ Peer Att. $=$ Peer Attachment $;$ Par. Att. $=$ Parental Attachment $;$ Sch. Com = Scholastic Competence; Int. Abil. = Intellectual Ability; GPA = College GPA; Locus $=$ Locus of Control; Optim $=$ Optimism; Self-est. $=$ Self-esteem; GlobalSE $=$ Global Self-esteem; Andrg. = Androgyny. 
Table 2

Frequencies and Proportions of Ethnic Categories in Attachment Groups

\begin{tabular}{|c|c|c|c|c|c|}
\hline $\begin{array}{l}\text { Attachment Group } \\
\text { (parent - peer) }\end{array}$ & $\begin{array}{l}\text { Hispanic-Amer. } \\
\quad(n=237) \\
\underline{\mathbf{n}} \%\end{array}$ & $\begin{array}{c}\text { Anglo-Amer. } \\
(n=43) \\
\underline{\mathrm{n}} \quad \%\end{array}$ & $\begin{array}{l}\text { African-Amer. } \\
\quad(n=56) \\
\underline{\text { n }} \%\end{array}$ & $\begin{array}{c}\text { Asian-Amer } \\
(n=12) \\
\underline{\mathrm{n}} \%\end{array}$ & $\begin{array}{c}\text { Other } \\
(n=9) \\
\underline{\mathbf{n}} \%\end{array}$ \\
\hline 1. Low-Low & $30(.13)$ & $10(.23)$ & $10(.18)$ & $3(.25)$ & $0(.00)$ \\
\hline 2.Low-Medium & $24(.10)$ & $6(.14)$ & $8(.14)$ & $3(.25)$ & $0(.00)$ \\
\hline 3.Low-High & $12(.05)$ & $3(.07)$ & $7(.13)$ & $3(.25)$ & $1(.11)$ \\
\hline 4.Medium-Low & $40(.17)$ & $4(.09)$ & $3(.05)$ & $0(.00)$ & $0(.00)$ \\
\hline 5.Medium-Medium & $35(.15)$ & $3(.07)$ & $4(.07)$ & $0(.00)$ & $3(.33)$ \\
\hline 6.Medium-High & $14(.06)$ & $8(.19)$ & $5(.09)$ & $1(.08)$ & $1(.11)$ \\
\hline 7.High-Low & $12(.05)$ & $3(.07)$ & $4(.07)$ & $0(.00)$ & $1(.11)$ \\
\hline 8.High-Medium & $25(.10)$ & $3(.07)$ & $6(.11)$ & $0(.00)$ & $2(.22)$ \\
\hline 9.High-High & $45(.19)$ & $3(.07)$ & $9(.16)$ & $2(.17)$ & $1(.11)$ \\
\hline
\end{tabular}

Note. Proportions are in parentheses; $x^{2}(1, N=357)=49.9, \mathrm{p}<.05$. 
cognitive and non-cognitive variables. For example, contrary to previous studies, this sample of students reported no significant mean differences by gender in self-esteem and locus of control (Chubb, 1997; Eccles et al., 1989; Findley \& Cooper, 1983; Stipek \& Weiszt, 1981). These results are summarized in Table 3.

Correlational Analyses of Attachment, Cognitive, and Non-Cognitive Variables

Pearson correlation coefficients were calculated between key academic variables, psychosocial variables, and parental attachment and peer attachment scores for the entire sample. These correlational analyses are presented in Table 4. Significant positive correlations $(\mathrm{p}<.01)$ were found among both peer attachment and parental attachment for self-esteem, locus of control, global self-esteem, optimism, scholastic competence, intellectual ability, masculine traits, and feminine traits. Neither parental attachment nor peer attachment was found to be significantly correlated with GPA. Several items from the Student Academic Profile (SAP) were significantly correlated ( $\mathrm{p}<.05)$ with parental and/or peer attachment. For example, average grade in high school (SAP 5) was significantly correlated with both parental and peer attachment, while a) winning academic awards in high school (SAP 7), and b) whether parents stressed academics while in high school (SAP 8) were both found to be significantly negatively correlated with peer attachment. Chi-square analyses performed using the nine attachment categories and father's or mother's educational attainment were not significant.

Pearson $r$ correlations for three attachment groups are presented in Table 5 through Table 7. Correlations for Group 1 (Low-Low) among peer attachment and parental attachment and key cognitive and non-cognitive variables revealed a significant positive 
Table 3

Means and Standard Deviations of Male and Female College Students on Measures of Attachment, Cognitive Variables, and Non-Cognitive Variables

\begin{tabular}{lcccc}
\hline \multicolumn{1}{c}{ Variable } & $\begin{array}{l}\text { Male students } \\
(n=102)\end{array}$ & \multicolumn{3}{c}{ Female students } \\
& $\mathrm{M} \quad \mathrm{SD}$ & $\mathrm{M}$ & $\mathrm{SD}$ & $F$ \\
\hline 1. Peer Attachment & $57.18(16.00)$ & 61.55 & $(13.56)$ & $6.99^{* *}$ \\
2. Parental Attachment & $54.48(18.48)$ & 56.27 & $(20.59)$ & .58 \\
3. Scholastic Competency & $2.61(.59)$ & 2.80 & $(.60)$ & .73 \\
4. Intellectual Ability & $2.79(.69)$ & 2.98 & $(.72)$ & 1.09 \\
5. Grade Point Average & $4.26(1.10)$ & 4.35 & $(.92)$ & 1.31 \\
6. Locus of Control & $44.18(6.33)$ & 45.30 & $(6.72)$ & 2.39 \\
7. Optimism & $18.42(4.47)$ & 18.85 & $(4.90)$ & .02 \\
8. Self-esteem & $33.60(5.67)$ & 33.02 & $(5.42)$ & .70 \\
9. Global Self-esteem & $2.68(.60)$ & 2.82 & $(.65)$ & .11 \\
10. Androgyny & $1.84(1.07)$ & 2.03 & $(1.22)$ & .11 \\
\hline Note: ** $<.01$ & & & & \\
\hline
\end{tabular}




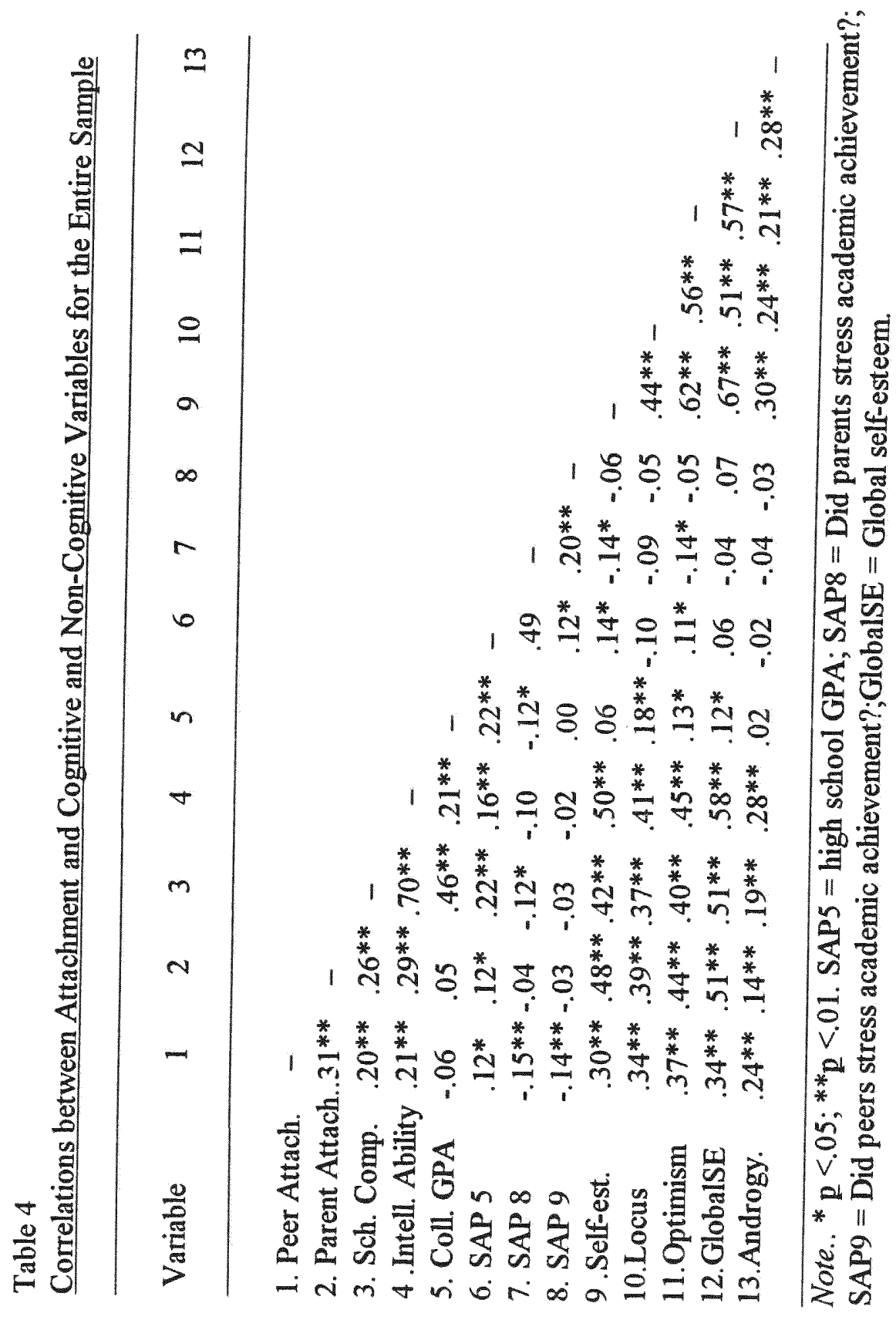


Table 5

Correlations for Attachment, Cognitive, and Non-Cognitive Variables for Group 1 (LowLow)

$\begin{array}{lllllllllll}\text { Variables } & 1 & 2 & 3 & 4 & 5 & 6 & 7 & 8 & 9 & 10\end{array}$

1. Peer Attachment

2. Parental Attach. .10

3. Schcomp $\quad .36^{*}-.07-$

4. Int. ability $\quad .34^{*} \quad .01 \quad .72^{* *}$

$\begin{array}{lllll}\text { 5. Coll. GPA } \quad-.03 & -.11 & .34 * * & .12 & -\end{array}$

6. Locus of cont. $\quad .30 * \quad .05 \quad .29 * \quad .39 * * .09 \quad-$

$\begin{array}{lllllll}\text { 7. Self-esteem } & .17 & .18 & .58 * * & .68 * * & .06 & .44 * *-\end{array}$

$\begin{array}{llllllll}\text { 8. Optimism } & .20 & . & .29 & .48 * & .05 & .49 * * & .58 * *\end{array}$

9. GlobalSE $\quad .22 \quad .36^{* *} .49 * * \quad .57^{* *}-.01 \quad .33^{*} \quad .84^{* *} .40^{* *}-$

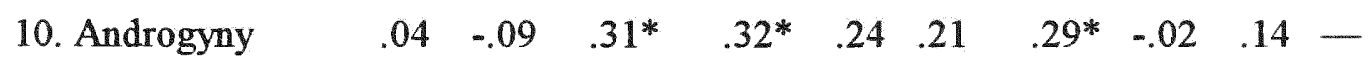

Note. ${ }^{*} \mathrm{p}<.05 ;{ }^{* *} \mathrm{p} .01$. 
Table 6

Correlations for Attachment, Cognitive, and Non-Cognitive Variables for Group 5 (Medium-Medium)

$\begin{array}{lllllllllll}\text { Variables } & 1 & 2 & 3 & 4 & 5 & 6 & 7 & 8 & 9 & 10\end{array}$

1.Peer Attach.

2. Parental Attach. $.02 \quad-$

3. Schcomp. $\quad-.03 \quad .41^{* *}-$

4. Int. Ability $\quad-.09 \quad .34^{* *} .74^{* *}$

5. Coll. GPA $\quad-.30^{*} \quad-.02 \quad .42 * * \quad .23 \quad-$

6. Locus of con. $\quad .06 \quad .05 \quad .45^{* *} \quad .41^{* *} .22 \quad-$

$\begin{array}{llllllll}\text { 7. Self-esteem } & -.13 & .15 & .28 & .27 & -.04 & .04 & -\end{array}$

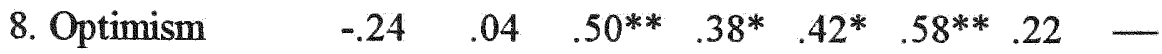

9. GlobalSE $\quad .12 \quad .20 \quad .55^{* *} \quad .61^{* *} .04 \quad .34^{*} \quad .36^{*} .31^{*}-$

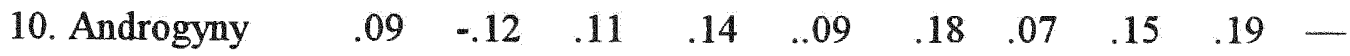

Note. ${ }^{*} \mathrm{p}<.05 ;{ }^{* *} \mathrm{p}<.01$. 
Table 7

Correlations for Attachment, Cognitive, and Non-Cognitive Variables for Group 9 (HighHigh.

$\begin{array}{lllllllllll}\text { Variables } & 1 & 2 & 3 & 4 & 5 & 6 & 7 & 8 & 9 & 10\end{array}$

1. Peer Attach.

2. Parental Attach. $.06 \quad-$

3. Schcomp $\quad-.03 \quad-.17 \quad-$

4. Int. Ability $\quad .07 \quad .02 \quad .76^{* *} \quad-$

$\begin{array}{lllll}\text { 5. Coll. GPA } \quad .01 & -.12 & .50^{* *} & .35^{* *}-\end{array}$

6. Locus of con. $\quad .00 \quad .14 \quad .37^{* *} \quad .26^{*} \quad .33^{*}-$

$\begin{array}{llllllll}\text { 7. Self-esteem } & -.06 & .04 & .55^{* *} & .60^{* *} & .25 & .29 * & -\end{array}$

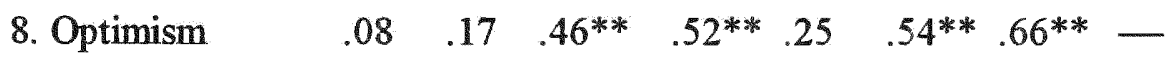

9. GlobalSE $\quad-.21 \quad .01 \quad .52 * * \quad .27 * \quad .15 \quad .35^{* *} .38^{* *} .28^{*}-$

10. Androgyny $\quad-.15 \quad .00 \quad .32^{*} \quad .31 * \quad .22 \quad .31^{*} \quad .47^{* *} .34^{* *} .31^{*}-$

Note. $\mathrm{p}^{*<.05 ; \mathrm{p}^{* *}<.01}$ 
correlation between peer attachment and two of the three cognitive variables. Peer attachment was significantly correlated with scholastic competence $(\underline{r}=.36, \underline{p}<.05)$ and intellectual ability $(\underline{\mathrm{r}}=.34, \mathrm{p}<.05)$. Parental attachment was significantly correlated with global self-esteem $(\underline{r}=.36, \underline{p}<.01)$. Several of the non-cognitive psychosocial variables were significantly correlated with intellectual ability and scholastic competence which suggests that these variables may be potential protective factors against academic adversity or alternatively, that the most academically competent students also function better in non-academic domains. Scholastic competence was the only variable, cognitive or non-cognitive, that was significantly correlated with college GPA $(\underline{r}=.34, \underline{p}<.01)$. Within the Low-Low Group, these results suggested that specific psychosocial variables may moderate low attachment risk status and facilitate academic competence for some individuals within this group. These results are summarized in Table 5.

Correlations among attachment variables, cognitive variables, and non-cognitive variables for the Medium-Medium Group and the High-High Group are presented in Tables 6 and 7. Significant correlations were described for both groups between scholastic competence and college GPA, while intellectual ability was significantly correlated with college GPA $(\underline{r}=.35, \underline{p}<.01)$, in the High-High Group. Locus of control was the only non-cognitive variable significantly correlated to college $\operatorname{GPA}(\underline{\mathrm{r}}=.33, \mathrm{p}<.05)$ in the High-High Group. In the Medium-Medium Group, optimism was the only non-cognitive variable significantly correlated with college GPA $(r=.42, p<.05)$. Correlations among attachment and other variables were considerably different for these two groups. In the Medium-Medium Group, parental attachment was significantly correlated with scholastic 
competence and intellectual ability while peer attachment was negatively correlated with college GPA $(\underline{r}=-.30, \underline{p}<.05)$. Peer and parental attachment were not significantly correlated with any of the cognitive or non-cognitive variables in the High-High Group. Hierarchical Multiple Regression and MANCOVA Analyses

Hierarchical multiple regression analyses were conducted to assess relations between cognitive or non-cognitive variables and academic achievement (i.e., college GPA). The first regression of analysis attempted to predict college GPA using selected cognitive variables, non-cognitive variables, and demographic variables. Predictor variables were entered in four blocks with the order of entry based on preliminary descriptive analyses. The first block of demographic variables (i.e., age, ethnicity, gender) was not significantly predictive of college GPA, $\mathrm{F}(3,346)=.82$, accounting for only $0.7 \%$ of the variance. The second block entered consisting of parent attachment and peer attachment was not significantly predictive, $\mathrm{E}(5,344)=1.46$, and did not account for a significant proportion $(1.3 \%)$ of the variance in college GPA. The third block consisting of several cognitive variables (intellectual ability, scholastic competence, and high school GPA) significantly predicted college GPA, $\underline{F}(8,341)=18.94, \underline{p}<.01$. The third block of variables accounted for an additional $28.7 \%$ of the variance in college GPA. The fourth block of variables entered consisting of non-cognitive variables significantly predicted college GPA, $\underline{\mathrm{F}}(12$, $337)=13.73, p<.01$, and accounted for an additional $2.0 \%$ of the variance in college GPA.

The combined $R^{2}$ for all four of the blocks of variables entered was $32.8 \%$ of the variance in college GPA. Analysis of individual beta weights for each significant predictor 
revealed peer attachment, intellectual ability, and high school GPA were negatively correlated to college GPA while scholastic competence and self-esteem were positively related to college GPA. These findings are summarized in Table 8 . Sixteen interaction variables (e.g., peer attachment $\mathrm{x}$ optimism, parental attachment $\mathrm{x}$ self-esteem) were entered in a separate block. In the final equation, none of the interaction variables were significant predictors of college GPA and this block accounted for only $1.4 \%$ of additional variance in college GPA.

A second hierarchical multiple regression equation analyzed predictors of perceived scholastic competence. The first block of demographic variables (i.e., age, ethnicity) did not significantly predict scholastic competence, accounting for only $0.4 \%$ of the variance, $\underline{F}(3,346)=.47$. The second block of variables entered included peer and parent attachment. The block of attachment variables accounted for $9.0 \%$ of the variance and significantly predicted scholastic competence, $\underline{F}(5,344)=7.15, \mathrm{p}<.01$. The third block of variables entered included cognitive variables (intellectual ability, high school GPA) and accounted for a significant proportion (42.0\%) of the variance in scholastic competence, $\underline{F}(7,342)=51.79, \underline{p}<.01$. The final block of variables entered, non-cognitive variables, accounted for an additional $1.7 \%$ of the variance which was statistically significant, $\underline{F}(12,337)=31.98, \underline{p}<.01$. Analysis of individual beta weights for each variable in the final equation revealed significant effects only for the two cognitive variables: intellectual ability and high school GPA. These results are summarized in Table 9. Interaction variables (i.e., parental attachment $\mathrm{x}$ intellectual ability, peer attachment $\mathrm{x}$ optimism)were entered in a separate block. In the final equation, none of the interaction variable were 
Table 8

Hierarchical Multiple Regression Model Predicting Students' College GPA by

Demographic Variables, Attachment Variables, Cognitive Variables, and Non-Cognitive Variables

\begin{tabular}{|c|c|c|c|c|c|}
\hline & Standardized & $\mathbf{t}$ & Cumulative & $R^{2}$ & $F$ \\
\hline Predictor & Beta & $t$ value $d f$ & $R^{2}$ & Change & Change \\
\hline
\end{tabular}

1. Demographics

Gender

Age

Ethnicity

Beta

$t$ value $d f$

$.007 \quad .007$

.49

$\begin{array}{rrr}-.07 & -1.32 & 346 \\ -.03 & -.52 & 346 \\ .04 & .72 & 346\end{array}$

2. Attachment

Parent

.10

$1.79 \quad 344$

.021

.014

2.42

Peer

$-.10$

$-1.88^{*} 344$

3. Cognitive

Intell. Ability $\quad-.19 \quad-3.01 * * 341$

H.S. GPA $\quad-.20 \quad-3.01 * * 341$

Sch. Competence $.68 \quad 9.61^{* *} 341$

.308

.287

$47.08 * *$

4. Non-Cognitive

Self-Esteem

.16

$2.46 * 337$

Optimism .07

$1.11 \quad 337$

Androgyny

.04

$.02 \quad 337$

Locus of Cont. $\quad .11$

$1.92 \quad 337$

.328

.021

$2.15 * *$

5. Interactions

Interactions $\mathbf{s}^{\mathrm{a}}$

Note: Overall significance of the model: $\underline{F}(12,337)=13.73, \underline{p}<.0001$.

${ }^{*} \mathrm{p}<.05 ; * * \mathrm{p}<.01$.

a 2-way interactions between parent/peer attachment scores and other predictors $(n=16)$; none was significant. 
Table 9

Hierarchical Multiple Regression Model Predicting Students' Scholastic Competence by Demographic Variables, Attachment Variables, Cognitive Variables, and Non-Cognitive Variables

\begin{tabular}{|c|c|c|c|c|c|}
\hline & Standardized & $\mathbf{t}$ & Cumulative & $R^{2}$ & $F$ \\
\hline Predictors & Beta & $t$ value $d f$ & $R^{2}$ & Change & Change \\
\hline
\end{tabular}

1. Demographics

$\begin{array}{lrrr}\text { Gender } & -.04 & -.80 & 346 \\ \text { Age } & .03 & .60 & 346 \\ \text { Ethnicity } & -.03 & -.54 & 346\end{array}$

2. Attachment

$\begin{array}{llll}\text { Parent } & .22 & 4.02 * * & 344 \\ \text { Peer } & .15 & 2.73 * * & 344\end{array}$

3. Cognitive

$\begin{array}{lrrr}\text { H.S. GPA } & -.13 & -3.21 * * & 342 \\ \text { Intell. Ability } & .66 & 16.31 * * & 342\end{array}$

.515

.420

$148.12 * *$

Intell. Ability $\quad .66 \quad 16.31 * * \quad 342$

4. Non-Cognitive

Self-Esteem $\quad .02$

Optimism $\quad .04$

Androgyny $\quad-.04$

Loc. of Cont. .04

$\begin{array}{lll}.02 & .38 & 337\end{array}$

Global Self-Est. .16

$.75 \quad 337$

$-.93 \quad 337$

$.79 \quad 337$

$2.67 * * \quad 337$

5.Interactions

.538

.006

2.42

Interactions $^{\text {a }}$

Note. Overall significance of the model: $\underline{\mathrm{F}}(12,337)=31.98, \mathrm{p}<.0001$.

${ }^{*} \mathrm{p}<.05 ;{ }^{*} \mathrm{*} p<.01$.

a 2 -way interactions between parent/peer attachment scores and other predictors $(n=16)$; none was significant. 
significant predictors of scholastic competence and this block of variables accounted for only an additional $1.0 \%$ of the variance.

A MANCOVA containing three cognitive variables (intellectual ability, scholastic competence, and GPA) revealed a multivariate main effect for attachment group (Wilks's lambda $=.811, d f=24,327, \underline{\mathrm{p}}<.001)$. In addition, univariate tests were significant for both scholastic competence, $\mathrm{F}(8,346)=4.79, \underline{p}<.001$ and intellectual ability, $\mathrm{F}(8,346)$ $=5.70, \underline{p}<.001$. The univariate test for GPA was not statistically significant, $\underline{F}(8,346)=$ 1.90. Participants' age was not a significant covariate in this MANCOVA model. In addition, a MANCOVA containing five non-cognitive variables (self-esteem, locus of control, global self-esteem, androgyny and optimism) revealed a multivariate main effect for attachment group (Wilks's lambda $=.58, d f=40,311 \mathrm{p}<.001$ ). Univariate tests were statistically significant for all five non-cognitive variables: self-esteem, $\underline{F}(8,341)=12.01$, $\mathrm{p}<.001$, locus of control, $\underline{\mathrm{F}}(8,341)=10.75, \underline{\mathrm{p}}<.001$, global self-esteem, $\underline{\mathrm{F}}(8,341)=$ $15.64, \underline{p}<.001$, androgyny, $\underline{F}(8,341)=4.09, \underline{p}<.001$, and optimism, $\underline{F}(8,341)=14.06$, $\mathrm{p}<.001$. Once again, participants' age was not a significant covariate in this MANCOVA model.

\section{Attachment Group Analyses}

Further descriptive analyses were conducted to decompose and interpret the results of the previous MANCOVA analyses. Contrary to previous hypotheses, one-way ANOVAs revealed no significant differences among the Low-Low Group and the majority of the other attachment groups on academic achievement variables. While the Low-Low Group was consistently the lowest among the nine groups for self-reported intellectual ability, 
grade point average (GPA), and scholastic competence, post-hoc Student-Newman Keuls comparisons revealed that the Low-Low Group only differed significantly from the HighHigh Group for self-reported intellectual ability and scholastic competence, and did not differ significantly from the other groups for self-reported GPA . Comparisons via oneway ANOVA of the nine attachment groups revealed that the Low-Low Group was not significantly different from seven of the eight other groups for the majority of the psychosocial variables and the academic variables. Post-hoc analyses showed that the High-High Group was the group that differed significantly from the other attachment groups for two of the three academic variables. The High-High Group differed significantly from seven of the other groups for Scholastic Competence and this group also showed a statistically significant difference from six other groups for Intellectual Ability. No significant differences were found among attachment groups for the third academic variable, self-reported college GPA. Contrary to the existing research literature that finds a) strong attachment to parents or peers to be related to academic achievement, and, b) that weak attachment to parents or peers places students at academic risk, students in this study who perceived themselves to be weakly attached to both peers and parents did not show particularly negative academic outcomes. Table 10 summarizes differences for cognitive variables by attachment groups.

Comparisons among attachment groups revealed consistencies with previous attachment research for psychosocial variables including self-esteem, locus of control, optimism, and global self-esteem. Weak attachment to parents or weak attachment to peers appears to negatively influence the psychological well-being of the college students. 
Existing literature suggests that the lack of meaningful attachment to parents or peers may have a deleterious effect on psychological well-being or self-esteem (Antonucci, 1990; Cohen \& Willis, 1985; Paterson et al., 1995). In this study, means for optimism, locus of control and global self-esteem for the Low-Low Group were significantly lower than those of five of the other eight groups, while for self-esteem, the mean of the Low-Low Group was significantly lower than those of the other eight groups. Table 11 summarizes differences for non-cognitive variables by attachment group.

ANOVAs and post-hoc mean comparisons were also calculated for masculine personality characteristics, feminine personality characteristics, and for overall androgyny. This analysis revealed significant group differences among the attachment groups for feminine traits, $\underline{F}(8,348)=9.58, \underline{p}<.01$. The Low-Low Group's mean for feminine personality characteristics was the lowest of all the attachment groups $(M=49.4)$ and it was significantly different from four of the other eight groups including the High-High Group ( $M=63.9$ ). The Low-Low Group's mean for masculine personality characteristics ( $M=46.1)$ was significantly different from only that of the High-High Group ( $M=52.8), \underline{F}$ $(8,348)=2.12, \mathfrak{p}<.05$. For overall androgynous personality characteristics, a one-way ANOVA revealed that the Low-Low Group mean $(M=2.0)$ was significantly different from three of the other eight groups including the Medium-High Group $(M=2.9), \underline{F}(8$, $348)=4.17, \mathrm{p}<.001$. Masculine characteristics were found to be significantly correlated with both intellectual ability $(\underline{\underline{r}}=.38, \underline{p}<.001)$ and scholastic competence $(\underline{r}=.27, \underline{p}<$ .001 ), while feminine traits were significantly correlated only with intellectual ability ( $\underline{\mathrm{r}}$ $=.16, \mathrm{p}<.01$ ). These findings suggest that among this sample of college students, 
Table 10

Means and Standard Deviations of Academic Variables by Attachment Groups

\begin{tabular}{|c|c|c|c|c|c|c|}
\hline \multirow[b]{2}{*}{ Group (N) } & \multicolumn{2}{|c|}{ College GPA } & \multicolumn{2}{|c|}{ Intellectual Ability } & \multicolumn{2}{|c|}{ Scholastic Competence } \\
\hline & Mean & SD & Mean & $\mathrm{D}$ & Mean & SD \\
\hline Low-Low (53) & 4.32 & $(.97)$ & 2.91 & $(.71)$ & 2.73 & $(.60)$ \\
\hline Low-Med (41) & 4.41 & $(.95)$ & 2.88 & $(.88)$ & 2.64 & $(.70)$ \\
\hline Low-High (26) & 3.92 & $(1.38)$ & 3.06 & $(.63)$ & 2.86 & $(.83)$ \\
\hline Med.-Low (47) & 4.32 & (1.11) & 3.12 & $(.67)$ & 2.87 & $(.67)$ \\
\hline Med.-Med.(45) & 4.33 & $(1.22)$ & 3.16 & $(.75)$ & 2.96 & $(.75)$ \\
\hline Med.-High(29) & 3.79 & $(1.15)$ & 3.27 & $(.72)$ & 2.99 & $(.72)$ \\
\hline High-Low (20) & 4.68 & $(.95)$ & 3.44 & $(.60)$ & 3.15 & $(.62)$ \\
\hline High-Med.(36) & 4.55 & (.94) & 3.22 & $(.72)$ & 2.88 & $(.71)$ \\
\hline High-High(60) & 4.45 & $(1.11)$ & 3.63 & $(.51)$ & 3.35 & $(.60)$ \\
\hline
\end{tabular}

Note. GPA (College Grade Point Average): $\underline{\mathrm{F}}(8,347)=1.90 ; \underline{\mathrm{p}}<.06$; Intellectual ability: $\underline{F}(8,348)=5.72, \underline{p}<.01 ;$ Scholastic Competence: $\underline{F}(8,348)=4.70 ; \underline{p}<.01$. 
Table 11

Means and Standard Deviations of Non-Cognitive Variables by Attachment Group

Self-esteem Locus of Control Optimism Global self-esteem

\begin{tabular}{lccccc} 
Group(N) & Mean SD & Mean SD & Mean SD & Mean SD \\
\hline Low-Low(53) & $29.47(5.3)$ & $44.9(6.5)$ & $18.7(4.71)$ & $2.78 \quad(.6)$ \\
Low-Med (41) & $31.17(5.0)$ & $49.6(6.4)$ & $20.0(4.5)$ & $2.80 \quad(.6)$ \\
Low-High (26) & $31.38(6.4)$ & $47.4(10.2)$ & $21.7 \quad(5.1)$ & $3.10 \quad(.7)$ \\
Med-Low (47) & $32.17(5.2)$ & $47.3(7.3)$ & $21.7(4.7)$ & $3.01 \quad(.6)$ \\
Med-Med (45) & $32.91(5.4)$ & $50.2(6.1)$ & $2.7(3.9)$ & $3.18 \quad(.6)$ \\
Med-High (29) & $33.93(5.3)$ & $50.6(6.6)$ & $23.4(4.8)$ & $3.35 \quad(.6)$ \\
High-Low (20) & $34.05(3.6)$ & $50.5(4.3)$ & $21.0(3.3)$ & $3.25 \quad(.6)$ \\
High-Med (36) & $35.39(4.4)$ & $52.7(6.9)$ & $24.6(5.0)$ & $3.48 \quad(.5)$ \\
High-High(60) & $37.48(3.3)$ & $54.9(5.4)$ & $26.4(3.6)$ & $3.73 \quad(.3)$
\end{tabular}

Note. Self-Esteem: $\mathrm{F}(8,344)=11.99, \mathrm{p}<.01 ;$ Locus of control: $\underline{\mathrm{F}}(8,343)=10.15$, $\mathrm{p}<.01$; Optimism: $\underline{\mathrm{F}}(8,347)=14.01 ; \underline{\mathrm{p}}<.01$; Global self-esteem: $\underline{\mathrm{F}}(8,348)=15.48$, $\mathrm{p}<.01$. 
masculine traits (e.g., analytical, ambitious, competitive) more so than feminine traits (e.g., compassionate, loyal, soft-spoken), may have moderated the effects of weak attachment on academic achievement. While both masculine and feminine traits are associated with academic success in college, masculine traits may be more advantageous than feminine traits for those behaviors associated with GPA. There were no significant differences by gender or ethnicity for masculine and feminine traits.

Due to interest in those students who composed the Low-Low Group, further descriptive analyses of this group were conducted, although they were limited by the size of the group. A preliminary analysis of the Low-Low Group revealed that this group of 53 students was a heterogeneous group of individuals with at least one important commonality: a shared perception of weak attachment to both parents and peers. Table 2 summarizes the ethnic mixture of this group. While more than half of the group (56.6\%) is Hispanic, this group is ethnically diverse. Similar to the entire sample, this group has twice as many women as men. The mean age of the group was 21.4 years, $81.1 \%$ live at home, $88.7 \%$ are not members of fraternities/sororities, and $93.0 \%$ are single. T-tests revealed a statistically significant gender difference for peer attachment, $\underline{F}$ $(2,53)=7.02, \underline{p}<.02$. No other gender differences for key variables were revealed. Pearson $r$ correlations (see Table 5) for this group identified statistically significant correlations between peer attachment and scholastic competence, intellectual ability, feminine characteristics, and locus of control, as well as statistically significant correlations between parental attachment and global self-esteem. These results suggest that for this sample of weakly attached students, peer attachment, although comparatively weak for 
their age, has more of an influence on their academic success than does weak parental attachment.

Exploratory hierarchical multiple regressions were conducted to predict variance in college GPA and scholastic competence within the Low-Low Group. The first set of analyses attempted to predict self-reported college GPA using selected cognitive variables, non-cognitive variables, and demographic variables. The first block of demographic variables (i.e., age, ethnicity, gender) was not significantly predictive of college GPA, $\underline{F}$ $(3,49)=.35$, accounting for only $6.0 \%$ of the variance. The second block entered, consisting of cognitive variables (i.e., intellectual ability and high school GPA), was not significantly predictive, $\underline{F}(5,47)=.82$, accounting for $3.0 \%$ of the variance in college GPA. The final block consisting of non-cognitive variables (self-esteem, locus of control, androgyny, and optimism) was not significantly predictive of college GPA, $\underline{F}(9,43)=.92$, accounting for an additional $7.0 \%$ of the variance in college GPA. Analysis of individual beta weights revealed that none of the predictor variables were significant. Another hierarchical multiple regression attempting to predict variance in college GPA within the Low-Low Group using selected demographic variables and non-cognitive variables was conducted. Neither block was significantly predictive of college GPA and analysis of individual beta weights revealed that none of the predictor variables were significant.

A third exploratory hierarchical multiple regression equation analyzed cognitive and non-cognitive predictors of scholastic competence within the Low-Low Group. The first block of demographic variables (i.e., age, ethnicity, gender) did not significantly predict scholastic competence, $\underline{F}(3,49)=.63$, accounting for $4.0 \%$ of the variance. The second 
block entered consisting of non-cognitive variables (self-esteem, locus of control, androgyny, and optimism) significantly predicted scholastic competence, $\mathrm{F}(7,45)=$ $5.8, p<.001$. The second block of variables accounted for $33 \%$ of the variance in scholastic competence. The third block, consisting of cognitive variables (i.e., intellectual ability, high school GPA) significantly predicted scholastic competence, $\underline{F}(9,43)=11.1$, $p<.001$, accounting for an additional $22 \%$ of the variance in scholastic competence. Analyses of the individual beta weights for each predictor revealed significant effects only for intellectual ability.

A final exploratory hierarchical regression equation attempted to predict scholastic competence with the Low-Low Group using demographic variables and non-cognitive variables. The first block of demographic variables (i.e., age, ethnicity, and gender) was not significantly predictive of scholastic competence, $\underline{F}(3,49)=.63$, accounting for $4.0 \%$ of the variance. The second block entered consisting of non-cognitive variables (i.e., selfesteem, locus of control, androgyny, and optimism), significantly predicted scholastic competence, $\underline{F}(7,45)=5.8, \underline{p}<.01$. The second block of variables accounted for $33 \%$ of the variance in scholastic competence. Analysis of the individual beta weights for each predictor revealed a significant effect only for self-esteem. These findings are summarized in Table 12.

Histograms of data from the Low-Low Group (Figures 1 and 2) reveal wide variation in several cognitive and non-cognitive psychosocial variables for the this group. For example, while the majority of students (70\%) in this group assessed their college GPA as a "B" average, 10 of the 53 students $(19 \%)$ reported a GPA of "C", one (2.0\%) 
Table 12

Hierarchical Multiple Regression Model Predicting Low-Low students' Scholastic Competence by Demographic Variables and Non-Cognitive Variables

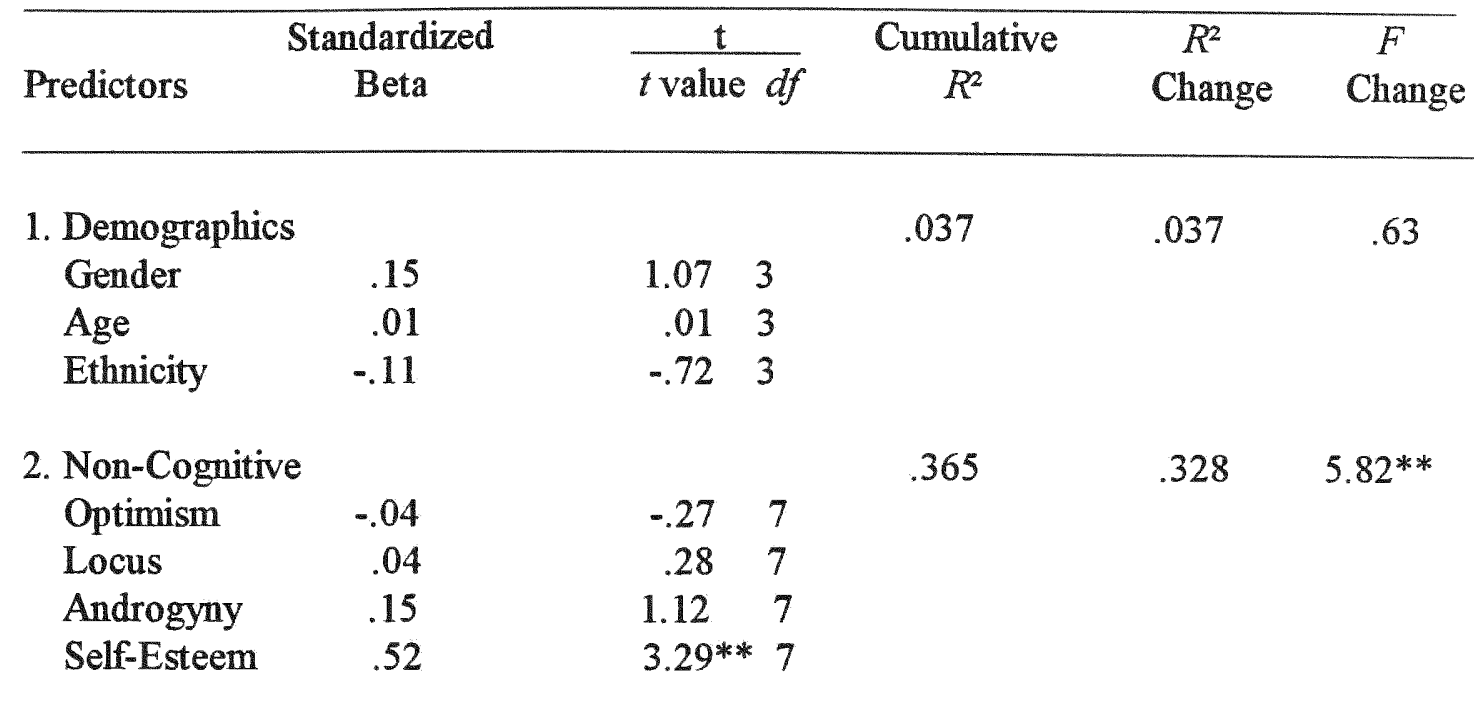

Note. Overall significance of the model: $\underline{E}(7,45)=3.70, p<.01$. ${ }^{* *} \mathrm{p}<.01$. 
reported a "D" average, and five $(9.0 \%)$ rated their GPA as an "A" average. This diversity in college GPA was also found in the High-High Group and to a lesser extent in the Medium-Medium Group. Additional evidence of heterogeneity of non-cognitive variables in the Low-Low Group is provided in the histograms for global self-esteem and locus of control (Figures 1 and 2). The data reveal weak parental and peer attached students' self-reported global self-esteem and locus of control ratings that fall across the entire continuum for these specific variables. Group heterogeneity among the Low-Low students is also revealed in the histograms for cognitive variables (Figures 3, 4, and 5). These results suggest that perceived weak attachment to parents and peers influences academic and non-academic domains differently within this sample of students. In addition, contrary to the hypothesis, the intragroup findings of the Low-Low Group along with the between attachment group results argue against a main effects model of relations between weak attachment to parents and peers and academic adversity. 
FIGURE 1

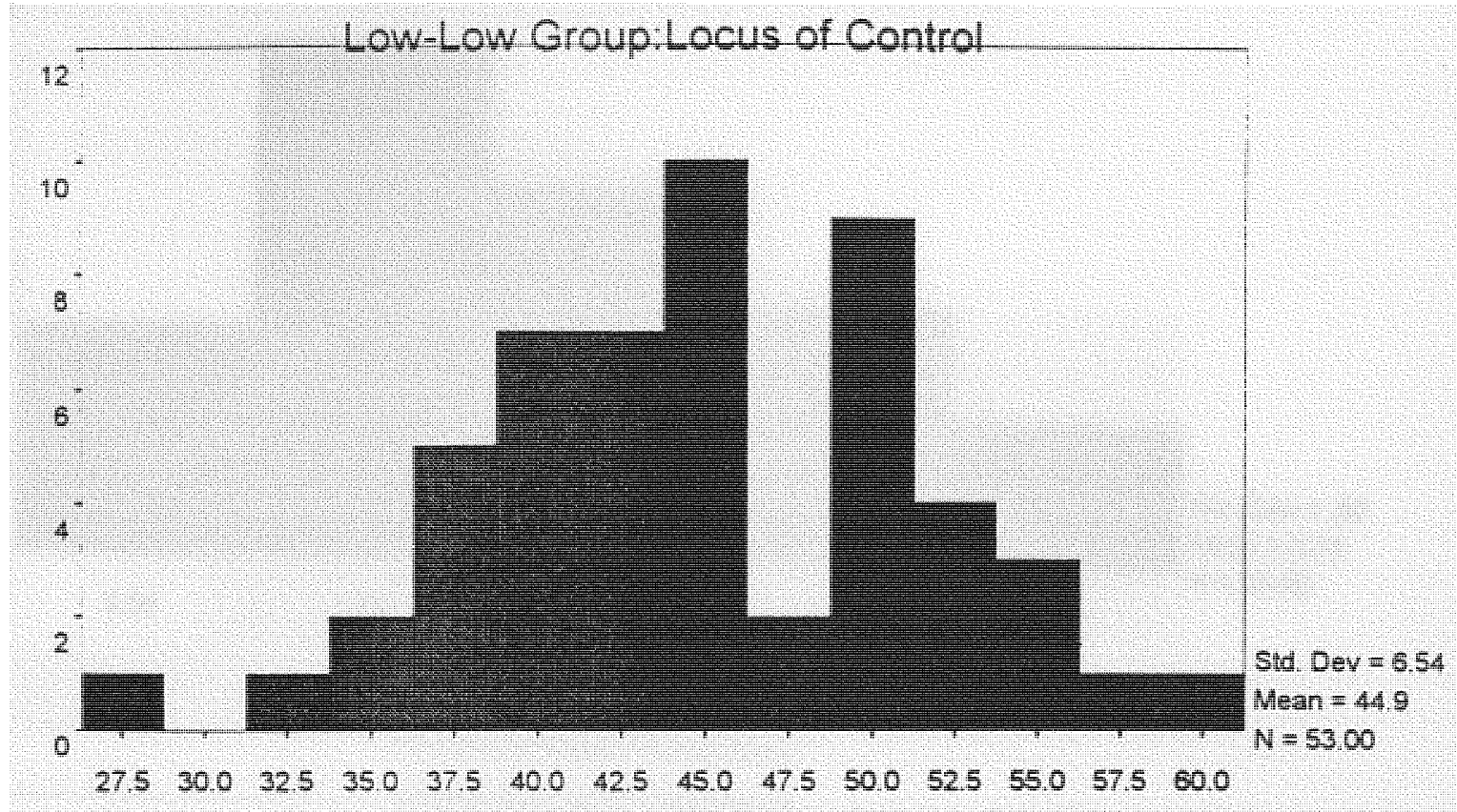

FIGURE 2

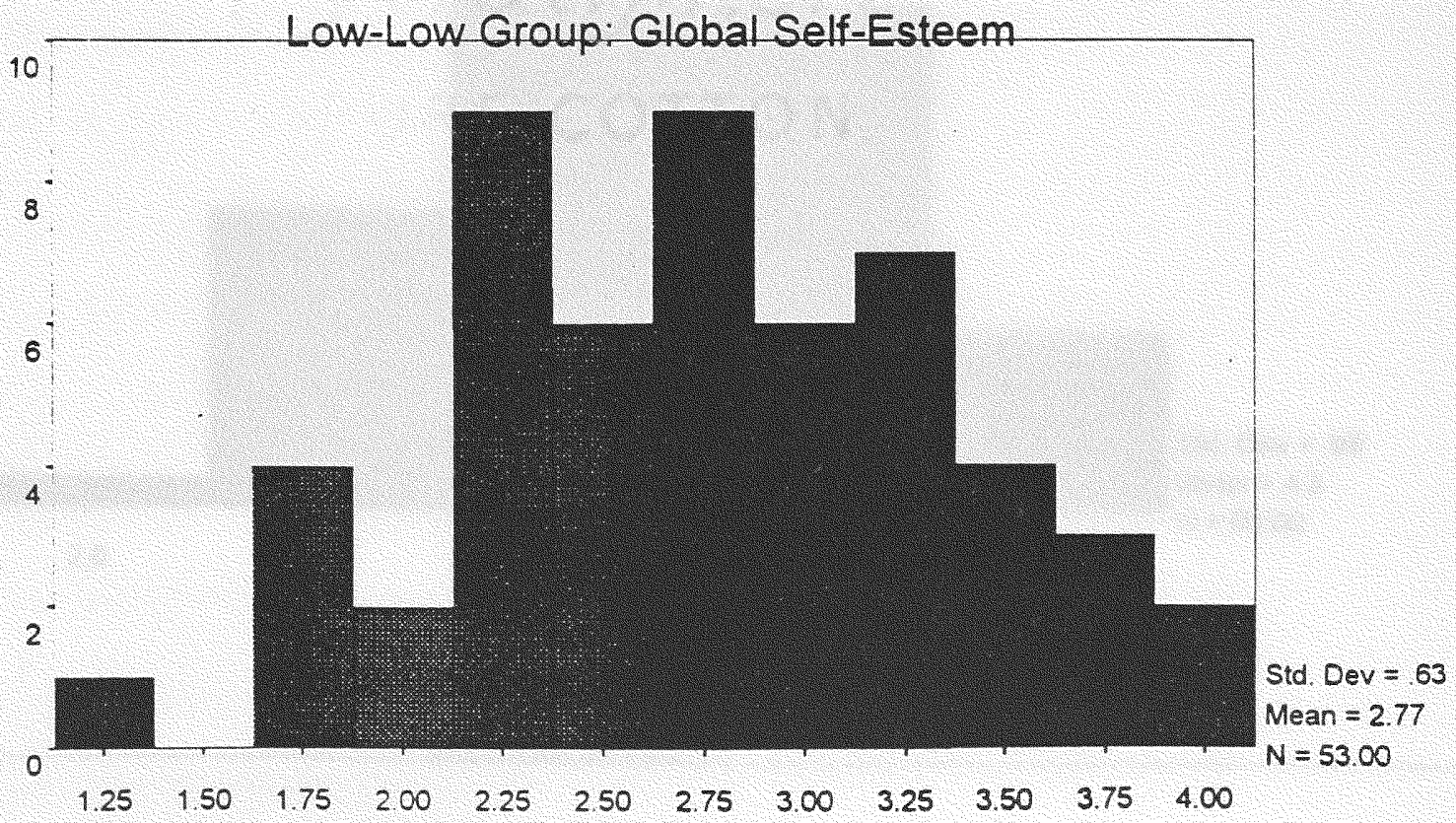




\section{FIGURE 3}

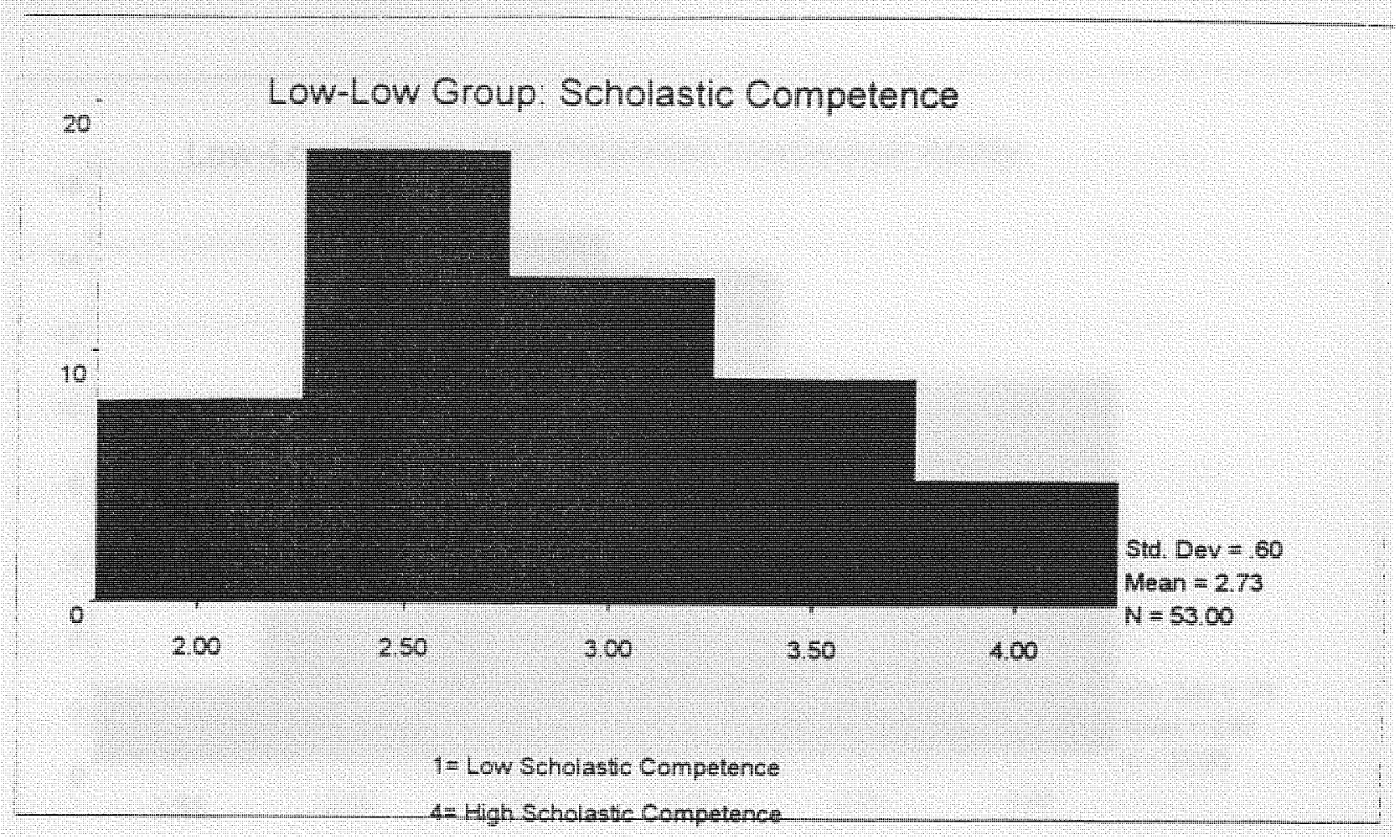

\section{FIGURE 4}

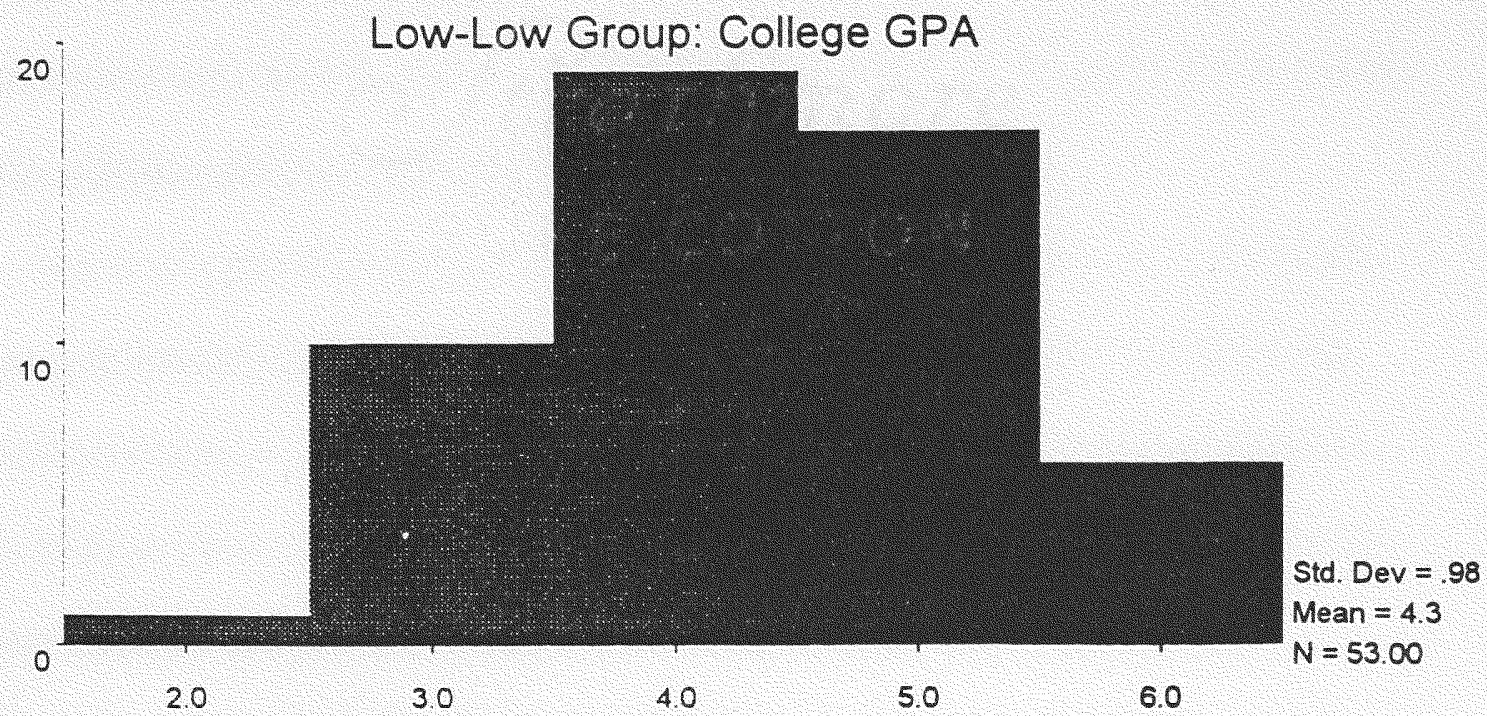

$2=1.5-1 \cdot 99 \cdot 3=2 \cdot 0-2 \cdot 49,4=2.5-2.99$ 
FIGURE 5

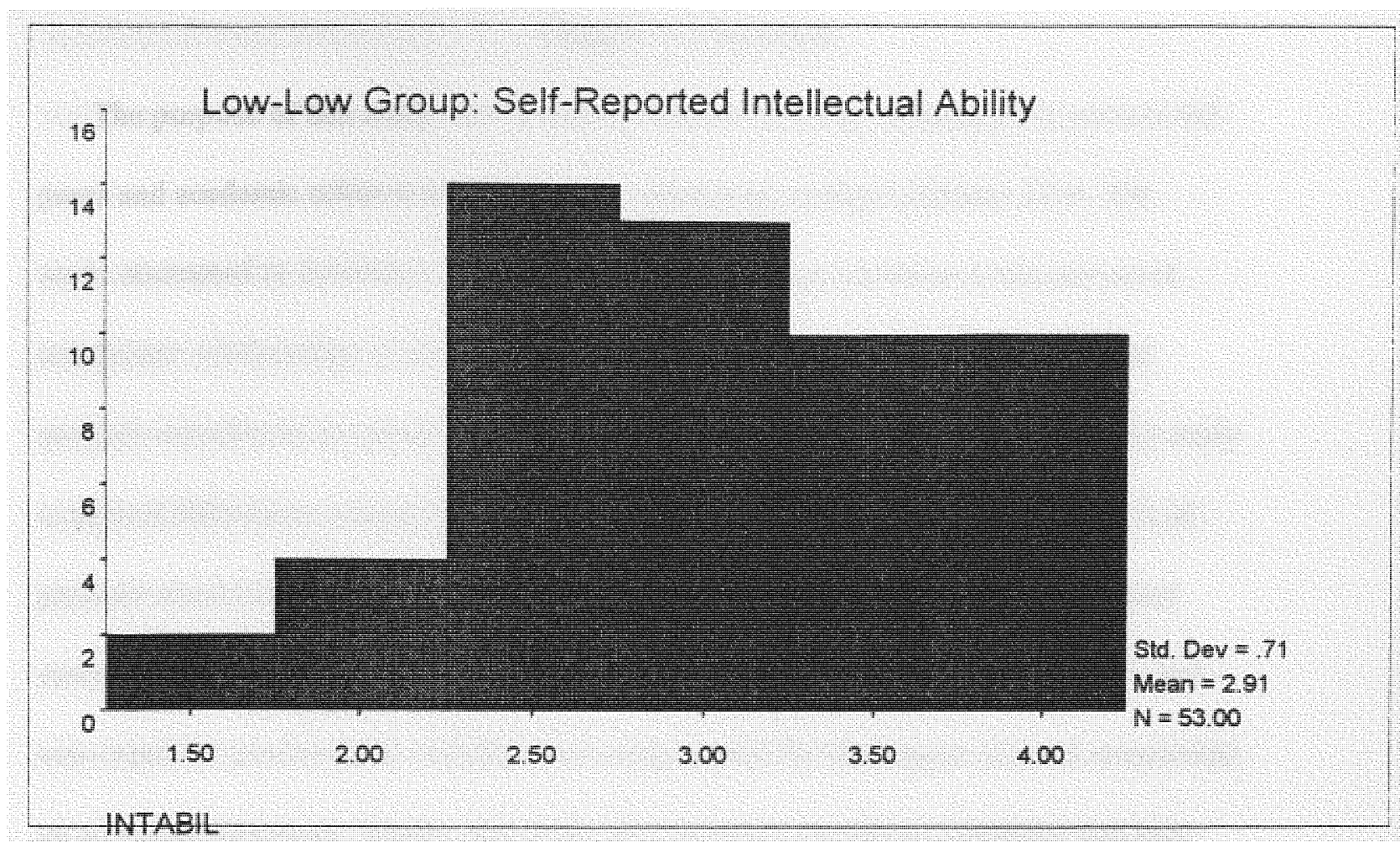




\section{Chapter 5: Discussion}

The purpose of this study was to assess relations between attachment to parents and peers and academic achievement among late adolescent college students. First, this study attempted to determine whether there was significant variation in the perceived attachment relationships of late adolescent college students. Differences in parental and peer attachment by gender, age, and ethnicity were also examined. Second, this study examined differences among nine attachment groups and determined whether levels of parental attachment and peer attachment were associated with academic achievement among this sample of undergraduate students. Third, this study identified cognitive and non-cognitive psychosocial variables that compensated for the impact of weak attachment on academic outcomes. Finally, this study also identified significant cognitive and noncognitive correlates of academic success within a group of students who were weakly attached to both parents and peers. These findings are discussed in the following sections.

\section{The Influence of Weak Parental and Peer Attachment}

The results partially supported hypotheses about perceived differences in attachment strength and the influence of attachment strength upon academic achievement among college students. Consistent with the first hypothesis, late adolescent college students' level of perceived parental and peer attachment showed substantial variability and there was a significant association between the two types of attachment. In addition, while the majority of this sample of college students remained moderately to strongly attached to parents and/or to peers, a minority of students perceived themselves to be weakly attached to both parents and peers. Contrary to the second hypothesis, the 
influence of weak attachment to both parents and peers upon academic achievement was not adverse. The data from this study suggest that, in general, college students' academic success or failure is not significantly influenced by their perception of weak parental and peer attachment status. Finally, the expectation that the group of students who are weakly attached to both parents and peers would be protected from academic adversity by specific cognitive and/or non-cognitive variables was partially supported. The results suggest that cognitive variables protected against academic adversity to a greater degree than the non-cognitive variables included in this study.

While late adolescent college students continue to perceive themselves as being attached to parents and peers, there were significant variations in the degree or magnitude of their attachment relations. These findings appear to support the life span perspective that views attachment as an evolving but enduring relationship between children and parents (Levitt, 1991; Ryan \& Lynch, 1989). The majority of participants in this study perceived themselves to be moderately to strongly attached to their parents. These results were consistent with studies that show college students remain attached to parents regardless of living with or away from them (Kenny, 1990; Kenny \& Donaldson, 1991, 1992). In addition, the majority of college students perceived themselves to be moderately to strongly attached to their peers although gender differences were found in this pattern of attachment. The overall findings suggest that this sample of college students is attached to both parents and peers to a moderate to strong degree. Based on previous studies and the findings of this present study, strong attachment to both parents and peers appears to assist students in their transition to college, and as well as to facilitate successful academic 
outcomes (Cutrona et al, 1994; Kenny, 1990). By buffering stress, providing emotional support, providing informational support or enhancing the student's self-esteem, strong peer and parental attachment appear to have a positive influence on students' overall adaptation to college (Cohen \& Wills, 1985; Zea et al., 1995).

As expected, a minority of college students (14.8\%) perceived themselves to be weakly attached to both parents and peers. The scores for this Low -Low Group of students were equivalent to the low scores found in a normative college sample (Armsden \& Greenberg, 1987). This finding is consistent with several studies that found a small percentage of adolescents to be weakly attached to both parents and peers ( Armsden \& Greenberg, 1987; Fass, 1996; Licitra-Klecker \& Waas, 1993; Sebald, 1993). A crosssectional study of this phenomenon cannot determine whether this group of students has continually perceived themselves to be weakly attached to both parents and peers or whether this is a recent development. Explanations for this subsample of students perceiving themselves to be weakly attached to both parents and peers are likely to be multifaceted and may include bi-directional effects between attachment and self-esteem.

Surprisingly, the findings show that as a group, students who perceived themselves to be weakly attached to both parents and peers (Low-Low Group) revealed few significant differences from seven of the eight other groups for the majority of cognitive variables. Therefore, this study suggests that weak attachment to parents and weak attachment to peers was not a uniformly negative influence on the academic achievement of this subgroup of college students. Contrary to the hypothesis that weak attachment to parents and peers placed students at risk for academic failure, it appears that this sample of 
college students with weak attachment to parents and peers is not academically less successful than the majority of their college cohort. With the exception of students with the highest degree of parental and peer attachment, students who perceive themselves to have joint weak attachment to parents and peers are achieving academically as well as all other students regardless of attachment levels. The results suggest that there is no linear relation between attachment strength and academic achievement. A main effect model for relations between attachment to parents and peers and academic achievement is not clearly supported by these data. It appears, moreover, that for some students who are weakly attached to parents and peers, specific salient cognitive and non-cognitive variables may protect them from increased risk of academic failure or compensate for the potentially deleterious impact of weak attachment. While the Low-Low Group was not significantly different from 7 of the other groups in levels of academic achievement, other data (e.g., regarding job competence, social acceptance) did reveal that this subsample of students may be less competent in a work environment or social setting.

These findings suggest that previous investigations of the influence of attachment on academic achievement may have been too restrictive in their scope (Cutrona et al., 1994; Weir \& Okun, 1989). For example, Cutrona et al., (1994) found parental social support to be a significant predictor of college grade point average although the effect on GPA was minimal. A limitation of the Cutrona et al. study (1994) was that with the exception of academic efficacy, important variables that potentially may have explained some of the variance in academic achievement were not included in the research design. Studies that have examined the influence of parental and peer attachment needed to include potentially 
moderating non-cognitive variables such as self-esteem, locus of control, and optimism. It is suggested by the current study that future studies on relations between of attachment and academic achievement also include cognitive variables of several types such as intellectual ability, scholastic competence, academic efficacy, and past academic performance.

The implications of the findings of the current study are that the combined effects of weak parental and peer attachment may potentially place college students at risk for academic failure when several potential protective or compensatory factors are absent, but that weak attachment to both parents and peers may not be a significant predictor of college achievement. While weak parental and peer attachment interacting with other academic risk factors (i.e., low scholastic competence or low intellectual ability) may produce adverse academic outcomes for college students, joint weak attachment to parents and peers is not a single omnibus predictor of poor academic outcomes. These findings illustrate the complexity of the nature of academic risk while also calling attention to the need for future attachment-academic achievement research to include a broad spectrum of dispositional and contextual variables that may act as protective factors and predictors of academic adversity among at-risk students.

Rather than the weak attachment group being significantly different from the other eight attachment groups, for the majority of variables examined, the High-High Group was significantly better functioning than the other groups, for both cognitive and noncognitive variables. This finding confirms previous studies that found that students who perceived themselves to have strong attachment to both parents and peers have better self- 
concept, higher self-esteem, a more optimistic view of life, and better coping ability (Antonucci, 1990; Sarason, Levine, Basham, \& Sarason, 1983). Whether strong attachment is viewed through the lens of a "stress-buffering" hypothesis or if it is viewed using a "lifetime cumulative effect" hypothesis, combined strong attachment is hypothesized to facilitate academic achievement to a greater degree than weak attachment facilitates academic failure. The psychological benefits of positive parental and peer attachments are likely to be more salient during transition linked turning points in adolescence and young adulthood. Strong attachment to parents and peers may be critical for a student's negotiation of the cumulative transactions and multiple stressors of the college experience. As suggested by Holahan et al. (1994), the adaptive importance of attachment or social support during this transition period may be both direct and indirect.

Not only does the current study offer valuable information for understanding the similarities and differences in correlates of several levels of college students' perceived peer and parental attachment, the data also reveal a heterogeneous subgroup of weakly attached students. Although the Low-Low Group appears to be a variegated subsample of students, the overwhelming majority of the students in this group are academically successful, despite being weakly attached to both parents and peers. Data from this group suggest that attachment is not a significant predictor of academic achievement among college students. Other data suggest that some students in the Low-Low Group were protected against negative academic outcomes by cognitive variables (e.g., intellectual ability) and/or non-cognitive variables (e.g., self-esteem).

Exploratory analyses of the Low-Low Group reveals a diverse group of students. 
Some of these weakly attached students had high self-esteem, an internal locus of control, and were optimistic even though as a group their self-reported ratings on the noncognitive variables were low compared to other attachment groups. Data reveal that noncognitive variables (i.e., self-esteem) and cognitive variables (i.e., intellectual ability) are significantly correlated with scholastic competence and also account for a sizable portion of the variance in scholastic competence for this group of weakly attached students. While these cognitive and non-cognitive variables do not significantly predict college GPA for this group of students, it appears that due to its compensatory role, strong scholastic competence truncates potential pathways of academic adversity. The diversity within this Low-Low Group may be the result of numerous factors such as continuity or discontinuity of attachment to both parents and/or peers, differences in physical appearances, or involvement in romantic relationships. While the small size of the Low-Low Group limits further statistical analyses, this group's data provide some evidence of the differential influences of weak parental and peer attachment.

The Influence of Cognitive and Non-Cognitive Variables

The correlational findings from this study are consistent with previous literature that has shown that moderate to strong attachment to parents and/or peers enhances an individual's sense of self and promotes higher self-esteem, internal locus of control, greater androgyny and an optimistic outlook (Blain et al., 1993; Cohen \& Willis, 1985; O'Koon, 1997). These data suggests a linear relationship between attachment and the key non-cognitive variables included in this study. The subgroup of students who were weakly attached to both parents and peers, although not adversely affected academically, were 
nevertheless affected by their attachment quality on a potentially more crucial level, i.e., sense of self. While low self-esteem, external locus of control, less androgyny, and less optimism may not have negative effects on these students' academic functioning, weak attachment status may adversely affect them in future career choices, employment, and social domains.

Data for parental and peer attachment and the three cognitive variables (i.e., intellectual ability, scholastic competence, and college GPA) indicate that parental and/or peer attachment is significantly correlated with scholastic competence and intellectual ability, but neither parental attachment nor peer attachment is significantly correlated with college GPA. Not surprisingly, the data reveal that scholastic competence and intellectual ability are significantly correlated with college GPA. One possible explanation for this is a scaffolding effect. The benefits of attachment or social support are initially felt on a self-esteem level which then may lead to improved scholastic competence and related self-perceived intellectual ability. It is enhanced scholastic competence and intellectual ability that in turn influence college GPA. While the reciprocal nature of scholastic competence and college GPA must be considered, the scaffolding effect suggests that attachment strength may have a direct or an indirect effect on academic success.

The findings related to the three key cognitive variables are consistent with a number of other studies that have found that intellectual ability, scholastic competence, and past academic performance are the most important predictors of academic achievement at various educational levels (Hauser, Sewell, \& Alwin, 1976; Horn, Bruning, Schraw, 
Curry, \& Katanant, 1993; Sewell \& Hauser, 1980). Not only were there high correlations between intellectual ability and college GPA, as well as between scholastic competence and college GPA, but these two cognitive variables explained $31 \%$ of the variance in college GPA (academic achievement). In the present study, although high school GPA did not explain a very large percentage of the variance in college GPA, it was significantly correlated with college GPA in the entire student sample. The influences of intellectual ability and past academic achievement are undoubtedly powerful predictors of current academic achievement but they are not the only influences for most students. For at-risk subsamples of students the influence of cognitive variables may be attenuated (Abrams \& Jerrigan, 1984; Larose \& Roy, 1991; Maxwell, 1981). Due to the potential for multicolinearity in the analysis of the joint influence of intellectual ability and scholastic competence, further research is needed to ascertain whether these variables are conceptually different.

The correlational data for cognitive and non-cognitive variables for the three congruent attachment groups (Low-Low, Medium-Medium. High-High) suggest salient similarities, as well as noticeable differences. For all three groups, several noncognitive variables were correlated with key cognitive variables but these correlations differed among the three attachment groups. For example, intellectual ability is highly correlated with college GPA in all three groups, but scholastic competence is significantly correlated with college GPA only in the High-High Group. Similarly, self-esteem is highly correlated with scholastic competence in the Low-Low and High-High groups but not in the Medium-Medium Group. College GPA was not significantly correlated with the 
majority of the key non-cognitive variables in all three groups.

The size of each of these groups limits additional, finer grained analyses but certain tentative conclusions can still be drawn. Since students' college GPAs may be perceived to be externally controlled by the subjective assessments by faculty, grade inflation, or arbitrary final exam schedules, students may perceive their GPAs as less of a reflection of themselves and their abilities than are self-reported intellectual ability and scholastic competence. Another explanation may be that although this sample's average GPA is relatively high, the majority of students might still be disappointed in their GPAs based on their perceived intellectual ability and scholastic competence.

The Influence of Ethnicity, Gender, and Parental Educational Level

The findings of students from the four ethnic groups included in this study revealed no significant differences in relation to the cognitive and non-cognitive variables by ethnicity. The means for locus of control by ethnicity contribute to the existing literature's mixed findings. For example, the finding that locus of control did not significantly differ among the four ethnic groups, is consistent with a literature review on locus of control by Findley and Cooper (1983) but is inconsistent with the findings of a recent study (Zea et al., 1995) that found Latinos and African-Americans to be significantly more internal than white students. In the current study, Hispanic-Americans were the most internal of all the ethnic groups but this group was not significantly different from the other three ethnic groups. As expected, these findings did not reveal any significant differences in peer attachment by ethnicity. Surprisingly, Asian-American students' level of self-reported parental attachment was significantly lower than that of the other three ethnic groups. 
This finding is contrary to literature that suggests individuals from cultures that emphasize collectivism over autonomy should show a higher degree of attachment (Harrison, Wilson, Pine, Chan, \& Buriel, 1990). Two possible explanations for this finding are that a) the Asian-American group in this study was extremely limited in size $(n=12)$ and therefore may not be representative of the population or, b) Asian-American students' reliance on coping strategies involving self-discipline techniques may lessen their need for social support (Liang \& Bogat, 1994).

Several points of interest emerge from the gender analyses included in this study. First, consistent with previous studies, females were found to have significantly stronger perceived attachment to peers than men while there was no significant difference between females and males for parental attachment (Armsden \& Greenberg, 1987; Claes, 1992; Nada Raja et al., 1992). Explanations for this consistent finding of gender differences for peer attachment include Gilligan's (1982) work that suggests women's psychosocial development is more highly based more on caring and an emphasis on interpersonal relationships. In addition, research literature suggests that females are more often socialized to define themselves in terms of their attachment relations (Greenglass, 1982). It appears that females are not only more oriented toward open, communicative relations with their friends but that they also have more intense friendships due to early maturation (Burke \& Weir, 1978; Frey \& Rothlisberger, 1996). There is no reason to believe that late adolescent college females should manifest atypical peer attachment behaviors (i.e., departing from this socialized pattern).

Contrary to some previous studies, no other significant gender differences were 
found for any of the cognitive or non-cognitive variables. Most studies have found that at most ages including adolescence, females had significantly lower self-esteem than males (Caims et al., 1990; Chubb et al., 1997; Eccles et al., 1989). In the current study, however, female college students had marginally lower self-reported self-esteem scores than their male counterparts. One explanation for this finding is that since the majority of Hispanic-American participants in this study were Cuban-Americans, Cuban-American parents may facilitate their daughters' self-esteem in culturally positive ways (Portes \& MacLeod, 1996). Another explanation for self-esteem equivalency by gender is related to female and male perceptions of the cognitive variables included in this study. Previous findings have shown that females report lower intellectual and academic self-esteem even though they had higher GPAs (Cranston \& Leonard, 1990). In the current study, females not only had slightly higher GPAs but they also had slightly higher self-reported scholastic competence and intellectual ability. Perhaps the effect of higher combined academic efficacy was influential in boosting the self-esteem of the females in this study. Remarkably, although no significant gender differences were revealed for the cognitive and non-cognitive variables included in this study, females were found to have slightly higher scores for all variables with the exception of self-esteem. This suggests that as a group, the females participating in this study were potentially a non-normative group, i.e., an extremely high functioning sample.

Data presented in this study appear to support previous findings suggesting that parents' academic achievement influences students' level of academic achievement (Lin, 1990; Peng, 1994; Winfield, 1991). Data on fathers' educational level and mothers' 
educational level showed only minor differences among the nine attachment groups. For both parents' educational levels, the only statistically significant difference by group was between the High-High Group and the Low-High Group. The entire sample's mean for fathers' educational level was 14.19 and mothers' educational level was slightly less at 13.88. It would appear that the students in this study are the children of parents who attained relatively high levels of educational success as demonstrated by their high school graduation rates and the high percentage of them attending college. While explaining little of the variance for college GPA and scholastic competence, it is likely that parental educational attainment was, nonetheless, a subtle influence among this sample of students. For the entire sample, parental modeling and subsequent internalization of parents' academic values may have been an indirect, yet significant influence upon their degree of academic achievement and educational persistence.

More importantly, parental educational attainment may have been one of the many moderating factors that protected weakly attached students from academic adversity. The Low-Low Group's mean for mother's educational attainment was the fourth highest $(M=14.08)$ in the sample. Considering the predominant female composition of this group, the influence of modeling the mother's academic achievement/attainment may be an important factor leading to academic competence of many of the students in this group. While parental modeling is probably most influential when parent and child are strongly attached, parental modeling of educational attainment for sons or daughters who perceive weak parental attachment, may still be a factor influencing educational aspirations. 


\section{Interventions}

For both low-risk students and high-risk students, the college experience is marked by numerous new opportunities and challenges. In addition, late adolescents are faced with normative developmental tasks that when combined with the college experience produce a transition-linked turning point that may initially lead to feelings of incompetence, that are soon replaced by competent adaptation (Stewart, 1982). The findings of this study suggest that along with the many intervention programs high schools and colleges already have established for students at-risk for academic failure (i.e., minority students, students from families with low socioeconomic status), some students who are weakly attached to both parents and peers may be in need of, and also benefit from, intervention programs. Whether these intervention programs are initiated in high school or in college, the focal points of such programs should be: to improve attachment relations between the student and parents and/or the student and his or her peers; to help the student develop greater scholastic competence and a greater degree of perceived intellectual ability, or to provide the student with salient opportunities and experiences for purposes of enhancing the student's self-esteem, optimism, or related non-cognitive variables during this transitional period of development. Although, the findings reveal students who perceive themselves to be weakly attached to parents and peers are not academically different from the majority of the other students, the diversity within Low-Low Group suggests that some weakly attached students may benefit from scholastic competence interventions while the majority of students within the group may benefit from non-cognitive interventions. 
While data from this study revealed that non-cognitive variables accounted for a considerable proportion of the variance in the scholastic competence of students in the Low-Low Group, self-esteem was found to be the strongest non-cognitive predictor of scholastic competence for the subsample of weakly attached students. A positive intervention approach based on the findings of this study would be for high school counselors and college student affairs administrators to provide students with low selfesteem and/or high external locus of control perceptions with opportunities to demonstrate successful internal control and competence within the school environment (Nunn \& Parish, 1992). For example, self-esteem coaching provides a controlled experience that demonstrates the relation between behavior and outcome for groups of students with low self-esteem. Bandura (1986) has suggested that self-efficacy is a malleable construct that can be improved by coaching and modeling. Academic efficacy (perceived intellectual ability and scholastic competence) should also improve or have the potential for improvement through the use of similar methods.

In addition to interventions designed to enhance the student's cognitive and/or psychosocial self-beliefs, counseling programs should also be established to foster greater attachment between students and parents or students and peers. For example, students who have been found to be weakly attached to parents and/or peers could be placed in a social skills training program or friendship therapy program (Gerken, 1987). Counselors and administrators may also assist by providing opportunities for students and their parents to improve lines of communication in hopes of strengthening attachment bonds. Students and parents may receive counseling related to the developmental task of 
separation-individuation, thereby enhancing their awareness that this process involves a balance between family enmeshment and complete disengagement (Cooper, Grotevant, \& Condon, 1983). Members of college student affairs departments may also reassure students that turning to a parent rather than a peer for psychological assistance is a normative behavior for college students (Kenny, 1990). "Booster" interventions for selfesteem and/or scholastic competence are also suggested for low-risk and high-risk students due to the stressful developmental transition accompanying adaptation to college (Cicchetti, 1993). Further research is needed to develop effective intervention programs for weakly attached students whose risk of academic failure is not moderated by specific cognitive or non-cognitive variables included in this study. The results of these analyses should have salient practical implications for interventions by counselors and college administrators that include: a) a greater effort to identify students who are weakly attached to parents or peers (weak social support) and, b) the development of intervention programs to enhance academic efficacy and self-efficacy.

\section{Limitations and Implications}

Although this study has contributed to understanding relations between weak parental and peer attachment and academic achievement among late adolescent college students, limitations of this study need to be mentioned. First, the cross-sectional and correlational nature of this study makes it impossible to make causal inferences. Second, the participants in this study were drawn from one urban university, thereby, limiting generalizability. Third, this study relied on self-report data including self-reported GPA for statistical analysis. Greater use of observational and behavioral assessments would have 
been helpful in validating the self-reported data. While a number of studies have reported high correlations between self-reported GPA and GPA obtained from official registrar records (Rabow, Radcliffe-Vasile, Newcomb, \& Hernandez, 1992), use of registrar GPA would reduce the potential risk of bias in these data. Fourth, this study may have other limitations due to shared method variance. The exclusive use of self-report measures may have resulted in high correlations that were artifacts of design similarities among the measures included in this study.

Two additional limitations need further discussion. While the sample of students was ethnically diverse, the vast majority of the participants were Hispanic-Americans comprised largely of Cuban-American females. Therefore, these findings should not be assumed to generalize to college students from other cultures and ethnic groups. As a group, Cuban-American parents living in Miami, regardless of their socioeconomic status, view their children's educational persistence and success as a fait accompli (Portes \& MacLeod, 1996). Children of Cuban-American parents may feel compelled and pressured to attain academic success in college. This parental-collective expectation related to educational success may filter down and influence peer relations as well. In addition, although it has a diverse student population, Florida International University is mainly Cuban-American in composition and this university has had great success in attracting and matriculating Cuban-American females who are scholastically competent and extremely self-confident.

In the data collection phase of this study, counterbalancing for all the measures was included in hopes of guarding against the possibility of test adaptation or potentiation 
of reaction to test responses (Reese, 1997). Half the participants received the parental attachment questionnaire first, followed by the peer attachment questionnaire. This procedure was reversed for the other half of the sample. Moreover, the sequencing for all the other measures ( i.e., self-esteem, locus of control) was also counterbalanced. The only significant ordering effect was found for parental attachment when the parent attachment measure was given first $(\underline{F}=7.5, p<.05)$. Significant counterbalancing differences have not been reported in previous studies using the IPPA ( Armsden \& Greenberg, 1987; Blain et al, 1993; Fass, 1996; Nada Raja et al., 1992; O'Koon, 1997; Paterson et al., 1995; Schneider \& Younger, 1996). One plausible explanation for the ordering effect was that the random sequencing of the IPPA among the other measures (i.e., LOT-R, RSE) may have resulted in shared method variance more often on the parent-peer ordering than the peer-parent ordering. Unintentionally, night classes comprised of slightly older students may also have been given parent attachment questions first more often than the day psychology classes leading to subtle but significant differences in order effects.

Despite methodological limitations, the findings of this study are conceptually important. First, this study draws attention to a neglected population of at-risk individuals: late-adolescents who perceive themselves to be weakly attached to both parents and peers. Second, while most college students in this sample remained strongly attached to both parents and peers, attachment did not appear to be a significant predictor of academic achievement in college. Third, weakly attached college students who are scholastically competent and perceive themselves to have high levels of intellectual ability 
should be able to attain academic success in college and complete their college matriculation. Fourth, these results support previous findings that suggest that weak attachment to parents and/or peers has potentially negative psychological effects (i.e., low self-esteem, external locus of control) to the individual (Coie, 1990; Paterson et al., 1995; Rice, 1990). Fifth, this study suggests that academic achievement in college is multiply determined and that both distal and proximal variables play a significant role in whether a student is academically successful or has negative academic outcomes. Finally, and most importantly, the results of this study argue against a main effects model for relations between attachment and academic achievement and in support of a multidimensional model that requires the inclusion of cognitive and non-cognitive variables in predicting academic competence.

Suggestions for future research include incorporating longitudinal designs that would provide information on relations between attachment and academic outcomes and their continuous or discontinuous development. In addition, future research should continue to search for other potential moderating variables in order to gain greater insight into relations between attachment and academic achievement. Additional studies with larger and more diverse populations of late adolescent college students, as well as late adolescents who are not attending college (i.e., military personnel) need to be conducted to ascertain the influence of weak attachment status on broader areas of competence. Finally, future research needs to focus on the underlying processes that enable specific cognitive or non-cognitive psychosocial variables to moderate the effects of risk upon academic competence (Luthar, 1993). 
This present study extends existing research on the influence of parental and peer attachment upon academic achievement among college students and contributes to a growing body of literature describing the importance of cognitive and non-cognitive moderating variables. Findings suggest that while very strong attachment may provide a "boost" to academic achievement, weak attachment to both parents and peers is not a predictor of academic adversity. While the results of the present study suggest that the joint effect of perceived weak parental and peer attachment does not place the late adolescent at-risk for academic adversity, these attachment deficits may be more deleterious in social settings or in certain work/employment environments. 


\section{References}

Abby, A., Abramis, D.J., \& Caplan, R.D. (1985). Effects of different sources of social support and social conflict on emotional well-being. Basic and Applied Social Psychology, 6. 111-129.

Abrams, H. G., \& Jerrigan, L.P. (1984). Academic support services and success of high-risk students. American Educational Research Journal, 21, 261-274.

Adame, D. A., Johnson, T. C., \& Cole, S. P. (1989). Physical fitness, body image, and locus of control in college freshman men and women. Perceptual and Motor Skills, 68, 400-402.

Ainsworth, M. D. S., Blehar, M., Waters, E., \& Wall, S. (1978). Patterns of attachment. Hillsdale, NJ: Erlbaum.

Ainsworth, M. D. S. (1982). Attachment: Retrospect and prospect. In C. M. Parkes \& J. Stevenson-Hinde (Eds.), The place of attachment in human behavior (pp. 3-30). New York: Basic Books.

Ainsworth, M. D. S. (1989). Attachment beyond infancy. American Psychologist, 44, 709-716.

Amato, P. R, \& Ochiltree, G. (1986). Family resources and the development of child competence. Journal of Marriage and the Family, 48, 47-56.

Antonucci, T. C. (1990). Social supports and social relationships. In R. H. Binstock \& L. K. George (Eds.). Handbook of aging and the social sciences (pp. 105-126). New York: Academic Press.

Armsden, G. C., \& Greenberg, M. T. (1987). The inventory of parent and peer 
attachment: Individual differences and their relationship to psychological well-being in adolescence. Journal of Youth and Adolescence, 16, 427-454.

Aspinwall, L. G., \& Taylor, S. E. (1992). Modeling cognitive adaptation: A longitudinal investigation of the impact of individual differences and coping on college adjustment and performance. Journal of Personality and Social Psychology, 63, 989-1003.

Baker, R. W., \& Siryk, B. (1984). Measuring adjustment to college. Journal of Counseling Psychology, 31, 179-189.

Bandura, A. (1986). Social foundations of thought and action: A social cognitive theory. Englewood Cliffs, NJ: Prentice-Hall.

Bank, B. J., Slavings, R. L., \& Biddle, B. J. (1990). Effects of peer, faculty, and parental influences on students' persistence. Sociology of Education, 63, 208-225.

Bartholomew, K, \& Horowitz, L. M. (1991). Attachment styles among young adults: A test of a four-category model. Journal of Personality and Social Psychology, 61, 226244.

Bean, J. P. (1983). The application of a model of turnover in work organizations to the student attrition process. Review of Higher Education, 6, 129-148.

Bean, J. P., \& Metzner, B. S. (1985). A conceptual model of nontraditional undergraduate student attrition. Review of Educational Research, 55, 485-540.

Bell, K. L., Allen, J. P., Hauser, S. T., \& O'Conner, T. G. (1996). Family factors and young adult transitions: Educational attainment and occupational prestige. In J. A. Graber, J. Brooks-Gunn, \& A. C. Petersen (Eds.), Transitions through adolescence: Interpersonal domains and context (pp. 345-366). Hillsdale, NJ: Erlbaum. 
Bell, N. J., Avery, A. W., Jenkins, D., Feld, J., \& Schoenrock, C. J. (1985). Family relationships and social competence during late adolescence. Journal of Youth and Adolescence, 14, 109-119.

Bem, S. L. (1974). The measurement of psychological androgyny. Journal of Consulting and Clinical Psychology, 42, 155-162.

Bem, S. L. (1975). Sex role adaptability: One consequence of psychological androgyny. Journal of Personality and Social Psychology, 31, 634-643.

Bem, S. L. (1981). Gender schema theory: A cognitive account of sex-typing. Psychological Review, 88, 354-364.

Bem, S. L. (1987). Probing the promise of androgyny. In M. R. Walsk (Ed.), The psychology of women: Ongoing debates (pp. 206-225). New Haven, CT: Yale University Press.

Bem, S. L., \& Lenney, E. (1976). Sex typing and the avoidance of cross-sex behavior. Journal of Personality and Social Psychology, 33, 48-54.

Bem, S. L., Martyna, W., \& Watson, C. (1976). Sex-typing and androgyny: Further explorations of the expressive domain. Journal of Personality and Social Psychology, 34 , 1016-1023.

Benassi, V. A., Sweeney, P. D., \& Dufour, C. L. (1988). Is there a relation between locus of control orientation and depression? Journal of Abnormal Psychology, 97, 169182.

Berndt, T. J. (1979). Developmental changes in conformity to peers and parents. Developmental Psychology, 15, 608-616. 
Berndt, T. J., Laychak, A. E., \& Park, K. (1990). Friends' influence on adolescents' academic achievement motivation: An experimental study. Journal of Educational Psychology, 82, 664-670.

Bishop, J. H. (1989). Why the apathy in American high schools? Educational Researcher, $18,6-10$.

Blain, M. D., Thompson, J. M., \& Whiffen, V. E. (1993). Attachment and perceived social support in late adolescence: The interaction between working models of self and others. Journal of Adolescent Research, 8, 226-241.

Blechman, E. A. (1990). A model of effective family communication. In E. A. Blechman (Ed.), Emotions and the family (pp. 201 - 224). Hillsdale, NJ: Erlbaum.

Blechman, E. A. (1991). Effective communication: Enabling multiproblem families to change. In P. A. Cowan \& M. Hetherington (Eds.), Family transitions (pp. 219-224). Hillsdale, NJ: Erlbaum.

Blechman, E. A., \& Wills, T. A. (1992). Process measures in interventions for drugusing women: From coping to competence. In M. M. Kilbey \& K. Asghar (Eds.), Methodological issues in epidemiological, prevention, and treatment on drug-exposed women and their children (pp. 314-343). Rockville, MD: National Institute on Drug Abuse.

Blustein, D. L., Walbridge, M. M., Friedlander, M. L., \& Palladino, D. E. (1991). Contributions of psychological separation and parental attachment to the career development process. Journal of Counseling Psychology, 38, 39-50.

Bowlby, J. (1969). Attachment and loss. Vol. 1. Attachment. New York: Basic 
Books.

Bowlby, J. (1973). Attachment and loss. Vol. 2. Separation. New York: Basic Books. Brack, G., Gay, M. F., \& Matheny, K. B. (1993). Relationships between attachment and coping resources among late adolescents. Journal of College Student Development, 34, 212-215.

Bradford, E., \& Lyddon, W. I. (1993). Current parental attachment: Its relation to perceived psychological distress and relationship satisfaction in college students. Journal of College Student Development, 34, 256-260.

Brems, C., \& Johnson, M. E. (1990). Reexamination of the Bem sex-role inventory: The interpersonal BSRI. Journal of Personality Assessment, 53, 484-498.

Brennan, K. A., Shaver, P. R. \& Tobey, A. E. (1991). Attachment styles, gender, and parental problem drinking. Journal of Social and Personal Relationships, 8, 451-466.

Bretherton, I. (1985). Attachment theory: Retrospect and prospect. In I. Bretherton, \& E. Waters (Eds.), Growing points in attachment theory and research. Monographs of the Society for Research in Child Development, 50, (1-2, Serial No. 209), 3-35.

Brooks, R. B. (1992). Self-esteem during the school years: Its normal development and hazardous decline. Pediatric Clinics of North America, 39, 537-550.

Brooks, R. B. (1994). Children at risk: Fostering resilience and hope. American Journal of Orthopsychiatry, 64, 545-553.

Brown, B. B., Clasen, D. R., \& Eicher, S. A. (1986). Perceptions of peer pressure, peer conformity dispositions, and self-reported behavior among adolescents.

Developmental Psychology, 22, 521-530. 
Brown, L. L., \& Robinson Kuripus, S. E. (1997). Psychosocial factors influencing academic persistence of American Indian college students. Journal of College Student Development, 38, 3-8.

Brown, S. D., Lent, R. W., \& Larkin, K. C. (1989). Self-efficacy as a moderator of scholastic aptitude-academic performance relationships. Journal of Vocational Behavior, $\underline{35,64-75 .}$

Burke, R. J., \& Weir, T. (1978). Benefits to adolescents of informal helping relationships with parents and peers. Psychological Reports, 42, 1175-1184.

Byme, B. M. (1984). The general / academic self-concept nomological network: A review of construct validation research. Review of Educational Research, 54, 427-456.

Cairns, E., McWhirter, L., Duffy, U., \& Barry, R. (1990). The stability of self-concept in late adolescence: Gender and situational effects. Personality and Individual Differences, $11,937-944$.

Chubb, N. H., Fertman, C. J., \& Ross, J. L. (1997). Adolescent self-esteem and locus of control: A longitudinal study of gender and age differences. Adolescence, 32, 113-129.

Cicchetti, D. (1993). Developmental psychopathology: Reactions, reflections, projections. Developmental Review, 13, 471-502.

Cicchetti, D., \& Garmezy, N. (1993). Prospects and promises in the study of resilience. Development and Psychopathology, 5, 497-502.

Claes, M. (1982). Friendship and personal adjustment during adolescence. Journal of Adolescence, 15, 39-55.

Clark, R. M. (1983). Family life and school achievement: Why poor black children 
succeed or fail. Chicago: University of Chicago Press.

Cohen, S., \& Wills, T. A. (1985). Stress, social support, and the buffering hypothesis. Psychological Bulletin, 98, 310-357.

Coie, J. D., Lochman, J. E., Terry, R., \& Hyman, C. (1992). Predicting early adolescent disorder from childhood aggression and peer rejection. Journal of Consulting and Clinical Psychology, 5, 783-792.

Coie, J. D., Terry, R., Lenox, K., Lochman, J., \& Hyman, C. (1995). Childhood peer rejection and aggression as predictors of stable patterns of adolescent disorder. Development and Psychopathology, 7, 697-713.

Colby, A., \& Damon, W. (1983). Listening to a different voice: A review of Gilligan's in a different voice. Merrill-Palmer Quarterly, 29, 473-481.

Collins, N. L., \& Reed, S. J. (1990). Adult attachment, working models, and relationship quality in dating couples. Journal of Personality and Social Psychology, 58 , 644-663.

Cone, A. L., \& Owens, S. J. (1991). Academic and locus of control enhancement in a freshman study skills and college adjustment course. Psychological Reports, 68, 12111217.

Cooper, C., Grotevant, H., \& Condon, S. (1983). Individuality and connectedness in the family as a context for adolescent identity formation and role-playing skill. In W. Damom (Series Ed.,) \& H. Grotevant \& C. Cooper (Vol. Eds.), New directions in child development: Vol. 22. Adolescent development in the family (pp. 43-59). San Francisco: Jossey-Bass. 
Coopersmith, S. (1967). The antecedents of self-esteem. San Francisco: Freeman.

Cotterell, J. L. (1992). The relation of attachments and supports to adolescent wellbeing and school adjustment. Journal of Adolescent Research, 7, 28-42.

Cowan, P. A., Cowan, C. P, \& Schulz, M. S. (1996). Thinking about risk and resilience in families. In E. M. Hetherington \& E. A. Blechman (Eds.), Stress, coping, and resiliency in children and families (pp. 1-39). Hillsdale, NJ: Erlbaum.

Cranston, P., \& Leonard, M. M. (1990). The relationship between undergraduates' experiences of campus micro-inequities and their self-esteem and aspirations. Journal of College Student Development, 31, 395-401.

Cutrona, C. E., Cole, V., Colangelo, N., Assouline, S. G., \& Russell, D. W. (1994). Perceived parental social support and academic achievement: An attachment theory perspective. Journal of Personality and Social Psychology, 66, 369-378.

deJong, M. L. (1992). Attachment, individuation, and risk of suicide in late adolescence. Journal of Youth and Adolescence, 21, 357-373.

Dornbusch, S. M., Ritter, P. L., Leiderman, P. H., Roberts, D. F., \& Fraleigh, M. J. (1987). The relation of parenting style to adolescent school performance. Child Development, 58, 1244-1257.

Downey, G., \& Coyne, J. C. (1990). Children of depressed parents: An integrative review. Psychological Bulletin, 108, 50-76.

Dubois, D. J., Felner, R. D., Brand, S., Adam, A. M., \& Evans. E. G. (1992). A prospective study of life stress, social support, and adaptation in early adolescence. Child Development, 63, 542-557. 
Dubow, E. F., \& Tisak, J. (1989). The relation between stress life events and adjustment in elementary school children: The role of social support and social problemsolving skills. Child Development, $60,1412-1423$.

Eccles, J. S., Wigfeld, A., Flanagan, C. A., Miller, C., Reuman, D. A., \& Yee, D. (1989). Self-concepts, domain values, and self-esteem: Relations and changes at early adolescence. Journal of Personality, 57, 283-310.

Ekstrom, R. B., Goertz, M. E., Pollack, J. M., \& Rock, D. A. (1986). Who drops out of high school and why? Findings from a national study. Teachers College Record, 87, 356-373.

Elder, G. H. (1974). Children in the great depression: Social change in life experiences. Chicago: University of Chicago Press.

Fass, M. E. (1996). The effect of parental and peer attachment on late adolescents' attitudes toward cheating. Unpublished master's thesis.

Felsten, G., \& Wilcox, K. (1992). Influences of stress and situation-specific mastery beliefs and satisfaction with social support on well-being and academic performance. Psychological Reports, 70, 291-303.

Findley, M. J., \& Cooper, H. M. (1983). Locus of control and academic achievement: A literature review. Journal of Personality and Social Psychology, 44, 419-427.

Finn, J. D. (1989). Withdrawing from school. Review of Educational Research, 59, $117-142$

Finn, J. D., \& Rock, D. A. (1997). Academic success among students at risk for school failure. Journal of Applied Psychology, 82, 221-234. 
Fitts, W. H. (1965). Tennessee Self-Concept Scale Manual. Counselor Recordings and Tests, Nashville, TN.

French, D. C., Conrad, J., \& Turner, T. M. (1995). Adjustment of antisocial and nonantisocial rejected adolescents. Development and Psychopathology, 7, 857-874.

Frey, C. U., \& Rothlisberger, C. (1996). Social support in healthy adolescents. Journal of Youth and Adolescence, 25, 17-31.

Galambos, N. L., \& Silbereisen, R. K. (1987). Income change, parental life outlook, and adolescent expectations for job success. Journal of Marriage and the Family, 49 , 141-149.

Garmezy, N. (1974). Children at risk: The search for the antecedents of schizophrenia. Part II: Ongoing research programs, issues, and intervention. Schizophrenia Bulletin, 9, $55-125$.

Garmezy, N. (1983). Stressors in childhood. In N. Garmezy \& M. Rutter (Eds.), Stress, coping, and development in children (pp. 43-84). New York: McGraw-Hill.

Garmezy, N. (1985). Stress-resistant children: The search for protective factors. In J. E. Stevenson (Ed.), Recent research in developmental psychopathology. Journal of Child Psychology and Psychiatry Book Supplement No. 4. 213-233.

Garmezy, N., Masten, A.S., \& Tellegen, A. (1984). The study of stress and competence in children: A building block for developmental psychopathology. Child Development, 55, 97-111.

Gecas, V., \& Schwalbe, M.L. (1983). Beyond the looking glass self: Social structure and efficacy based self-esteem. Social Psychology Quarterly, 46, 77-88. 
Gerdes, H., \& Mallinckrodt, B. (1994). Emotional, social, and academic adjustment of college students: A longitudinal study of retention. Journal of Counseling and Development. $72,281-288$.

Gerken, K. (1987). Children and peer relations. In A. Thomas \& J. Grimes (Eds.), Children's needs: Psychological perspectives (pp. 404-412). Washington, DC: National Association of School Psychologists.

Gilbert, L. A. (1981). Toward mental health: The benefits of psychological androgyny. Professional Psychology, 12, 29-38.

Gilligan, C. (1982). In a different voice. Cambridge: Harvard University Press.

Gloria, A., \& Robinson, S. (1994). Factors influencing the academic persistence of Chicanola undergraduates. Poster session presented at the annual meeting of the American Psychological Association, Los Angeles.

Goodlad, J. I. (1984). A place called school. New York: McGraw-Hill. Gose, A., Wooden, S., \& Muller, O. (1980). The relative potential of self-concept and intelligence as predictors of achievement. Journal of Psychology, 104, 279-287.

Graber, J. A., \& Brooks-Gunn, J. B. (1996). Transitions and turning points: Navigating the passage from childhood through adolescence. Developmental Psychology, $\underline{32}, 768-776$.

Graber, J. A., Brooks-Gunn, J. B., \& Petersen, A. C. (1996) Adolescent transitions in context. In J. A. Graber, J. B. Brooks-Gunn, \& A. C. Petersen (Eds.). Transitions through adolescence: Interpersonal domains and context (pp. 369-383). Hillsdale, NJ: Erlbaum.

Greenberg, M. T., Siegel, J. M., \& Leitch, C. J. (1983). The nature and importance of 
attachment relationships to parent and peer during adolescence. Journal of Youth and Adolescence, 12, 373-386.

Greenglass, E. R. (1982). A world of difference: Gender roles in perspective. Toronto: Wiley.

Hansford, B. B., \& Hattie, J. A. (1982). The relationship between self and achievement/performance measures. Review of Educational Research, 64, 123-142.

Harrison, A. O, Wilson, M. N., Pine, C. J., Chan, S., \& Buriel, R. (1990). Family ecologies of ethnic minority children. Child Development, 61, 347-362.

Harter, S. (1990). Causes, correlates, and the functional role of global self-worth: A life-span perspective. In R. J. Sternberg \& J. Kolligian, Jr. (Eds.), Competence considered (pp. 67-97). New Haven, CT: Yale University Press.

Hauser, R. M., Sewell, W. H., \& Alwin, D. F. (1976). High school effects on achievement. In W. H. Sewell, R. M. Hauser, \& D. L. Featherman (Eds.), Schooling and Achievement in American Society (pp. 309-341). New York: Academic Press.

Hays, R B., \& Oxley D. (1986). Social network development and functioning during a life transition. Journal of Personality and Social Psychology, 50, 305-313.

Hazen, C., \& Shaver, P. R. (1987). Romantic love conceptualized as an attachment process. Journal of Personality and Social Psychology, 52, 511-524.

Hearn, J. C. (1985). Determinants of college students' overall evaluations of their academic programs. Review of Higher Education, 23, 413-437.

Heller, K. \& Swindle, R. W. (1983). Social networks, perceived social support, and coping with stress. In F. D. Felner, L. A. Jason, J. Moritsugu, \& S. I. Farber (Eds.), 
Preventive psychology: Theory, research, and practice in community intervention (pp. $87-$ 103). New York: Pergamon.

Hershberger, S. L., \& D'Augelli, A. R. (1992). The relationship of academic performance and social support to graduation among African-American and White university students: A path-analytic model. Journal of Community Psychology, 20, 188199.

Hoffman, J. (1984). Psychological separation of late adolescents from their parents. Journal of Counseling Psychology, 31, 170-178.

Hoffmam, J., \& Weiss, B. (1987). Family dynamics and presenting problems in college students. Journal of Counseling Psychology, 34, 157-163.

Holahan, C. J., \& Moos, R. H. (1982). Social support and adjustment: Predictive benefits of social climate indices. American Joumal of Community Psychology, 15, 403415.

Holahan, C. J., Valentiner, D. P., \& Moos, R. H. (1994). Parent support and psychological adjustment during the transition to young adulthood in a college sample. Journal of Family Psychology, 2, 215-223.

Holmbeck, G. N. (1997). Toward terminological, conceptual, and statistical clarity in the study of mediators and moderators: Examples from the child-clinical and pediatric literatures. Journal of Consulting and Clinical Psychology, 65, 599-610.

Horn, C., Bruning, R., Schraw, G., Curry, E., \& Katkanant, C. (1993). Paths to success in the college classroom. Contemporary Educational Psychology, 18, 464-478.

James, W. (1963). The principles of psychology. New York: Holt, Rhinehart, \& 
Winston. (Original work published 1890).

Jensen, A. R. (1973). Educability and group differences. New York: Harper and Row.

Kahn, S. B. (1966). The contribution of attitudinal factors to be predictors of academic achievement in secondary school. Unpublished Doctoral Thesis, Florida State University Press, 1966.

Kahn, R. L., \& Antonucci, T. C. (1980). Convoys over the life course: Attachment, roles, and social support. In P. B. Baltes \& O. G. Brim (Eds.), Life span development and behavior: Vol. 3. (pp. 253-286). New York: Academic Press.

Kalish, R A., \& Knudtson, F. W. (1976). Attachment versus disengagement: A lifespan conceptualization. Human Development, 19, 171-181.

Kanoy, K. W., Wester, J., \& Latta, M. (1990). Understanding differences between high- and low-achieving women: Implications for effective placement and teaching. Journal of College Student Development, 31, 133-140.

Kassin, S. (1995). Psychology Boston: Houghton Mifllin.

Kenny, M. E. (1990). College seniors' perceptions of parental attachments: The value and stability of family ties. Journal of College Student Development, 31, 39-46.

Kenny, M. E., \& Donaldson, G. A. (1991). Contributions of parental attachment an family structure to the social and psychological functioning of first-year college students. Journal of Counseling Psychology, 38, 479-486.

Kenny, M. E., \& Donaldson, G. A. (1992). The relationship of parental attachment and psychological separation to the adjustment of first-year college women. Journal of College Student Development, 92, 431-438. 
Klein, J. D., \& Keller, J. M. (1990). Influence of student ability, locus of control, and type of instructional control on performance and confidence. Journal of Educational Research, 83, 140-146.

Kleinfeld, J. (1971). The validity of Sense-of-Fate Control Scale and the relationships of beliefs about internal and external control and academic self-concept to school achievement. Dissertation Abstracts International 31(8-A), 3960.

Kobak, R. R. \& Sceery, A. (1988). Attachment in late adolescence: Working models, affect regulation, and representation of self and others. Child Development, 59, 135-146.

Kupersmidt, J. B., \& Coie, J. D. (1990). Preadolescent peer status, aggression, and school adjustment as predictors of externalizing problems in adolescence. Child Development 61, 306-312.

Kupersmidt, J. B., Coie, J. D., \& Dodge, K. A. (1990). The role of poor peer relationships in the development of disorder. In S. R. Asher \& J. D. Coie (Eds.), Peer rejection in childhood. Cambridge studies in social and emotional development (pp. 274305). New York: Cambridge University Press.

Ladd, G. W. (1990). Having friends, keeping friends, making friends, and being liked by peers in the classroom: Predictors of children's early school adjustment. Child Development, $61,1081-1100$.

Lamke, L. K. (1982). The impact of sex-role orientation on self-esteem in early adolescence. Child Development, 53, 1530-1535.

Lapsley, D. K., Rice, K. G., \& Fitzgerald, D. P. (1990). Adolescent attachment, identity, and adjustment to college: Implications for the continuity of adaptation 
hypothesis. Journal of Counseling and Development, 68, 561-565.

Lapsley, D. K., Rice, K G., \& Shadid, G. E. (1989). Psychological separation and adjustment to college. Journal of Counseling Psychology, 36, 286-294.

Larose, S., \& Roy, R. (1991). The role of prior academic performance and nonacademic attributes in the prediction of the success of high-risk college students. Journal of College Student Development, 32, 171-177.

Lefcourt, H. M. (1982). Locus of control: Current trends in theory and research. Hillsdale, NJ: Erlbaum.

Lempers, J. D., \& Clarke-Lempers, D. S. (1992). Young, middle, and late adolescents comparisons of the functional importance of five significant relationships. Journal of Youth and Adolescence, 21, 54-96.

Lent, R. W., \& Hackett, G. (1987). Career self-efficacy: Empirical status and future directions [Monograph]. Journal of Vocational Behavior, 30, 347-382.

Levenson, H. (1974). Activism and powerful others: Distinctions within the concepts of internal-external control. Journal of Personality Assessment, 38, 377-383.

Levitt, M. J. (1991). Attachment and close relationships: A life span perspective. In J. L. Gewirtz \& W. F. Kurtines (Eds.), Intersections with attachment (pp. 183-205). Hillsdale, NJ: Erlbaum.

Levitt, M. J, Coffman, S., Guacci-Franco, N., \& Loveless, S. C. (1994). Attachment relationships and life transitions: An expectancy model. In M. B. Sperling \& W. H. Berman (Eds.), Attachment in adults: Clinical and developmental perspectives (pp. 232255). New York: The Guilford Press. 
Levitt, M. J., Guacci-Franco, N., \& Levitt, J. L. (1993). Convoys of social support in childhood and adolescence: Structure and function. Developmental Psychology, 29, 811818.

Lewis, F. M., Woods, N. F., \& Ellison, E. (1987). The Family Impact Study: The impact of cancer on the family. Grant R01-NU-01000, University of Washington, Division of Public Health Service.

Liang, B., \& Bogat, G. A. (1994). Culture, control, and coping: New perspectives on social support. American Journal of Community Psychology, 22, 123-147.

Licitra-Klecker, D. M. \& Waas, G. A. (1993). Perceived social support among highstress adolescents: The role of peers and family. Journal of Adolescent Research, 8 , 381-402.

Liddle, H. A. (1994). Contextualizing resiliency. In M. C. Wang \& E. W. Gordan (Eds.). Educational Resilience in Inner-City America: Challenges and Prospects (pp. 167177). Hillsdale, NJ: Erlbaum.

Lin, R. (1990). Perception of family background and personal characteristics among Indian college students. Journal of American Indian Education, 29, 19-28.

Loeber, R. (1990). Development and risk factors of juvenile antisocial behavior and delinquency. Clinical Psychological Review, 10, 1-41.

Lopez, F. G. (1991). Patterns of family conflict and their relation to college student development. Journal of Counseling and Development, 69, 257-260.

Lopez, F. G, \& Gover, M. R. (1993). Self-report measures of parent-adolescent attachment and separation-individuation: A selective review. Journal of Counseling \& 
Development, 71, 560-569.

Lumkin, J. R. (1988). Establishing the validity of an abbreviated locus of control scale: Is a brief Levenson scale any better? Psychological Reports, 63, 519-523.

Luthar, S. S. (1993). Annotation: Methodological and conceptual issues in research on childhood resilience. Journal of Child Psychology and Psychiatry and Allied Disciplines, 34, 441-453.

Mallinckrodt, B. (1988). Student retention, social support, and dropout intention: Comparison of Black and White students. Joumal of College Student Development, 28, $60-64$

Maqusud, M., \& Rouhani, S. (1991). Relationships between socioeconomic status, locus of control, self-concept, and academic achievement of Botswana adolescents. Journal of Youth and Adolescence, 20, 107-114.

Marsh, H. W. (1986). Global self-esteem: Its relation to specific facets of self-concept and their importance. Joumal of Personality and Social Psychology, 51, 1224-1236.

Marsh, H. W., \& Byrne, B. M. (1991). Differentiated additive androgyny model: Relations between masculinity, femininity, and multiple dimensions of self-concept. Journal of Personality and Social Psychology, 61, 811-828.

Marsh, H. W., \& Myers, M. R. (1986). Masculinity, femininity, and androgyny: A methodological and theoretical critique. Sex Roles, 14, 397-430.

Masten, A. S. (1994). Resilience in individual development: Successful adaptation despite risk and adversity. In M. C. Wang \& E. W. Gordan (Eds.). Educational resilience in inner-city America: Challenges and prospects. (pp. 3-25). Hillsdale, NJ: Erlbaum. 
Masten, A. S. \& Garmezy, N. (1987). Risk, vulnerability, and protective factors in developmental psychopathology. In Lahey, B. B. \& Kazdin, A. E. (Eds.), Advances in clinical child psychology, Vol. 8, (pp. 1-52). New York: Plenum Press.

Maurer, J. (1982). Reported stress of college seniors as a function of gender and sex role orientation. (Report No. CG 016 789), ERIC Document Reproduction Service NO. ED 232 (095).

Maxwell, M. (1981). Improving student learning skills. San Francisco: Josey-Bass.

May, K. M., \& Logan, C. R. (1993). Family type and the accomplishment of developmental tasks among college students. Journal of College Student Development, 34. $397-400$.

McFarlane, A. H., Bellissimo, A., \& Norman, G. R. (1995). The role of family and peers in social self-efficacy: Links to depression in adolescence. American Journal of Orthopsychiatry, $65,402-410$.

McGinnis, A. L. (1987). The power of optimism. San Francisco: Harper \& Row. Milgram, N. A. (1989). Social support versus self-efficiency in traumatic and posttraumatic stress reactions. In B. Lehrer \& S. Gershon (Eds.), New directions in affective disorders (pp. 455-458). New York: Springer-Verlag.

Milgram, N. A., \& Palti, G. (1993). Psychosocial characteristics of resilient children. Journal of Research in Personality, 27, 207-221.

Miller, R., \& Irving, P. (1995). Academic locus of control in British undergraduate students. British Journal of Educational Psychology, 65, 331-340.

Mindel, C. H. (1980). Extended familism among urban Mexican Americans, Anglos, 
and Blacks. Hispanic Journal of Behavioral Science, $2,21-34$.

Moos, R. H. (1974). Family Environment Scale. Palo Alto, CA: Consulting Psychologists Press.

Nada Raja, S., McGee, R, \& Stanton, W. R. (1992). Perceived attachment to parents and peers and psychological well-being in adolescence. Journal of Youth and Adolescence, $21,471-485$.

Neemann, J., \& Harter, S. (1986). The self-perception profile for college students. Manual. Denver, CO: University of Denver.

Nolen-Hoeksema, S., \& Girgus, J. S. (1994). The emergence of gender differences in depression during adolescence. Psychological Bulletin, 115, 424- 443.

Nunn, G. D., \& Nunn, S. J. (1993). Locus of control and school performance: Some implications for teachers. Education, 113, 636-640.

Nunn, G. D., \& Parish, T. S. (1992). The psychosocial characteristics of at-risk high school students. Adolescence, 27, 435-440.

Ockerman, J. D. (1979). Self-esteem and social anchorage of adolescent white, black, and Mexican American students. Palo Alto, CA: R. \& E. Research Associates.

O'Koon, J. (1997). Attachment to parents and peers in late adolescence and their relationship with self-image. Adolescence, 32, 471-482.

Okun, M. A. (1991). Moderators of the semester GPA- college satisfaction relation: A judgment approach. Contemporary Educational Psychology, 16, 73-86.

Okun, M. A., Benin, M., \& Brandt-Williams, A. (1996). Staying in college: Moderators of the relation between intention and institutional departure. Journal of Higher 
Education, 67, 577-596.

Okun, M. A., \& Fournet, L. M. (1993). Academic self-esteem and perceived validity of grades: A test of self-verification theory. Contemporary Educational Psychology, 18, $427-441$.

Ollendick, T. H., Weist, M. D., Bordan, M. C., \& Greene, R. W. (1992). Sociometric status and academic, behavioral, and psychological adjustment: $A$ five-year longitudinal study. Joumal of Consulting and Clinical Psychology, 60, 80-87.

Orlofsky, J. L. (1977). Sex role orientation, identity formation and self-esteem in college men and women. Sex Roles, 3, 561-575.

Osborne, J. W. (1995). Academics, self-esteem, and race: A look at the underlying assumptions of the disidentication hypothesis. Personality and Social Psychology Bulletin. $21,449-455$.

Parker, J. G., \& Asher, S. R. (1987). Peer relations and later personal adjustment: Are low-accepted children at risk? Psychological Bulletin, 102, 357-389.

Paterson, J., Pryor, J., \& Field, J. (1995). Adolescent attachment to parents and friends in relation to aspects of self-esteem. Journal of Youth and Adolescence, 24. 365-376.

Pei-Hui, R. A., \& Ward, C. (1994). A cross-cultural perspective on models of psychological androgyny. The Journal of Social Psychology, 134, 391-393.

Pellegrini, D. S. (1990). Psychosocial risk and protective factors in childhood. Developmental and Behavioral Pediatrics, 11, 201-207.

Peng, S. S. (1994). Understanding resilient students: The use of national longitudinal 
databases. In M. C. Wang \& E. W. Gordon (Eds.), Educational resilience in inner-city America: Challenges and prospects (pp. 73-84). Hillsdale, NJ: Erlbaum.

Pickles, A., \& Rutter, M. (1991). Statistical and conceptual models of "turning points" in developmental processes. In D. Magnusson, L. R. Bergman, G. Rudinger, \& B. Torestad (Eds.), Problems and methods in longitudinal research: Stability and change (pp. 133-165). Cambridge, England: Cambridge University Press.

Portes, A, \& MacLeod, D. (1996). Educational progress of children of immigrants: The roles of class, ethnicity, and school context. Sociology of Education, 69, 255-275.

Procidano, M. E., \& Heller, K. (1983). Measures of perceived social support from friends and from family: Three validative studies. American Journal of Community Psychology, 11, 1-24.

Quintana, S. M., \& Lapsley, D. K. (1987). Adolescent attachment and ego identity: A structural equations approach to the continuity of adaptation. Journal of Adolescent Research, 2, 393-409.

Rabow, J., Radcliffe-Vasile, S., Newcomb, M. D., \& Hernandez, A. C. R. (1992). Teachers', students', and others' contributions to educational outcomes. Youth and Society, 24, 71-91.

Reese, H. W. (1997). Counterbalancing and other uses of repeated-measures Latin square designs: Analyses and interpretations. Journal of Experimental Child Psychology, 64, 137-158.

Reifman, A., \& Dunkel-Schetter, C. (1990). Stress, structural support, and well-being in university students. College Health, 38, 271-277. 
Rice, K G. (1990). Attachment in adolescence: A narrative and meta-analytic review. Journal of Youth and Adolescence, 19, 511-539.

Richardson, V, \& Colfer, P. (1994). Being at-risk in school. In J. I. Goodlad \& P. Keating (Eds.), The continuing agenda for our nation's schools. (pp. 109-120). New York: College Entrance Examination Board.

Riggio, R. E., Watring, K. P., \& Throckmorton, B. (1993). Social skills, social support, and psychosocial adjustment. Personality and Individual Differences, 15, 275280.

Robbins, S. B., Lese, K. P., \& Herrick, S. M. (1993). Interactions between goal instability and social support on college freshman adjustment. Journal of Counseling and Development, $71,343-348$.

Rosenberg, M. (1965). Society and the adolescent self-image. Princeton, NJ: Princeton University Press.

Rosenberg, M. (1979). Concerning the self. New York: Basic Books.

Rothbard, J. C., \& Shaver, P. R. (1994). Continuity of attachment across the life span. In M. B. Sperling, \& W. H. Berman (Eds.), Attachment in adults: Clinical and developmental perspectives (pp. 31-71). New York: Guilford Press.

Rotter, J. B. (1966). Generalized expectancies for internal versus external control of reinforcement. Psychological Monographs, 80, (Whole No. 609).

Rotter, J. B. (1975). Some problems and misconceptions related to the construct of internal versus external control of reinforcement. Journal of Consulting and Clinical Psychology, 43, 56-67. 
Rotter, J. B. (1990). Internal versus external control of reinforcement: A case history of a variable. American Psychologist, 45, 489-493.

Rutter, M. (1985). Resilience in the face of adversity: Protective factors and resistance to psychiatric disorder. British Journal of Psychiatry, 147, 598-611.

Rutter, M. (1987). Psychosocial resilience and protective mechanisms. American Journal of Orthopsychiatry, 57, 316-331.

Rutter, M. (1989). Pathways from childhood to adult life. Journal of Child Psychology and Psychiatry, 30, 23-31.

Rutter, M. (1990). Psychosocial resiliency and protective mechanisms. In J. E. Rolf, A. S. Masten, D. Cicchetti, K. Nuecherlein, \& S. Weintraub (Eds.), Risk and protective factors in the development of psychopathology (pp. 23-50). New York: Cambridge University Press.

Rutter, M. (1993). Resilience: Some conceptual considerations. Journal of Adolescent Health, 14, 626-631.

Rutter, M. (1994). Beyond longitudinal data: Causes, consequences, changes, and continuity. Journal of Consulting and Clinical Psychology, 62, 928-940.

Rutter, M. (1995). Clinical implications of attachment concepts: Retrospect and prospect. Journal of Child Psychology and Psychiatry and Allied Disciplines, 36, 549-571.

Ryan, R. M., \& Lynch, J. H. (1989). Emotional autonomy versus detachment: Revisiting the vissitudes of adolescence and young adulthood. Child Development, 60 , 340-356.

Sandler, I. N., \& Lakey, B. (1982). Locus of control as a stress moderator: The role 
of control perceptions and social support. American Journal of Community Psychology, $10,65-80$.

Sapp, S. G., \& Harrod, W. J. (1993). Reliability and validity of a brief version of Levenson's locus of control scale. Psychological Reports, 72, 539-550.

Sarason, I. G. (1981). Test anxiety, stress, social support. Journal of Personality, 49, 101-114.

Sarason, I. G, Levine, H. M., Basham, R. B., \& Sarason, B.R. (1983). Assessing social support: The social support questionnaire. Joumal of Personality and Social Psychology, 44, 127-139.

Scheier, M. F., \& Carver, C. S. (1992). Effects of optimism on psychological and physical well-being: Theoretical overview and empirical update. Cognitive Therapy and Research, 16, 210-228.

Scheier, M. F., Carver, C. S., \& Bridges, M. W. (1994). Distinguishing optimism from neuroticism (and trait anxiety, self-mastery, and self-esteem): A reevaluation of the life orientation test. Journal of Personality and Social Psychology, 67, 1063-1078.

Scheier, M. F., Weintraub, J. K., \& Carver, C. S. (1986). Coping with stress: Divergent strategies of optimists and pessimists. Journal of Personality and Social Psychology, 51, 1257-1264.

Schneider, B. H., \& Younger, A. J. (1996). Adolescent-parent attachment and adolescents' relations with their peers. Youth \& Society, 28, 95-108.

Sebald, H. (1989). Adolescents' peer orientation: Changes in the support system during the past three decades. Adolescence, 24, 937-945. 
Seligman, M. E. P. (1991). Learned optimism. New York: Knopf.

Sewell, W. H., \& Hauser, R. M. (1980). The Wisconsin longitudinal study of social and psychological factors in aspirations and achievements. Research in Sociology of Education and Socialization, 1, 59-99.

Silber, W., \& Tippett, J. S. (1965). Self-esteem: Clinical assessment and measurement validation. Psychological Reports, 16, 1017 - 1071.

Simmons, R. G., \& Rosenberg, F. (1975). Sex, sex roles, and self-image. Journal of Youth and Adolescence, 4, 229-258.

Stewart, A. J. (1982). The course of individual adaptation to life changes. Journal of Personality and Social Psychology, 42, 1100-1113.

Stewart, D., \& Vaux, A. (1986). Social support resources, behavior, and perceptions among Black and White students. Journal of Multicultural Counseling and Development, 14, 67-72.

Stipek, D. J., \& Weisz, J. R. (1981). Perceived personal control and academic achievement. Review of Educational Research, 51, 101-137.

Sroufe, L. A. (1983). Infant caregiver attachment and patterns of adaptation in preschool: The roots of maladaptation and competence. In M. Perlmutter (Ed.), Minnesota symposium on child psychology, Vol. 16 (pp. 41-81). Hillsdale, NJ: Erlbaum.

Takahashi, K. (1990). Affective relationships and their lifelong development. In P. B. Baltes, D. L. Featherman, \& L. R. Sherrod (Eds.), Life span development and behavior, Vol. 10 (pp. 1-29). Hillsdale, NJ: Erlbaum.

Taylor, S. E. (1989). Positive illusions: Creative self-deception and the healthy mind. 
New York: Basic Books.

Taylor, S. E., \& Brown, J. D. (1988). Mlusion and well-being: A social psychological perspective on mental health. Psychological Bulletin, 103, 193-210.

Teachman, J. D. (1996). Intellectual skill and academic performance: Do families bias the relationship? Sociology of Education, 69, 35-48.

Tennant, C, Bebbington, P., \& Hurry, J. (1981). The short-term outcome of neurotic disorders in the community: The relation of remission to clinical factors and to 'neutralizing' life events. British Journal of Psychiatry, 139, 213-220.

Tracey, T. J., \& Sedlacek, W. E. (1991). The relationship of non-cognitive variables to academic success: A longitudinal comparison by race. Journal of College Student Development, 26, 405-410.

Watt, M F., Anthony, E. J., Wynne, L. C., \& Rolf, J. E. (Eds.) (1984). Children at risk for schizophrenia: A longitudinal perspective. New York: Cambridge University Press.

Weir, R. M., \& Okun, M. A. (1989). Social support, positive college events, and college satisfaction: Evidence for boosting effects. Journal of Applied Social Psychology, 19. 758-771.

Weiss, R. S. (1982). Attachment in adult life. In C. Parkes \& J. Stevenson-Hinde (Eds.), The place of attachment in human behavior (pp. 171-184). New York: Basic Books.

Werner, E. E. (1986). Resilient offspring of alcoholics: A longitudinal study from birth to age 18. Journal of Studies on Alcohol, 47, 34-40. 
Werner, E. E. (1989). Children of the garden island. Scientific American, 260, 106111.

Werner, E. E. (1993). Risk, resilience, and recovery: Perspectives from the Kauai Longitudinal Study. Development and Psychopathology, 5, 503-515.

Werner, E. E., \& Smith, R. S. (1982). Vulnerable but invincible: A longitudinal study of resilient children and youth. New York: McGraw-Hill.

White, R. W. (1959). Motivation reconsidered: The concept of competence. Psychological Review, 36, 353-362.

Whitley, B. E. (1983). Sex role orientation and self-esteem: A critical meta-analytic review. Journal of Personality and Social Psychology, 44, 765-778.

Wills, T. A., Blechman, E. A., \& McNamara, G. (1996). Family support, coping, and competence. In E. M. Hetherington and E. A. Blechman (Eds.), Stress, coping, and resiliency in children and families (pp. 107-133). Hillsdale, NJ: Erlbaum.

Winemiller, D. R., Mitchell, M. E., Sutiff, J., \& Cline, D. J. (1993). Measurement strategies in social support: A descriptive review of the literature. Journal of Clinical Psychology, 49, 638-647.

Winfield, L F. (1991). Resilience, schooling, and development in African-American youth: A conceptual framework. Education and Urban Society, 24, 5-14.

Zarb, J. M. (1981). Non-academic predictors of successful academic achievement in a normal adolescent sample. Adolescence, 64, 891-900.

Zea, M. C., Jarama, S. L., \& Bianchi, F. T. (1995). Social support and psychosocial competence: Explaining the adaptation to college of ethnically diverse students. American 
Journal of Community Psychology, 23, 509-531. 
Appendixes

Appendix A: Inventory of Parent and Peer Attachment Appendix B: Self-Perception Profile for College Students

Appendix C: Rosenberg Self-Esteem Scale

Appendix D: Bem Sex-Role Inventory

Appendix E: Levenson's Locus of Control Scale

Appendix F: Life Orientation Test-Revised

Appendix G: Student Academic Profile 
Appendix A 
Directions:

\section{SECTION I}

Please look over the five choices below and select the choice you feel best describes your relationship with your friend/peers. Please circle the number on the right of each statement that corresponds to your answer.

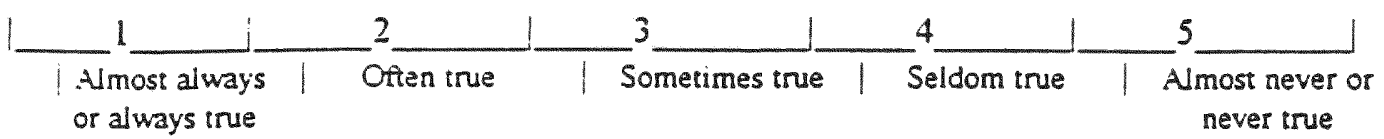

1. I like to get my friends' point of view on things

I'm concerned about.

$\begin{array}{lllll}1 & 2 & 3 & 4 & 5\end{array}$

2. My friends sense when I'm upset about something.

$\begin{array}{lllll}1 & 2 & 3 & 4 & 5\end{array}$

3. When we discuss things, my friends consider my point of view.

4. Talking over my problems with my fiends makes me feel ashamed or foolish.

5. I wish I had different friends.

6. My friends understand me.

7. My friends encourage me to talk about my difficulties. $\quad \begin{array}{lllll}2 & 3 & 4\end{array}$

8. My friends accept me as I am. 12345

9. I feel the need to be in touch with my friends more often. 122345

10. My friends don't understand what I'm going through these days.

11. I feel alone or apart when I am with my friends. 
13. I feel my friends are good friends.

14. My friends are fairly easy to talk to.

15. When I am angry about something, my friends try be understanding.

16. My friends help me to understand myself better.

17. My friends are concerned about my well-being.

18. I feel angry with my friends.

19. I can count on my friends when I need to get something off my chest.

20. I trust my friends.

21. My friends respect my feelings.

22. I get upset a lot more than my friends know about.

23. It seems as if my friends are irritated with me for no reason.

24. I tell my friends about my problems and troubles.

25. If my friends know something is bothering me, they ask me about it.
12345

$123 \quad 3 \quad 4 \quad 5$

12345

12345

$\begin{array}{lllll}1 & 2 & 3 & 4 & 5\end{array}$

$123 \quad 3 \quad 4 \quad 5$

12345

12345

12345

12345

12345

$\begin{array}{lllll}1 & 2 & 3 & 4 & 5\end{array}$

12345 
Identification code

\section{SECTION II}

Directions:

Please look over the five choices below and then select the choice you feel best describes your relationship with your parent/parents. Please circle the number on the right of each statement that corresponds to your answer.

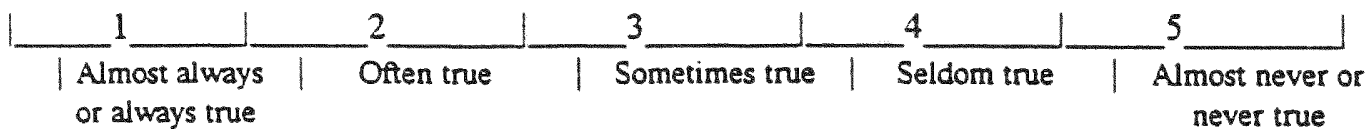

1. My parents respect my feelings.

2. I feel my parents are successful as parents.

3. I wish I had different parents.

4. My parents accept me as I am.

5. I have to rely on myself when I have a problem to solve.

6. I like to get my parents' point of view on things I'm concerned about.

7. I feel it's no use letting my feelings show

8. My parents sense when I'm upset about something. $\quad \begin{array}{llllll}1 & 2 & 3 & 4 & 5\end{array}$

9. Talking over my problems with my parents makes me feel ashamed or foolish.

10. My parents expect too much out of me.

11. I get upset easily at bome. $\begin{array}{lllll}1 & 2 & 3 & 4 & 5\end{array}$

12345

12345

$\begin{array}{lllll}1 & 2 & 3 & 4 & 5\end{array}$

$\begin{array}{lllll}1 & 2 & 3 & 4 & 5\end{array}$

$\begin{array}{lllll}1 & 2 & 3 & 4 & 5\end{array}$

12345 .

$123+5$

12345

12345 
12. I get upset a lot more than my parents know about. $\begin{array}{llllll}1 & 2 & 3 & 4 & 5\end{array}$

13. When we discuss things, my parents consider my point of view.

$\begin{array}{lllll}1 & 2 & 3 & 4 & 5\end{array}$

14. My parents trust my judgment.

$\begin{array}{lllll}1 & 2 & 3 & 4 & 5\end{array}$

15. My parents have their own problems, so I don't bother them with mine.

16. My parents help me to understand myself better.

$\begin{array}{lllll}1 & 2 & 3 & 4 & 5\end{array}$

17. I tell my parents about my problems and troubles.

$\begin{array}{lllll}1 & 2 & 3 & 4 & 5\end{array}$

18. I feel angry with my parents.

$\begin{array}{lllll}1 & 2 & 3 & 4 & 5\end{array}$

19. I don't get much attention at home.

$\begin{array}{lllll}1 & 2 & 3 & 4 & 5\end{array}$

20. My parents encourage me to talk about my difficulties.

$\begin{array}{lllll}1 & 2 & 3 & 4 & 5\end{array}$

21. My parents understand me.

$\begin{array}{lllll}1 & 2 & 3 & 4 & 5\end{array}$

22. I don't know who I can deperd on these days.

$\begin{array}{lllll}1 & 2 & 3 & 4 & 5\end{array}$

23. When I'm angry about something, my parents try to be understanding.

$\begin{array}{lllll}1 & 2 & 3 & 4 & 5\end{array}$

24. I trust my parents.

12345

25. My parents don't understand what I'm going through these days.

123345

26. I can count on my parents when I need to get something off my chest.

$\begin{array}{lllll}1 & 2 & 3 & 4 & 5\end{array}$

27. I feel that no one understands me.

12345

28. If my parents know something is bothering me, they ask me about it.

$\begin{array}{lllll}1 & 2 & 3 & 4 & 5\end{array}$ 
Appendix B 
Directions:

Appendix B

The following are statements which allow college students to describe themselves.

There are no right or wrong answers since students differ markedly. Please read the entire sentence across. First decide which one of the two parts of each statement best describes you; then go to that side of the starement and check whether that is just sort of true for you or really true for you. You will CBECK ONLY ONE of the four boxes in each statement (Place an "X"). Think about what you are like in the college environment as you read and answer each one.
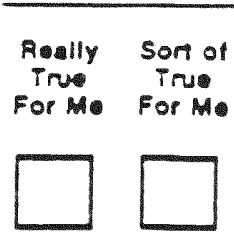

2.
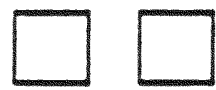

3.
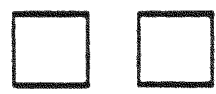

4.
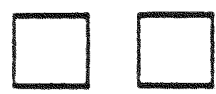

5.
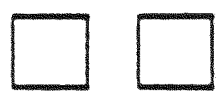

6.
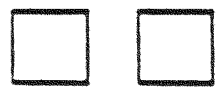

7.
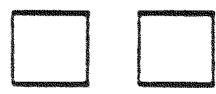

3.
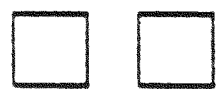

9.
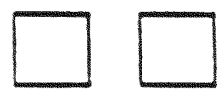

10
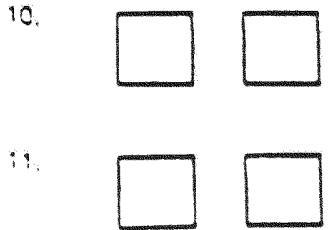

Som siuden! Itk ine kine of person they ars

Soma studen: are not very proud ol ho work theygoon inctir 100

Som students tool contlognt inat ingy ar mastering thair cours work

Some studenis ar not satisflod with their social skills

Somo siucen: aro not haopy wirn the way they look

Some siucerts tike the way iney ac: when they are around theil paronis

Some students get kind of lonely se cause they con't :eal. iy nave a close triend io snaro things with

Some studen:s lom like they aro just as sman op smarter than orner sivcents

Some stucen:s olien cuestion the noralliy of ineir benavior

Some siven:s teel

inat spoole ingy like

pomantically will 20

ariac:ec 10 inem

When some studenis do someining sor. of siuole inat isier aopears vory lunny insy lind 11 nard:0

laugh at inengoives

\begin{tabular}{|c|c|}
\hline BUT & $\begin{array}{l}\text { Olmor stucems wish } \\
\text { that inay wors } \\
\text { differant. }\end{array}$ \\
\hline BบT & $\begin{array}{l}\text { Oiner stucents are } \\
\text { very sroud of the } \\
\text { work they do on thetr } \\
\text { lob. }\end{array}$ \\
\hline 8บT & $\begin{array}{l}\text { Orner students do not } \\
\text { leol so contident. }\end{array}$ \\
\hline BUT & $\begin{array}{l}\text { Other stuegents think } \\
\text { theif social skills } \\
\text { are just lino. }\end{array}$ \\
\hline BUT & $\begin{array}{l}\text { Other stuconts are } \\
\text { happy with the } \\
\text { way they look. }\end{array}$ \\
\hline SUT & $\begin{array}{l}\text { Othor students wish } \\
\text { they actod differantly } \\
\text { around thetr paronts. }\end{array}$ \\
\hline BUT & $\begin{array}{l}\text { Other siucents don'l } \\
\text { usually eat :oo } \\
\text { lonely becaise iney do } \\
\text { have a close triend to } \\
\text { snare innss with. }\end{array}$ \\
\hline SUT & $\begin{array}{l}\text { Other stuesents wonder } \\
\text { if they ar as smart. }\end{array}$ \\
\hline BUT & $\begin{array}{l}\text { Omer siccenis teal } \\
\text { inoir sorivior is } \\
\text { usually noral. }\end{array}$ \\
\hline BUT & $\begin{array}{l}\text { Orner stucenis worry } \\
\text { asout whelner seoplo } \\
\text { iney lik iomantically } \\
\text { will so alliaciod io inem. }\end{array}$ \\
\hline aUT & 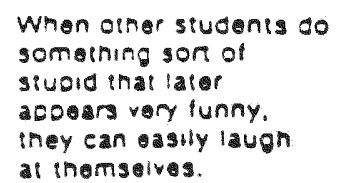 \\
\hline
\end{tabular}

Sor of Filly

PPu Tru

For M For M
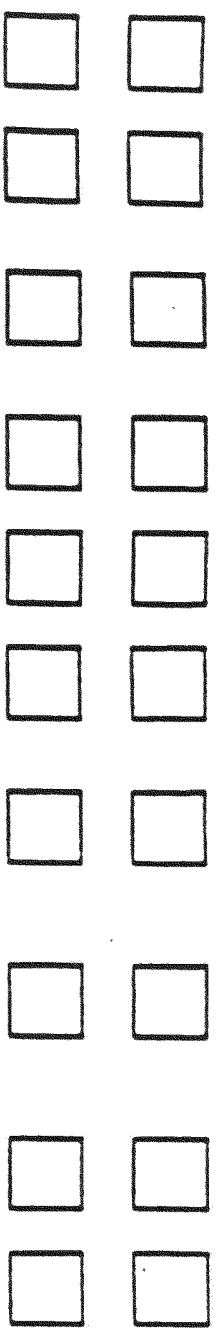

at เกตms 


\begin{tabular}{|c|c|c|c|c|c|c|c|}
\hline & $\begin{array}{l}\text { Ronily } \\
\text { True } \\
\text { For Me }\end{array}$ & $\begin{array}{l}\text { Sort of } \\
\text { Prue } \\
\text { For M. }\end{array}$ & & & & $\begin{array}{l}\text { Don ol } \\
\text { Prue } \\
\text { For we }\end{array}$ & $\begin{array}{l}\text { many } \\
\text { Prue } \\
\text { For He }\end{array}$ \\
\hline 12. & & & 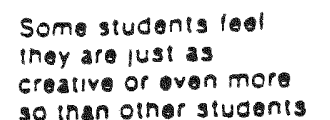 & OUT & $\begin{array}{l}\text { Other students wonder } \\
\text { it they are as } \\
\text { creative. }\end{array}$ & & \\
\hline 13. & & & $\begin{array}{l}\text { Some studonis feel } \\
\text { inoy could to well at } \\
\text { lust about any now }\end{array}$ & BUT & $\begin{array}{l}\text { Oimer siucenis are } \\
\text { atraid they mignt } \\
\text { nol do woll at arnlepic }\end{array}$ & & \\
\hline & & & $\begin{array}{l}\text { atmionic activity thoy } \\
\text { nayonit ifled botore }\end{array}$ & & $\begin{array}{l}\text { aetivifies inoy naven't } \\
\text { over tried. }\end{array}$ & & \\
\hline 14. & & & $\begin{array}{l}\text { Somo siudents are } \\
\text { often disaopointed } \\
\text { with themselves }\end{array}$ & BUT & $\begin{array}{l}\text { Oiher siccents aro } \\
\text { usually quite pleased } \\
\text { with themselves. }\end{array}$ & & \\
\hline 15. & & & $\begin{array}{l}\text { Some students foei } \\
\text { they are very good } \\
\text { at their joo }\end{array}$ & BUT & $\begin{array}{l}\text { Other aludenis worry } \\
\text { about whether they } \\
\text { can do ingir joo. }\end{array}$ & & \\
\hline 98. & & & $\begin{array}{l}\text { Some students do } \\
\text { very woll at } \\
\text { their sivdies }\end{array}$ & ВบT & $\begin{array}{l}\text { Other students don't } \\
\text { do vary woll at } \\
\text { inoir sivoles. }\end{array}$ & & \\
\hline 17. & & & $\begin{array}{l}\text { Some students lind } \\
\text { it hard to make } \\
\text { now triends }\end{array}$ & BUT & $\begin{array}{l}\text { Oinor students aro } \\
\text { able io make } \\
\text { new iptonds asily. }\end{array}$ & & \\
\hline 18. & & & $\begin{array}{l}\text { Some students are } \\
\text { hapoy with their } \\
\text { hoight and woight }\end{array}$ & BUT & $\begin{array}{l}\text { Orher students wish } \\
\text { thair height of } \\
\text { woight was different. }\end{array}$ & & \\
\hline 19. & & & $\begin{array}{l}\text { Some students find } \\
\text { it hard to aet nat. } \\
\text { urally when they aro }\end{array}$ & BUT & $\begin{array}{l}\text { Other students ind it } \\
\text { easy to act naturally } \\
\text { around ineir parents. }\end{array}$ & & \\
\hline 20. & & & $\begin{array}{l}\text { Some sfucents aro able } \\
\text { to make close priends } \\
\text { they can roally trust }\end{array}$ & BUT & $\begin{array}{l}\text { Other stucents find } \\
\text { it hard to make close } \\
\text { trionds they can really } \\
\text { trust. }\end{array}$ & & \\
\hline 21. & & & $\begin{array}{l}\text { Some students do not } \\
\text { lool they are yery } \\
\text { monially able }\end{array}$ & BUT & $\begin{array}{l}\text { Other students foel } \\
\text { that they are very } \\
\text { mentally able. }\end{array}$ & & \\
\hline 22. & & & $\begin{array}{l}\text { Some students usually } \\
\text { do what is } \\
\text { morally ilght }\end{array}$ & BUT & $\begin{array}{l}\text { Other students somo } \\
\text { times don't do what } \\
\text { they know is morally }\end{array}$ & & \\
\hline 23. & & & & & & & \\
\hline 23. & & & $\begin{array}{l}\text { Some siudents find } \\
\text { it hard to establish } \\
\text { romantic roiation. } \\
\text { snips }\end{array}$ & BUT & $\begin{array}{l}\text { Other siudents don't } \\
\text { nave difficulty } \\
\text { ostablishing romantic } \\
\text { relationships. }\end{array}$ & & \\
\hline 24. & & & $\begin{array}{l}\text { Some students don't } \\
\text { mind boing kldeded } \\
\text { oy their friends }\end{array}$ & BUT & $\begin{array}{l}\text { Other students are } \\
\text { bothared when } \\
\text { friends kid them. }\end{array}$ & & \\
\hline 25. & & & $\begin{array}{l}\text { Some students worry } \\
\text { inat iney are nol as } \\
\text { creative or inventive }\end{array}$ & BUT & $\begin{array}{l}\text { Othor givedents lool } \\
\text { they are very } \\
\text { croative and inventive. }\end{array}$ & & \\
\hline 26. & & & $\begin{array}{l}\text { Some students don't } \\
\text { low ingy are } \\
\text { vory atnietic }\end{array}$ & BUT & $\begin{array}{l}\text { Other siudonts do } \\
\text { lool inoy af } \\
\text { athielic. }\end{array}$ & & \\
\hline
\end{tabular}


Rolly Sort of

For Ma For He

7.
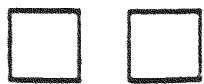

: 9.
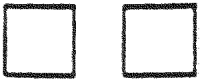

9.
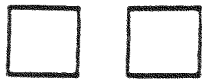

o.
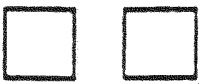

ห.
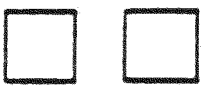

2.
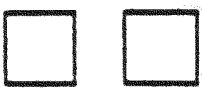

3.
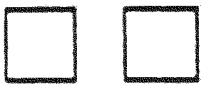

4.
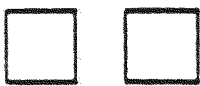

35.
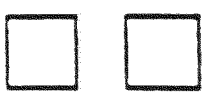

36.
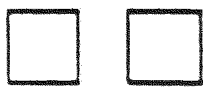

37
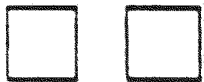

38
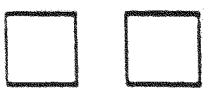

39
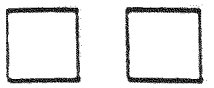

40
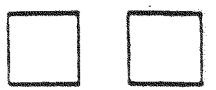

$\$ 1$

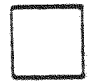

Somo siucents usually

lix inemsolvos

as arson

somo sucenis 1001

conflcent acoul

thele abllily 10

do a now 100

Some siudents have

irouvi llguing out

homework assignments

Somo sivents liko

the way ingy inter.

act with oiner peoplo

Som siudenis wish

theif body was

ditformt

Somo students tool comtorablo boino themsolves around thair parants

Some siudents don't havo a closo triend they can smare thoip personal thoughis and feellngs with

Some students loel iney are just as brignt or brignter than most pooplo

Some siudents would like 10 be a belter person morally

Some students have ine ability 10 ceveloo romantic relationships

Some sludents have a hard time laughing as ine piciculous or silly inings they do

Some studenis do not leel that they are very inventlve

Some sivenis leot iney are oelier mai others at sporis

Some sivcen:s really like the way they are iocing ineir lives

Some siucents are

not saustied wiln

ine way iney do

ineip 100
Oinap siucents ofton

BUT

don'! llk inam.

solvos as osson.

BUT

Orser sivdent wory about wether inoy can to new loo thoy havon't iplod botore.

BUT

Othor siudents rarely

mave trouble with thol. homework assienmenis.

Other siudents wish

inoir interactions

with othar pooplo wore differont.

Othar studants lik their body the way If is.

Othor students have

BบT

difficulty boing

thamsolves sround

their parants.

gUT

Other students do have - rlond who is elose enough for them to shar thoughts inat are roally personal.

BUT

Othar students wonder if they aro as bright.

BUT

Othar siudents think iney ara guilo moral.

BUT

BUT

gUT

Olner siudenis feet hal iney are very inventive.

Other sivenis con':

BUT

as well.

Other stidents ollen 8UT

- Orner siucenis aro cuile salistiog win the way they do thoir 100. ach the tha wa they

Sort of Aently

True Pru

For M. For M
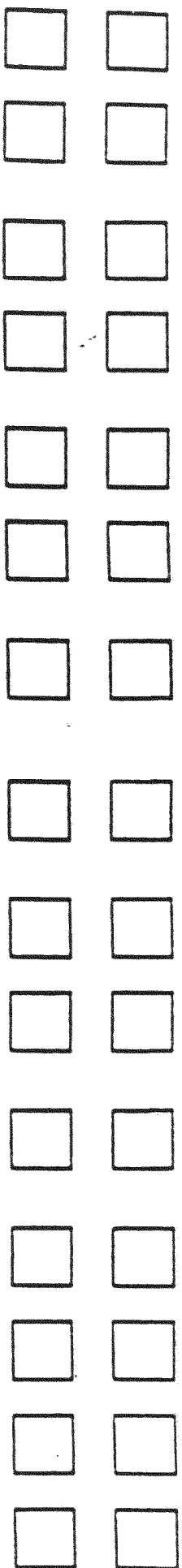
R日ily sont of

Tru Tru

For He For $\mathrm{M}$

42.
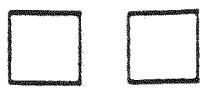

43.
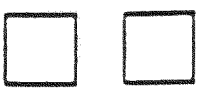

4.
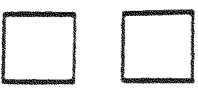

45.
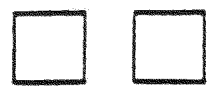

26.
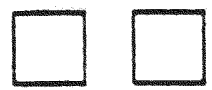

47.
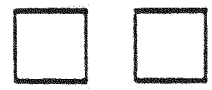

48.
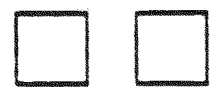

49.
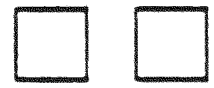

50.
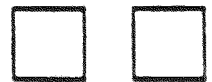

$\$ 1$.
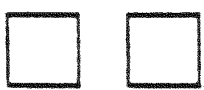

52.
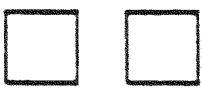

53.
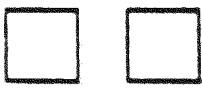

54 .

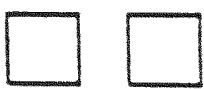

Sorr luden's some limes do nol loal intollectually compolen at mair siudies

Som givents leel that iney are so. c:ally acceorec sy many people

Some siveris like their onysical ao. pearance the way it is

Some stucents find inat they aro unaole to get along with their parenis

Some siudents are able to make really closa friends

Some siudenis would pally rather De difforent

Some students ques. tion whether they are very intelligent

Some studenis live up to their own moral siandards

Somo students worry that when they like someone romantically. that person won't lika like them sack

Some siudents can pally laugh at cap. iain inings they do

Some siudents teel iney nave a lot of original ldaas

Some students con's do woll al activilias recuiring pnysical skill

Some siudents are olten dissatistiod with themselves
QUT

Oener sucents usually do leat intallac

iually comogrent al

ineir siucies.

Other stucents wisn mors jecole accepred liam.

8UT

Ophar sucents co

not like meir

cnysical apoearanco.

8บ

Orner studants get along win thair paronts guite well.

gUT

Other students find it haro :s make rally clos lipionds.

Ormer slucents aro

8บT vory naoy boing the way they are.

Other sudents lael inoy aro

- intelligent.

Other students mavo trouble living uo 10. their moral standards.

Other students feel that when they are pomantically interested in someono, inat person will lik them oack.

Opher sudents nave a hard lim laughing at themselves.

Oiner siudenis cues. lion whether thelr ldeas are very original.

Other students are oood at activitios requiring pnysical skill.

Orner sucents are usually satistied with themselves.

gบT
Sort of ती

Tru

TिU

गिบ

of
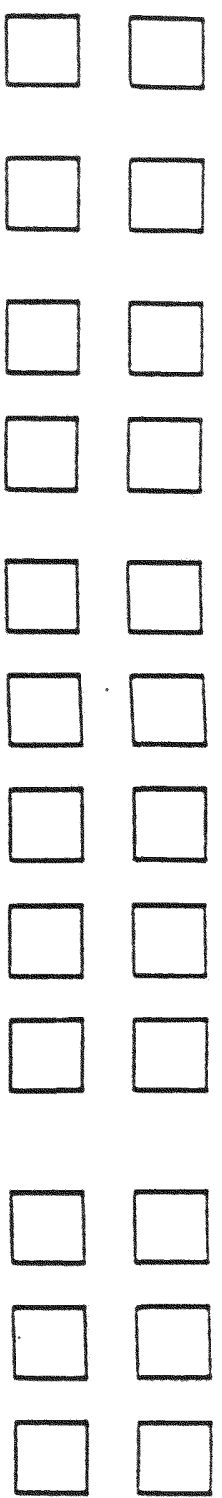
Appendix C 


\section{Appendix C}

Identification Code

Directions: For each statement there are four possible answers: strongly agree, agree, disagree, and strongly disagree. Please circle the number on the right of each statement that corresponds to your answer.

\begin{tabular}{|l|l|l|l|}
\hline 1 & 2 & 3 & 4 \\
\hline $\begin{array}{c}\text { STRONGLY } \\
\text { AGREE }\end{array}$ & AGREE & DISAGREE & $\begin{array}{c}\text { STRONGLY } \\
\text { DISAGREE }\end{array}$
\end{tabular}

1. On the whole, I am satisfied with myself. $\quad \begin{array}{lllll}1 & 2 & 3 & 4\end{array}$

2. At times I think I am no good at all $\quad \begin{array}{llllll} & 1 & 2 & 3 & 4\end{array}$

3. I feel I have a number of good qualities. $\quad \begin{array}{llllll} & 1 & 2 & 3 & 4\end{array}$

4. I am able to do things as well as most $\quad \begin{array}{llllll}1 & 2 & 3 & 4\end{array}$ other people.

5. I feel I do not have much to be proud of $\quad \begin{array}{llllll}1 & 2 & 3 & 4\end{array}$

6. I certainly feel useless at times. $\quad 1 \quad \begin{array}{llll}2 & 3 & 4\end{array}$

7. I feel I'm a person of worth, at least

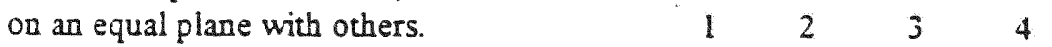

8. I wish I could have more respect for myself $\quad \begin{array}{llllll}1 & 2 & 3 & 4\end{array}$

9. All in all, I am inclined to feel that I am a failure.

10.I take a positive attitude toward myself. $\quad \begin{array}{lllll} & 1 & 2 & 3 & 4\end{array}$ 
Appendix D 


\section{Appendix D}

On this page, you will find listed a number of personaliry characteristics. We would like you to use those characteristics to describe yourself, that is, we would like you to indicate on a scaie from 1 to 7 , how true of you each of these characteristics is Please do not leave any characteristic unmarked.

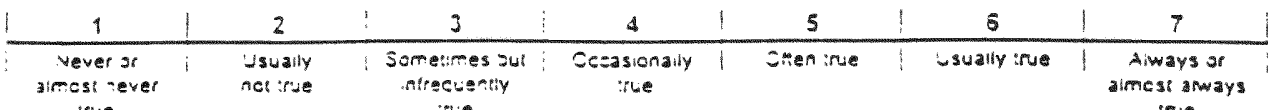

irse

pise

true

\begin{tabular}{|c|c|}
\hline 1. Deiend my own belie?s & $\vdots$ \\
\hline 2. Affectionate & \\
\hline 3. Conscientious & \\
\hline 4. Independent & \\
\hline 5. Sympathetic & \\
\hline 6. Moody & \\
\hline 7. Assertive & \\
\hline 8. Sensitive to needs of others & \\
\hline 9. Reliable & \\
\hline :0. Strong personality & \\
\hline i1. Understarding & \\
\hline 12. Jealous & \\
\hline 13. Forceinl & \\
\hline 14. Compassionate & \\
\hline is. Truthiul & \\
\hline 16. Have leadership abilities & \\
\hline 17. Eager to socthe nur feelings & \\
\hline 18. Secretive & \\
\hline 19. Willing to take risks & \\
\hline 20. Warm & \\
\hline 21. Adaptaole & \\
\hline 22. Dominant & \\
\hline 23. Tender & \\
\hline 24. Concelted & \\
\hline 25 Willing to : $3 k$ a s siand & \\
\hline 25. Love cnildren & \\
\hline 27 Tactul & \\
\hline 28. Aggressive & \\
\hline 29. Gentle & \\
\hline 30 Conventional & \\
\hline
\end{tabular}

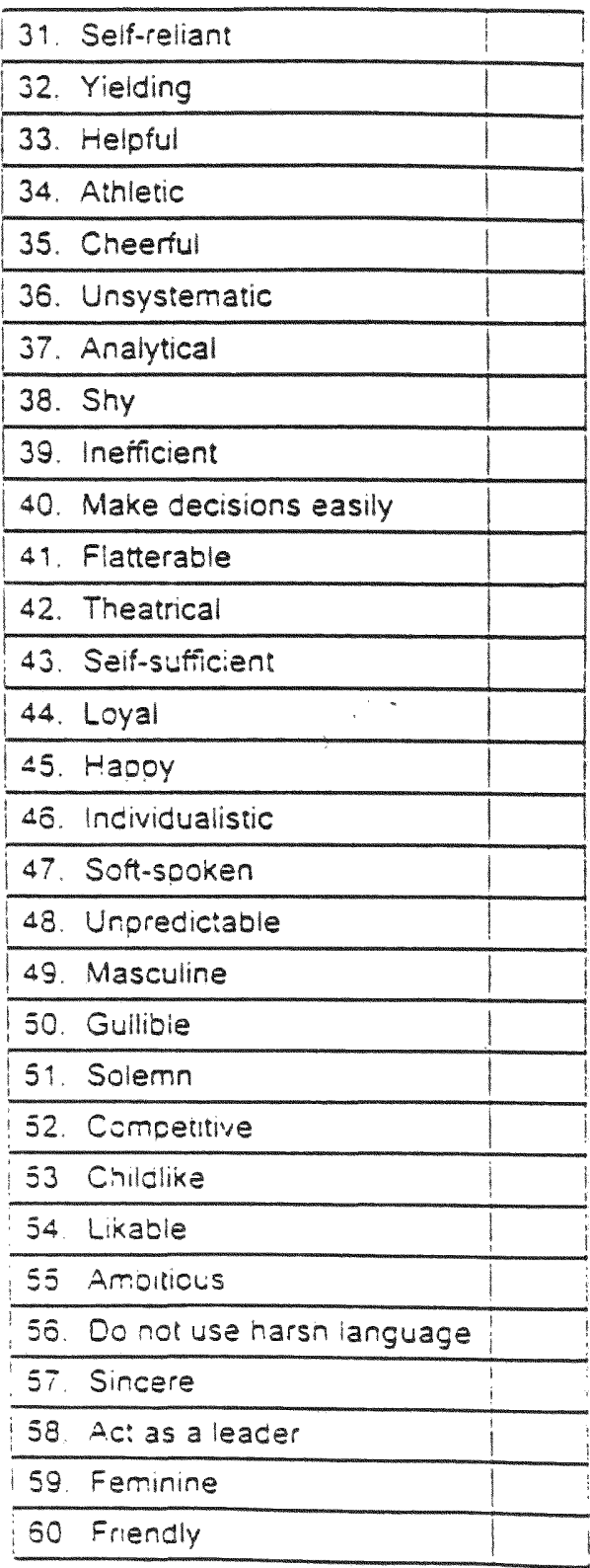


Appendix E 


\section{Appendix E}

Ideatification Code

\section{Directions:}

Indicate on a scale of $1-7$ how well each of the following statements describes you. Circle the corresponding number. Please circle the number on the right of each statement that corresponds to your answer.

\begin{tabular}{|c|c|c|c|c|c|c|c|}
\hline 1 & 2 & 3 & 4 & 5 & 1 & 5 & 7 \\
\hline $\begin{array}{c}\text { Never ap } \\
\text { aimosi gyer } \\
\text { true }\end{array}$ & $\begin{array}{l}\text { - Sually } \\
\text { ot ine }\end{array}$ & $\begin{array}{c}\text { Sumeires su: } \\
\text { nirocuentiy } \\
\text { :pus }\end{array}$ & $\begin{array}{c}\text { Ocsasionally } \\
\text { ipue }\end{array}$ & Chen irue & $i$ & - sually ifue & $\begin{array}{c}\text { Aiways or } \\
\text { amost suways } \\
\text { ine }\end{array}$ \\
\hline
\end{tabular}

1. My life is determined by my own actions.

2. I am usually able to protect my personal interests.

3. I can pretry much determine what will happen in my life.

4. To a great extent, my life is controlled by accidental happenings. 1234567

5. Often there is no chance of protecting my personal interest from bad luck happenings.

6. When I get what I want, it's usually because I'm lucky.

People like myself have very little chance of protecting our personal interests where they conflict with those of strong pressure groups.

8. My life is chiefly controlled by powerful others.

9. I feel like what happens in my life is mostly determined by powerful people. 
Appendix F 
Identification Code

Directions:

There are no "correct" or "incorrect" answers. Answer according to your own feelings, rather than how you think "most people" would answer. Please circle the number on the right of each statement that corresponds to your answer.

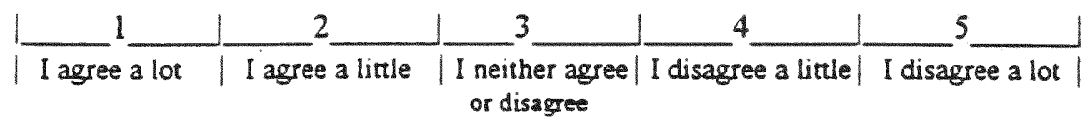

1. In uncertain times, I usually expect the best.

$\begin{array}{lllll}1 & 2 & 3 & 4 & 5\end{array}$

2. It's easy for me to relax.

$\begin{array}{lllll}1 & 2 & 3 & 4 & 5\end{array}$

3. If something can go wrong for me, it will

$\begin{array}{lllll}1 & 2 & 3 & 4 & 5\end{array}$

4. I'm always optimistic about my future.

12345

5. I enjoy may friends a lot.

12345

6. It's important for me to keep busy.

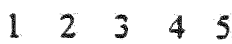

7. I hardly ever expect things to go my way.

12345

8. I don't get upset too easily.

12345

9. I rarely count on good things happening to me.

$\begin{array}{lllll}1 & 2 & 3 & 4 & 5\end{array}$

10. Overall, I expect more good things to happen to me than bad. $\quad \begin{array}{lllll}2 & 2 & 4 & 5\end{array}$ 
Appendix G 
Appendix $G$

Identification Code

Srudent Academic Profile

Circle the letter with the best response to the question.

1. My grade point average at the present time is
A. 1.0-1.5
B. $1.5-2.0$
C. $2.0-2.5$
D. $2.5-3.0$
E. 3.0-3.5
F. 3.5-4.0

2. How many times bave you changed your major since entering college?
A. None
B. Once
C. Twice
D. Three or more times
E. No major selected

3. How many courses have you dropped since entering college?
A. None
B. 1 or 2
C. 3 or 4
D. 5 or 6
E. More than 6

4. What grade do you expect to make in the required courses in your major?
A. A
B. A-
C. $\mathrm{B}+$
D. B
E. B-
F. Ct

5. What was your average grade in your high school classes?
A. A
B. B
C. C
D. D

6. While in bigh school, was there one teacher or administrator who acted as a model for you?
A. Yes
B. No

7. While in high school, did you win any academic awards or honors?
A. Yes
B. No

8. Was academic acbievement stressed by your parents while you were in high school ?
A. Yes
B. No

9. Was academic achievement stressed by your peers while you were in high school?
A. Yes
B. No

10. To what do you attribute your academic success in college?
A. Hard work
B. Intellectual ability
C. Both
D. Luck 


\section{VITA}

March 15, 1950

1973

1974

$1974-1977$

1977-1982

1982-19

1885-1987

1987

$1987-1988$

1989-1996

1996
Born, Brooklyn, New York

B.A., Psychology

Florida State University

Tallahassee, Florida

M. S., United States History

Florida State University

Tallahassee, Florida

Adult Education Instructor

Florida A. M. University

Tallahassee, Florida

Adult Education Project Manager

Palm Beach County School Board

West Palm Beach, Florida

Psychology and American History Instructor Santaluces Community High School

Lantana, Florida

Political Science Adjunct Instructor

Palm Beach Community College

Boca Raton, Florida

International Graduate Student

University of Oxford

Oxford, England

Political Science Adjunct Instructor

Broward Community College

Hollywood, Florida

Psychology Adjunct Instructor

Miami Dade Community College

Miami, Florida

M.S., Developmental Psychology

Florida International University 
Miami, Florida

1987-1998

AP Psychology and American History Instructor North Miami Beach High School

North Miami Beach, Florida

\section{PUbLiCATIONS AND PRESENTATIONS}

Fass, M. E. (1995). A Forensic Psychology Role Playing Exercise for an Introductory Psychology Course. Paper presented at the 9th Annual Conference on Undergraduate Teaching of Psychology, Farmingdale, New York.

Fass, M. E. (1995). The Use of Transference in Seventeenth-Century Massachusetts. American Studies, 36, 65-82. 